University of Louisville

ThinkIR: The University of Louisville's Institutional Repository

8-2018

\title{
Weight stigma and motivation to exercise : exploring associations and constructs from the basic needs theory.
}

Stephanie R. McDonough

University of Louisville

Follow this and additional works at: https://ir.library.louisville.edu/etd

Part of the Health Psychology Commons

\section{Recommended Citation}

McDonough, Stephanie R., "Weight stigma and motivation to exercise : exploring associations and constructs from the basic needs theory." (2018). Electronic Theses and Dissertations. Paper 3038. https://doi.org/10.18297/etd/3038

This Doctoral Dissertation is brought to you for free and open access by ThinkIR: The University of Louisville's Institutional Repository. It has been accepted for inclusion in Electronic Theses and Dissertations by an authorized administrator of ThinkIR: The University of Louisville's Institutional Repository. This title appears here courtesy of the author, who has retained all other copyrights. For more information, please contact thinkir@louisville.edu. 


\title{
WEIGHT STIGMA AND MOTIVATION TO EXERCISE: \\ EXPLORING ASSOCIATIONS AND CONSTRUCTS FROM THE BASIC NEEDS THEORY
}

\author{
By \\ Stephanie R. McDonough \\ B.S., University of Vermont, 2011 \\ M.A., University of Louisville, 2015

\begin{abstract}
A Dissertation
Submitted to the Faculty of the College of Arts and Sciences of the University of Louisville In Partial Fulfillment of the Requirements For the Degree of
\end{abstract}

Doctor of Philosophy in Clinical Psychology

Department of Psychological and Brain Sciences

University of Louisville

Louisville, KY

August 2018 
Copyright 2018 by Stephanie R. McDonough

All rights reserved. 

WEIGHT STIGMA AND MOTIVATION TO EXERCISE:

EXPLORING ASSOCIATIONS AND CONSTRUCTS FROM THE BASIC NEEDS THEORY

\author{
By \\ Stephanie R. McDonough \\ B.S., University of Vermont, 2011 \\ M.A., University of Louisville, 2015 \\ A Dissertation Approved on:
}

June 13, 2018

by the Following Dissertation Committee

\begin{tabular}{c}
\hline $\begin{array}{c}\text { Dissertation Director } \\
\text { Barbara Stetson }\end{array}$ \\
\hline Scott LaJoie \\
\hline Sandra Sephton \\
\hline Cheri Levinson
\end{tabular}

Cheri Levinson

Daniel DeCaro 


\section{ACKNOWLEDGEMENTS}

First and foremost, I would like to express my endless gratitude for my father, David McDonough, and all he has done to support me. He has provided an unshakeable foundation for me to reach my goals and I would not be where I am today without him. Thank you for the sacrifices, the late-night talks, and my fiery spirit which I owe all to you. I would also like to thank the rest of my family for your never-ending support and tolerance of all my graduate school-related moods and perceived crises. To my friends near and far, thank you for always believing in me. Thank you for all the laughs, dinnerand-a-movie nights, venting sessions and unwavering supportive presence. A special shout-out to my graduate school favorites, Ashlee Warnecke, Holly Knight, and Kala Phillips. You all bring the fire and I could not ask for better friends.

I would like to thank my mentor, Dr. Barbara Stetson, for all her guidance and support over the years. My time in the Health Behavior Research Program under her direction has fostered my scientist-practitioner skills and interest in the biopsychosocial perspectives of health and wellbeing. I would also like to thank my committee members for their expertise and helpful feedback. I would like to thank Dr. Bernadette Walter, Dr. Janet Woodruff-Borden and Dr. Lori Dubenske for all they have done to shape me as a clinician, but also for all the support and dissertation-related pep-talks, texts and memes. Lastly, I would like to acknowledge my lovely research assistants for all their hard work including Lilly, Elyse, Madison, Cassie and Maddey. 


\title{
ABSTRACT \\ WEIGHT STIGMA AND MOTIVATION TO EXERCISE: EXPLORING ASSOCIATIONS AND CONSTRUCTS FROM THE BASIC NEEDS THEORY
}

\author{
Stephanie R. McDonough
}

June 13, 2018

Social influences, such as weight stigma, perpetuate rates of overweight and obesity, as well as contribute to poor physical and psychological health. It has been postulated that weight stigma negatively affects motivation to exercise, though the literature is mixed and underlying mechanisms of action are not well conceived. The present study aimed to: (1) explore the relationship between frequency of experienced weight stigma and exercise motivation and behavior (2) assess how frequency of experienced weight stigma might differ based on participant characteristics such as body weight and (3) consider unique associations between frequency of personal experiences with weight-based stigma, exercise motivation, and psychological need satisfaction (autonomy, competence, and relatedness) as outlined by the Basic Needs Theory. Exploration and clarification of these relationships will inform future longitudinal studies that can test the proposed conceptual model which suggests that psychological need satisfaction may mediate the relationship between experienced weight stigma and motivation to exercise. Participants were 144 women recruited through online platforms, 
such as Facebook, as well as a local farmer's market. The present study utilized a crosssectional study design and online self-report measures. Participant weight was obtained through self-report, as well as objective methods, as possible. Frequency of experienced weight stigma was not associated with intention to exercise; however, it was positively associated with motivation to avoid exercise and controlled (extrinsic) exercise motivation style and negatively associated with exercise behavior. Individuals with worse health status and those of higher body weight endorsed more frequent experiences with weight stigma situations. Those who endorsed more frequent experiences with weight stigma also endorsed less satisfaction of psychological needs, with the exception of exercise relatedness. Multivariate findings suggested that perceived exercise competence may be most influential with regard to intention to exercise. Results offer partial support for the proposed conceptual model and highlight the need for further exploration of the weight stigma-exercise motivation relationship, with specific focus on mechanisms of action. This research has numerous clinical and research implications. Findings from the present study can inform intervention to increase exercise motivation and behavior, promote adaptive coping and buffer from the negative effects of weight stigma. 
TABLE OF CONTENTS

PAGE

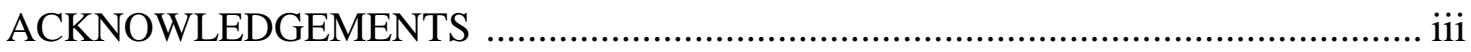

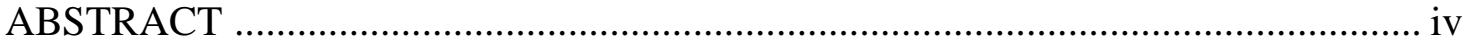

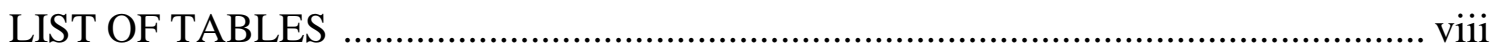

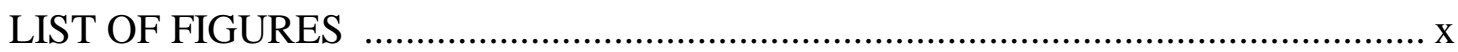

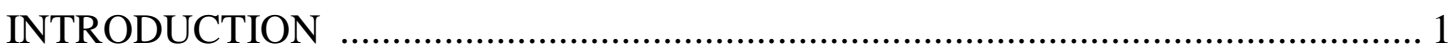

Background Information ............................................................................. 4

Weight Stigma and Exercise Literature ……………………………………..... 14

Exploring Unique Associations by Applying Basic Needs Construct ................. 21

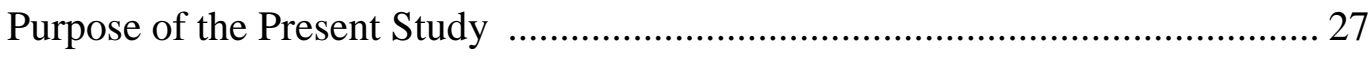

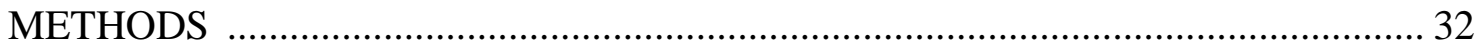

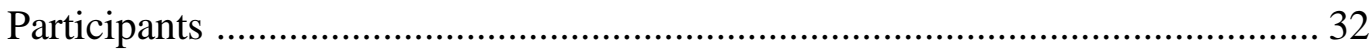

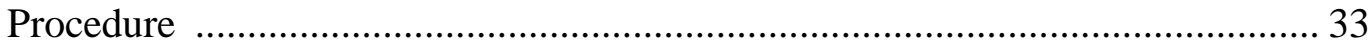

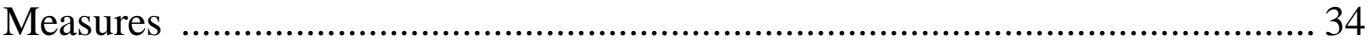

Statistical Approach and Data Analytic Plan ...................................................... 40

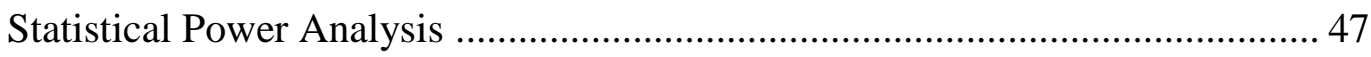

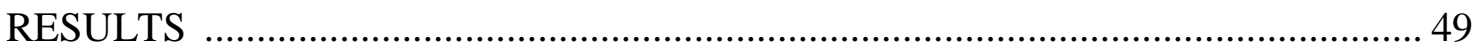

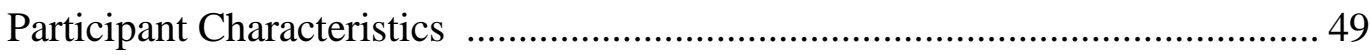

Primary Study Variables ……………………………………………………... 50

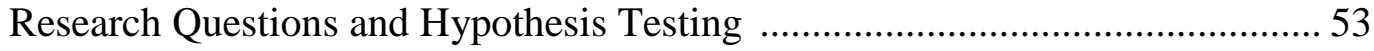

Supplemental Analyses ................................................................................ 57

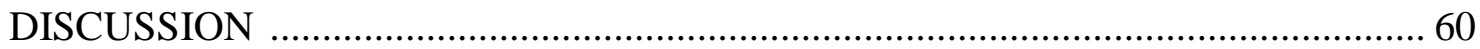


Experienced Weight Stigma Associations ...................................................... 61

Support for Proposed Conceptual Model ........................................................ 70

Study Characteristics Influencing Participation ........................................... 72

Participant Characteristics with Potential Influence on Outcomes ................... 75

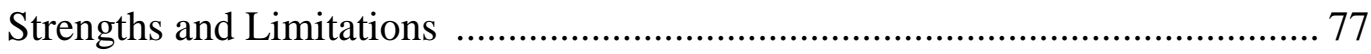

Implications and Recommendations ...................................................... 81

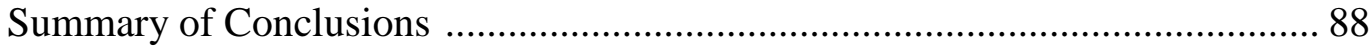

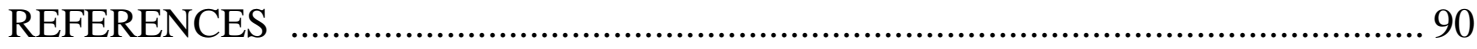

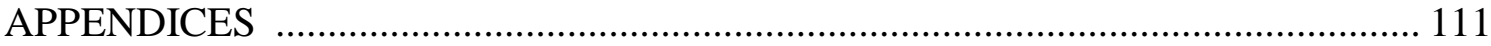

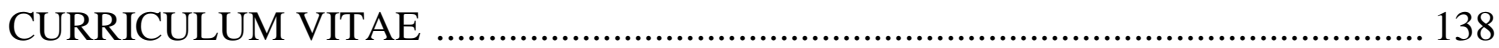




\section{LIST OF TABLES}

TABLE $\quad$ PAGE

1. Participants Removed from Data Analysis .......................................................... 112

2. Demographic Characteristics of Participants who Dropped Out Before

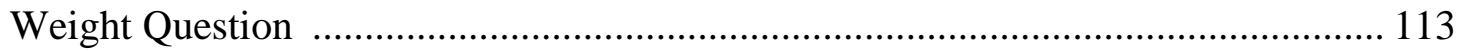

3. Demographic Characteristics of Participants who Dropped Out At

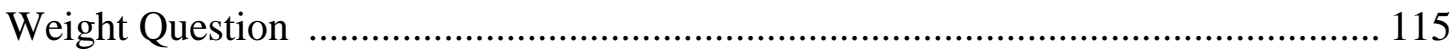

4. Missing Value Analysis for Primary Measures …………………………………... 116

5. Recruitment by Data Collection Method/Site …………………………………..... 117

6. Demographic Characteristics of Participants Included in Study ............................... 119

7. Health Characteristics of Sample …………………............................................. 122

8. Associations Among Demographic, Weight Stigma, Exercise

and Psychological Need Satisfaction Variables ………………….............................. 125

9. Stigmatizing Situations Inventory Scores by Participant

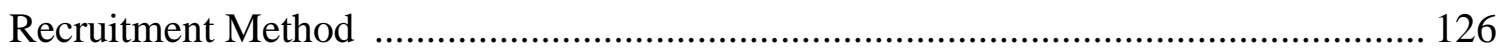

10. Descriptive Information on Stigmatizing Situations Inventory Subscales

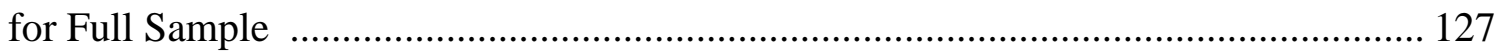

11. Participant's Physical Activity/Exercise Characteristics ........................................ 128

12. Participant's Psychological Need Satisfaction Scores …………………………..... 129

13. Post Hoc Analysis Summary for Experienced Weight stigma

and $\mathrm{BMI}$ associations

14. Regression Details for Research Question 2: How does experienced 
weight stigma relate to exercise motivation?

15. Regression Details for Research Question 5: What are the unique associations between psychological need satisfaction variables and exercise motivation when accounting for experienced weight stigma?

16. Regression Details for Supplemental Analysis: Exploring unique associations among internalized weight bias, experienced weight stigma, and psychological needs with exercise intention 


\section{LIST OF FIGURES}

FIGURE $\quad$ PAGE

1. Continuum of Motivation (Self-Determination Theory) ..................................... 134

2. Proposed Conceptual Model Integrating Basic Needs Theory Constructs ............... 135

3. Proposed Mediational Model ......................................................................... 136

4. Kruskal-Wallis H Test: Experienced Weight Stigma Scores by BMI Category ...... 137 


\section{INTRODUCTION}

Overweight and obesity continues to be a leading public health concern. The majority of adults age 20 and older in the United States (U.S.) are overweight or obese, with rates continuing to rise (National Institute of Diabetes and Digestive and Kidney Diseases, 2012). Many believe that weight status is contingent upon factors solely within a person's control, including dietary behavior and physical activity (Kushner, 2012; MacLean et al., 2009; Wright \& Aronne, 2012). However, the etiology of overweight and obesity is quite complex. A number of factors in addition to behavior have been shown to affect body weight including genetic, psychological, social, physiological (such as hormonal and metabolic factors), economic, and also political influences (Foster, Makris, \& Bailer, 2005; Wright \& Aronne, 2012). Notably, there is a plethora of social and cultural factors that have a significant impact on development and maintenance of obesity. For example, community factors such as availability of sidewalks and safe places to engage in physical activity as well as lack of affordable healthy food options can limit opportunities for engagement in health behaviors important for weight management and positive health outcomes (Committee on Accelerating Progress in Obesity Prevention, 2012).

Burgeoning research has examined specific social influences, such as the role of weight stigma (sometimes referred to as weight bias), in perpetuating both rates of overweight and obesity and poor health outcomes often seen in this population (Puhl \& Suh, 2015). 
Weight stigma can be described as negative attitudes and beliefs about people due to their weight status (Malterud \& Ulriksen, 2011; Papadopoulos \& Brennan, 2015).

These attitudes and beliefs often manifest through stereotypes, such as believing overweight and obese persons are lazy, lack motivation and will-power, and are unintelligent, as well as prejudice and discriminatory behavior (Papadopoulos \& Brennan, 2015; Puhl \& Heuer, 2010). In fact, discrimination due to weight is among the most frequently experienced forms of discrimination by adults (Puhl \& Suh, 2015). Researchers have proposed that weight stigma can negatively affect engagement in important health behaviors that promote both weight management and overall health and well-being, including diet and physical activity behavior (Puhl \& Heuer, 2010).

More recently, researchers have explored the potential negative impact of experienced weight stigma on exercise motivation and behavior (Vartanian \& Shaprow, 2008). Some examples of weight stigmatizing encounters include discrimination, rude or inappropriate comments from others, being avoided or excluded, and physical barriers because of body weight (Myers \& Rosen, 1999). While findings from such studies are mixed, there are a number of methodological and conceptual limitations that have yet to be addressed. For example, while many of these studies have examined exercise motivation, most have not applied empirically-supported theoretical frameworks of motivation.

A leading model of motivation in the context of health-related behaviors is the Self-Determination Theory (SDT; Ryan, Patrick, Deci, \& Williams, 2008). This theory focuses on the degree to which an individual is self-motivated or self-determined to engage in certain behaviors and provides a conceptual model for the processes that both 
facilitate and thwart motivation (Deci, Eghrari, Patrick, \& Leone, 1994; Deci \& Ryan, 2002; Ryan \& Deci, 2000). A sub-theory of the SDT is the Basic Needs Theory. This theory posits that individuals have three innate psychological needs, competence, relatedness, and autonomy, and these needs must be met in order to facilitate optimal motivation (Ryan \& Deci, 2000; Weman-Josefsson, Lindwall, \& Ivarsson, 2015). According to this theory, environments and situations that undermine fulfillment of these needs will ultimately have a negative impact on self-motivation, while those that promote satisfaction of these needs will lead to improved self-motivation.

\section{Present Study}

This study tests the hypothesis that experienced weight stigma (i.e., experienced prejudice and discrimination due to one's weight status) is negatively associated with motivation (as assessed by intention) to exercise. While many factors can influence a person's motivation to engage in regular exercise, it has been proposed that weight stigma experiences can impede exercise motivation (Vartanian \& Shaprow, 2008); however, few studies have explored these relationships. Given the dearth of studies, the specific processes by which experienced weight stigma might undermine exercise motivation are not well conceived. The aims of the present study are to (a) explore relationships between experienced weight stigma and exercise motivation and behavior (b) explore how experienced weight stigma might differ based on important factors such as body weight and demographic variables such as age and (c) explore unique associations among experienced weight stigma, exercise motivation, and psychological need satisfaction, as outlined by the Basic Needs Theory. Exploration of such unique associations will serve as the first step in testing the proposed conceptual model that 
psychological need satisfaction may mediate the relationship between experienced weight stigma and motivation to exercise, which can be formally examined in future longitudinal study designs. In the following sections, relevant literature within the domains of weight stigma and exercise motivation and behavior will be reviewed to address the proposed aims and research questions.

\section{Background Information}

\section{Overweight and Obesity}

Obesity can be defined as a complex medical disorder wherein an individual carries an excessive amount of body fat (Mayo Clinic, 2015). Body Mass Index (BMI), calculated from height and weight measurements, is the most commonly utilized tool for estimating overweight and obesity (National Institute of Diabetes and Digestive and Kidney Diseases, 2012; World Health Organization, 2016a). According to the Centers for Disease Control and Prevention (CDC), approximately $70.2 \%$ of adults in the United States (U.S.) are overweight or obese (The National Institute of Diabetes and Digestive and Kidney Disease, 2017).

Of particular concern, individuals with overweight and obesity are at an increased risk for a number of health problems, many of which are leading causes of preventable death (Kushner, 2012). Such conditions include Type 2 diabetes, cardiovascular disease, hypertension, high cholesterol, and some cancers as well as depression and poor quality of life (Centers for Disease Control and Prevention, 2015a; Kushner, 2012; Luppino et al., 2010; NHLBI Obesity Education Initiative Expert, 1998). Research has shown that overweight and obese individuals who lose $5-10 \%$ of their initial body weight can gain significant health benefits (such as improved blood glucose, blood pressure and lipid levels), effectively reducing their risk for a multitude of health ailments (LeBlanc, 
O'Connor, Whitlock, Patnode, \& Kapka, 2011; Levy, Finch, Crowell, Talley, \& Jeffery, 2007).

\section{The Importance of Physical Activity and Exercise}

In response to high rates of overweight and obesity and the large repercussions on health and well-being, much research has been devoted to the development of effective interventions. The most common and effective approaches include behavioral interventions, often targeting diet and physical activity, as well as medication and surgical procedures (Thompson, Cook, Clark, Bardia, \& Levine, 2007). Studies have found that individuals who engage in regular physical activity tend to be more successful in achieving and maintaining clinically meaningful weight loss (Jakicic et al., 2001). In addition, regular engagement in physical activity provides health benefits beyond weight control including reduced risk for cardiovascular disease, Type 2 diabetes, and cancer as well as improved psychological health, muscle and bone strength, and functional status (Centers for Disease Control and Prevention, 2015b). Interestingly, nascent evidence indicates that improved cardiorespiratory fitness obtained through increased engagement in physical activity and exercise may actually improve overall health and reduce all-cause mortality, regardless of weight status (Hainer, Toplak, \& Stich, 2009).

Despite documented importance of physical activity, data suggests that only $21 \%$ of adults in the U.S. meet physical activity guidelines, independent of weight status (Centers for Disease Control and Prevention, 2014). Further, data collected from the National Health and Nutrition Examination Survey (NHANES) between 1999 and 2006 $(n=7,695)$ suggests that overweight and obese adults are engaging in less moderate and vigorous physical activity and for a shorter duration when compared to adults of healthy 
weight (Spees, Scott, \& Taylor, 2012). This widespread tendency for adults, particularly those with overweight and obesity, to be sedentary and inactive holds important implications for health and the prevention and treatment of overweight and obesity.

For the purposes of the present study, the term exercise will be used as defined by Caspersen and colleagues (1985) such that exercise is a subset of physical activity that captures purposeful, structured, and planned activity which is often more difficult to initiate and maintain, particularly for sedentary individuals, as it moves beyond lifestyle activity (this conceptualization of exercise has also been adopted by many reputable sources; National Institute on Aging, 2016).

\section{Motivation to Exercise}

It is well documented that successful maintenance of exercise is difficult, regardless of weight status. It is common for individuals to go months at a time without exercising (Sallis et al., 1990; Thøgersen-Ntoumani \& Ntoumanis, 2006). Further, structured exercise programs are known for high attrition rates, with many facing nearly 50\% drop-out within the first six months (Hsu, Buckworth, Focht, \& O'Connell, 2013). Therefore, a plethora of research has been devoted to addressing barriers to exercise. Common self-reported barriers to exercise include finding exercise unenjoyable and boring, not having time, low exercise self-efficacy, lack of support from friends and family, and overall lack of self-motivation (Centers for Disease Control and Prevention, 2011; Ebben \& Brudzynski, 2008; Leone \& Ward, 2013; McAuley, 1992).

Importantly, individuals with overweight and obesity face additional barriers to exercise motivation. For example, many of the physiological and metabolic processes underlying development and maintenance of overweight and obesity can impact energy 
levels and also impede successful weight loss, which can affect motivation to exercise (Epel et al., 2000; Ervin, 2009; Maloney, Boneva, Lin, \& Reeves, 2010). Furthermore, research has demonstrated that overweight and obese individuals have less exercise capacity and experience more feelings of displeasure when exercising when compared to those of healthy weight (Ekkekakis \& Lind, 2005; Ekkekakis, Lind, \& Vazou, 2010; Hulens, Vansant, Lysens, Claessens, \& Muls, 2001). These findings hold important implications as they demonstrate not only physical differences in ability to exercise but also unique cognitive and affective experiences that can undermine motivation.

Since motivational factors have emerged as critical barriers for engagement in regular exercise, substantial research has been devoted to developing theoretical frameworks and interventions to better understand and facilitate motivational processes in activity (Ebben \& Brudzynski, 2008; Thøgersen-Ntoumani \& Ntoumanis, 2006; Wilson, Mack, \& Grattan, 2008). For example, the Theory of Planned Behavior is a prominent theoretical model of intention and behavior (Ajzen, 1991, 2011). This theory posits that behavioral intentions, which are influenced by attitudes and beliefs, subjective norms, and perceived behavioral control, can be used to predict actual behavior (Ajzen, 1991). Using the model provided by the Theory of Planned Behavior, intentions have frequently been utilized to assess exercise motivation (Courneya, Friedenreich, Arthur, \& Bobick, 1999; Karvinen et al., 2007).

Another empirically supported model of motivation is the SDT, which has been widely applied to exercise motivation and behavior (Hagger \& Chatzisarantis, 2008; Wilson et al., 2008). This theory presents motivation along a continuum, ranging from amotivation to intrinsic motivation, and identifies various processes and regulatory styles 
necessary to promote sustained motivation (see Figure 1; Ryan \& Deci, 2000; Ryan et al., 2008). For example, this theory proposes that more autonomous forms of motivation promote internally-driven, lasting motivation and well-being (Teixeira, Silva, Mata, Palmeira, \& Markland, 2012b). In contrast, controlled forms tend to be externally-driven and associated with poorer outcomes (Hagger \& Chatzisarantis, 2008). For a detailed description of the SDT and its related constructs, please reference the following: Ryan and Deci (2000), Ryan and colleagues (2008), and Ng and colleagues (2012). As aforementioned, the Basic Needs Theory (sub-theory of SDT) posits that developing a sense of autonomy, competence, and relatedness is critical for promoting effective motivation (Ryan et al., 2008). Autonomy refers to the innate need or desire to engage in activities and behaviors that are personally directed and endorsed (Deci \& Ryan, 2002; Edmunds, Ntoumanis, \& Duda, 2006). Competence refers to the innate need to feel effective and confident in navigating one's environment in an effort to achieve desired outcomes (Deci \& Ryan, 2002; Edmunds et al., 2006). Relatedness refers to the innate need to feel as though one belongs, is socially connected, cared for, and respected by others (Edmunds et al., 2006; Ryan et al., 2008).

\section{Basic Needs Theory Applied to Exercise Behavior}

The Basic Needs Theory has been widely explored in the domain of exercise motivation and behavior. Empirical findings indicate that autonomous motivation is positively associated with exercise engagement and adherence, perceived competence, exercise intention, and psychological well-being (Hagger \& Chatzisarantis, 2008). Additionally, studies have demonstrated strong connections between psychological need satisfaction and more self-determined motivational regulations (Edmunds et al., 2006; 
Weman-Josefsson et al., 2015). For example, Edmunds and colleagues (2006) completed a cross-sectional study of 369 adults (participant weight status was not reported) and found that psychological need satisfaction was positively associated with not only more self-determined motivation regulations, but also strenuous and total exercise behavior. In contrast, more controlled forms of motivation (externally-driven) were identified as negative predictors of strenuous exercise. Findings from this study support the notion that fostering psychological need satisfaction, as described by the Basic Needs Theory, promotes exercise motivation and behavior.

Other studies have examined Basic Needs Theory constructs and exercise motivation and behavior in overweight and obese samples in the context of weight loss treatment interventions (Silva et al., 2010a; Silva et al., 2010b; Teixeira et al., 2012b; Williams, Grow, Freedman, Ryan, \& Deci, 1996). Findings from these studies support results seen in healthy weight samples, such that autonomous motivation was positively associated with exercise behavior and psychological need satisfaction. Other studies, such as Hsu and colleagues (2013), have assessed the effectiveness of SDT-informed exercise interventions in overweight and obese samples. Findings indicate that such interventions are feasible and effective in promoting need satisfaction, particularly autonomy and competence, autonomous motivation regulations, as well as increasing energy expenditure through exercise.

Altogether, these findings suggest that the SDT and the Basic Needs constructs can help to not only inform exercise interventions for healthy weight as well as overweight and obese adults but also provide a deeper understanding of the processes by which motivation to exercise may be thwarted. Recently, attention has focused on social 
processes, such as weight stigma, that may have a negative impact on motivation to exercise. However, empirical research has yet to specifically address how experienced weight stigma can undermine motivation to exercise. The Basic Needs Theory (i.e., satisfaction of autonomy, competence, and relatedness facilitate motivational processes) may provide a deeper understanding of these relationships.

\section{Weight Stigma}

Discrimination due to weight is among the most frequently experienced forms of discrimination by adults (Puhl \& Suh, 2015). As such, research examining the impact of weight stigma is mounting. Presently, two distinct constructs are utilized within the weight stigma literature, including experienced and internalized stigmatization. Experienced weight stigma addresses frequency of weight stigma experiences, while internalized stigma is when an individual accepts (often implicitly) negative stereotypes about themselves as true (Papadopoulos \& Brennan, 2015). Negative effects of weight stigma may illustrate the significance and pervasiveness of weight stigma on health and well-being.

Health care. Health care professionals are not immune to ubiquitous negative stereotypes about overweight and obese persons. Burgeoning literature has examined weight bias among health care providers, including those specializing in the treatment of obesity. Schwartz and colleagues (2003) administered the Implicit Associations Test (IAT) to a group of 389 professionals at an international obesity conference and found a significant anti-fat implicit bias. Further, these professionals endorsed implicit stereotypes such that "fat people" are stupid, lazy, and worthless. Also problematic, health care professionals have been found to over-emphasize personal control and 
responsibility in weight management, often blaming the patient, and generally lack awareness for the multitude of factors that perpetuate obesity including metabolic and biological mechanisms (MacLean et al., 2009; Puhl \& Heuer, 2010). These negative stereotypes and beliefs about overweight and obese persons hold important implications for medical care and decision making.

Phelan and colleagues (2015) discuss the substantial empirical support surrounding the impact of weight stigma on quality of medical care as well as treatment outcomes for patients with obesity. For example, primary care providers have been shown to engage in less patient-centered communication and are less likely to refer to important diagnostic and screening tests when treating patients with obesity. Further, primary care providers have endorsed spending less time educating patients with obesity about their health and even report having less respect for them. Patients recognize how their weight status impacts quality of care and have often reported insensitive communication from their doctors and nurses and have issued complaints that providers blame any medical problem they may be experiencing due to their weight without exploring other causes (Malterud \& Ulriksen, 2011). Relatedly, overweight and obese persons have endorsed avoiding or delaying medical care due to weight-related reasons, including stigmatization (Ahmed, Lemkau, \& Birt, 2002; Alegria Drury \& Louis, 2002). These findings provide an example of how weight stigma can negatively impact the health of overweight and obese persons, who are already at an increased risk for medical co-morbidities and poor health outcomes.

Psychological well-being. Mounting empirical evidence indicates that experienced and internalized weight stigma negatively affects psychological well-being. 
In a recent review, Papadopoulos and Brennan (2015) surmised that frequent experiences with weight stigma are associated with psychiatric symptoms, psychological distress, and mood disturbances. Further, experienced and internalized weight stigma has been associated with depression and decreased self-esteem. A limited number of studies have examined perceived stress, antisocial behavior, substance abuse, and maladaptive coping in the context of experienced weight stigma. Preliminary findings indicate some positive associations. (Papadopoulos \& Brennan, 2015)

It is important to note that overweight and obese persons may be especially vulnerable to the negative psychological effects of weight stigma. Unlike many other forms of bias and stigma, weight stigma remains socially acceptable and is present in a number of interpersonal and institutional settings and contexts (Puhl \& Heuer, 2010; Puhl \& Brownell, 2006). Examples of commonly endorsed forms of interpersonal stigma include comments from children, health care providers, and family members while institutional weight stigma may include physical barriers and obstacles such as small plane seats (Wott \& Carels, 2010). Further, while other stigmatized groups such as ethnoracial minorities often view in-group members positively, many overweight and obese individuals have internalized weight stigma and harbor negative attitudes and beliefs about their own group, limiting the protective role that in-group identity can normally provide (Wang, Brownell, \& Wadden, 2004). In this regard, individuals with overweight and obesity may be more vulnerable to both negative psychological and physiological consequences of stigma, which can not only impact overall well-being but also body weight. 
Weight loss. Emergent evidence suggests that more frequent weight stigma experiences can hinder successful weight loss (Puhl \& Heuer, 2010). For example, Wott and Carels (2010) found that more frequent weight stigma experiences was associated with increased caloric intake and decreased exercise energy expenditure in a sample of overweight and obese adults participating in a weight loss treatment program. Similarly, Carels and colleagues (2009) found that greater internalized weight bias was associated with higher rates of attrition, greater caloric intake, and lower energy expenditure through exercise in a sample of overweight and obese adults participating in a separate weight loss treatment program. Perceived weight discrimination has also been found to predict changes in obesity status over time. For example, a longitudinal study completed by Sutin and Terracciano (2013) found that those who reported experiencing weight discrimination were approximately 2.5 times more likely to become obese at a 4 -year follow-up when compared to those who did not endorse weight discrimination. Further, obese participants who reported experiencing weight discrimination were approximately 3 times more likely to remain obese at follow-up.

Dietary behavior. Similar to previously discussed findings from weight loss treatment programs, a number of studies have demonstrated that encounters with weight stigma are associated with poor diet behavior including increased food consumption, less dietary restraint, and more frequent binge eating (Major, Hunger, Bunyan, \& Miller, 2014; Puhl \& Suh, 2015). Both experienced and internalized weight stigma is associated with maladaptive coping such as refusing to diet and eating more food (Puhl \& Heuer, 2010). These findings suggest that weight stigma may actually increase engagement in 
unhealthy dietary habits, which can ultimately perpetuate overweight and obesity as well as poor health outcomes.

\section{Summary}

Emergent evidence indicates that both experienced and internalized weight stigma negatively affects psychological and physical well-being. One subset of weight stigma research that requires more attention is the potential impact of weight stigma on exercise motivation and behavior. Empirical evidence has shown that overweight and obese individuals tend to exercise less than those of healthy weight, which contributes to both the development of chronic and life-threatening health ailments as well as unhealthy weight status. While many factors can influence a person's motivation to engage in regular exercise, it has recently been proposed that experienced and internalized weight stigma can impede exercise motivation. At present, the specific processes by which weight stigma may undermine exercise motivation are not well conceived.

\section{Weight Stigma and Exercise Literature}

The present study aims to explore associations between experienced weight stigma (i.e., frequency of personal experiences with weight-related stigmatizing situations) and exercise motivation. Specific and recent prevalence rates of weight-based stigma and discrimination are not well-known, however, some studies have found comparable rates of weight-related discrimination and discrimination due to race (Puhl, Andreyeva, \& Brownell, 2008). Additionally, prevalence of weight/height discrimination in U.S. adults increased by 66\% between 1995-1996 and 2004-2006 (Andreyeva, Puhl, \& Brownell, 2008). Qualitative studies have identified commonly endorsed weight stigma experiences of persons with overweight and obesity that can undermine exercise 
motivation and behavior, such as being laughed at or verbally degraded when exercising and feeling unwilling to engage in exercise due to the expectation and fear that they would be laughed at, stared at, abused and ridiculed (Lewis et al., 2011a). Studies specifically examining experienced weight stigma, exercise motivation and exercise behavior in adults are scarce. The sections below provide a review and critical analysis of experienced weight stigma and exercise studies. For studies exploring internalized weight stigma, please see Vartanian and Novak (2011) and Pearl, Puhl and Dovidio (2015).

Experienced weight stigma. In an early cross-sectional study of the association between experienced weight stigma and exercise motivation and behavior in a non-youth sample (Vartanian \& Shaprow, 2008), 100 female undergraduates completed a battery of self-report questionnaires to assess experiences with weight stigma, self-esteem, body dissatisfaction, as well as exercise-avoidance motivation. Exercise-avoidance motivation was assessed with an 8-item measure designed to convey the degree to which an individual is motivated to avoid exercise due to negative experiences with weight stigma. Weight stigma experiences were positively associated with BMI, body dissatisfaction, and exercise-avoidance motivation, but not with self-esteem. Further, stigma experience and BMI were both uniquely associated with exercise-avoidance motivation (explained $47 \%$ of the variance). Individuals who were motivated to avoid exercise reported less engagement in moderate and strenuous exercise behavior. Interestingly and contrary to what one may hypothesize, stigma experiences were not associated with self-reported exercise behavior.

Participant weight status is a likely explanation for the non-significant weight stigma-exercise behavior relationship, as the majority of participants were at a healthy 
weight and did not report frequent experiences of weight stigma. However, $85 \%$ reported experiencing weight stigma on at least one previous occasion. Secondary analyses comparing these relationships by BMI group (overweight and obese participants vs. not) indicated that the magnitude of the association between weight stigma experiences and exercise-avoidance motivation was larger for the heavier participants. Negative associations between weight stigma experience and self-reported exercise behavior were noted for overweight and obese participants; however, correlations did not reach statistical significance. This can likely be attributed to lack of statistical power from the small sub-sample of overweight and obese participants $(\mathrm{n}=25)$.

One salient limitation of this early study was the lack of instrument validity in assessment of motivation, beyond demonstration of good internal consistency. Use of validated and theoretically-driven measures assessing exercise motivation would prove useful in future studies as it would allow researchers to make stronger conclusions about study findings. Moreover, researchers utilized an unspecified self-report measure to obtain data on exercise behavior. While this measure included detailed information about exercise frequency, duration, and intensity, a notable strength, it only inquired about behavior over the past week which may not reflect usual behavior. An additional limitation of this study is the very small proportion of individuals with overweight and obesity in the sample. In order to understand how weight stigma affects these health behaviors, it is important to include a sample that is regularly subjected to weight stigma. However, it is interesting that even individuals who are not physically overweight or obese still have experienced some form of weight stigma, which demonstrates the pervasiveness of this problem. With these methodological limitations in mind, study 
findings must be interpreted with caution, particularly since most of these participants did not frequently experience weight stigma.

Stereotype threat. The construct of stereotype threat, when a person is confronted with a negative stereotype relevant to their social identity, feels at-risk for confirming this stereotype, and ultimately performs poorly, has been commonly applied to other stigmatized groups such as ethnoracial minorities (Seacat \& Mickelson, 2009; Steele \& Aronson, 1995). Seacat and Mickelson (2009) examined weight-related stereotype threat influences on exercise self-efficacy, motivation, and behavior in a sample of 100 overweight women. Participants were randomly assigned to one of two conditions, a stereotype prime condition or control condition. In the stereotype prime condition, participants were presented with a brief vignette incorporating weight-related stereotypes within a fictitious study of women's health behaviors and then were asked to report weight and height prior to completing a battery of self-report measures. In the control condition the vignette did not prime weight stereotypes and height and weight was reported upon conclusion of the study. Participants who were primed to think about weight-related stereotypes endorsed significantly lower exercise intentions (i.e., exercise motivation) and exercise self-efficacy when compared to those in the control condition.

The findings from this study hold several important implications. If experiences with stereotype threat contribute to decreased health self-efficacy, intentions, and behaviors, then negative stereotypes about weight may actually be interfering with successful initiation and maintenance of exercise. This point is quite important given the critical role of regular engagement in exercise in weight management and health outcomes. However, it is important to note that women in this study were recruited from 
exercise-specific settings (such as Curves) and reported exercising for at least 30 minutes per week. Studies examining non-exercisers is an important direction for future research, as this will provide insight into how exposure to weight-related stereotypes can affect motivation to exercise in sedentary individuals.

Medical populations. Only one study has been completed examining these relationships among samples with co-morbid medical conditions. Potter and colleagues (2015) completed a cross-sectional study examining the effects of perceived weight discrimination on well-being, self-care, and disease status in 185 adults with poorly controlled Type 2 diabetes. Results showed that participants who endorsed discrimination due to weight had higher HbA1c (an important indicator of diabetes control; U.S. Department of Health and Human Services Health Resources and Services Administration, 2012), higher diabetes-related distress, and engaged in healthy diet practices, blood glucose testing and exercise behaviors less days when compared to those who did not report weight discrimination. These results remained true even when controlling for BMI and total discrimination experienced (including racial).

These findings suggest that weight-related discrimination can negatively affect individuals' ability to engage in important disease self-care behavior such regular engagement in exercise, regardless of weight status, which is consistent with patterns seen in relatively healthy samples. Importantly, participants recruited from this study had poorly controlled diabetes (high $\mathrm{HbA1c}$, majority overweight and obese), and therefore these results may not generalize to those with more controlled diabetes. Additionally, because this study did not focus on exercise, we do not have information related to participants' motivation to exercise. However, given that there was a negative association 
between perceived weight discrimination and exercise behavior, exercise motivation may also have been low.

Application of SDT Constructs. Two studies examining weight stigma and exercise motivation and behavior have been completed that incorporate constructs present within the SDT. Pearl, Dovidio, Puhl, and Brownell (2015) assessed the relationships between experienced weight stigma and exercise motivation and behavior and the potential impact of stigmatizing media. Seventy-four community-dwelling female participants were randomly assigned to view either a weight-stigmatizing video comprised of various popular media clips or a neutral video. Following presentation of the video, participants completed self-report measures assessing the constructs of interest including exercise intention, exercise-avoidance motivation, SDT motivational regulations (i.e., controlled/extrinsic or autonomous/intrinsic) and exercise behavior. Exercise behavior and intentions were assessed one week later.

Findings revealed that the frequency of past experience with weight stigma was associated with worse psychological well-being and more controlled (vs. autonomous) exercise motivation. Controlled exercise motivation was associated with higher body dissatisfaction and drive for thinness, but not current exercise behavior. This finding suggests that experiences with weight stigma may contribute to poor psychological outcomes and attitudes toward exercise, which do not promote engagement in regular exercise. Interestingly, participants in the stigma video condition with more frequent past experiences of weight stigma endorsed greater exercise intentions, exercise behavior, and drive for thinness. At follow-up, regression analyses revealed that higher frequency of weight stigma experiences predicted less exercise behavior for the neutral video 
condition but higher exercise behavior in the stigma condition. It is important to note that while intentions and exercise behavior increased in the short-term, this study provides no data on the impact in the long-term. However, previous research has suggested that individuals with more controlled motivational styles have worse outcomes in the longterm (Pearl et al., 2015b). This is one of the few studies examining SDT constructs in the context of weight stigma; however, it was not the primary focus. Future research should examine the impact weight stigma has on exercise motivation and behavior utilizing validated SDT measures, which could further elucidate the manner by which weight stigma can impact motivation to exercise (increase motivation or interfere with motivation, for example).

In a separate study incorporating SDT and Basic Needs Theory constructs, Schmalz (2010) aimed to (1) explore the relationship between awareness of weightrelated stigma (i.e. consciousness) and perceived competence in physical activity and (2) explore the possible mediation effects of body esteem and BMI on the weight-stigma consciousness and perceived competence relationship. Seventy-six adults who were enrolled in a weight management program were recruited for this study. Path modeling analyses revealed that body esteem mediated the relationship of consciousness of weight stigma and perceived competence in physical activity; BMI did not emerge as a mediator in this relationship. BMI, however, was negatively associated with perceived physical activity competence. These findings suggest that subjective perception of weight (e.g. body esteem) is important to consider when examining engagement in physical activity, rather than simply examining BMI status. Further, perceived competence is an important 
construct within many influential theories of motivation including self-determination theory.

This study has several limitations. First, the sample was comprised of mostly White middle-aged/older women, which certainly limits the generalizability of these findings. Additionally, this sample consisted of people who were currently enrolled in a weight management program, which suggests higher motivation to lose weight and engage in healthy behaviors. Further, additional studies should employ objective and validated measures of physical activity and exercise to examine these relationships on actual behavior.

\section{Exploring Unique Associations by Applying Basic Needs Constructs}

The Basic Needs Theory has yet to be widely explored in the context of weight stigma and exercise motivation, yet it may provide a useful conceptual explanation for the preliminary empirical findings indicating the negative impact experienced weight stigma can have on exercise motivation and behavior in adults.

\section{Proposed Associations}

While studies have shown that experienced weight stigma can negatively affect exercise motivation and behavior, researchers have yet to establish the mechanisms through which this could be occurring. In keeping with the Basic Needs Theory, three innate needs (i.e., autonomy, competence, relatedness) must be fulfilled in order to promote self-determined motivation (Ryan \& Deci, 2000). This theory has been applied to a plethora of behaviors, including health behaviors such as diet and physical activity (Ryan et al., 2008); however, constructs have not yet been applied to the study of experienced weight stigma. The present study aims to explore unique associations 
among experienced weight stigma, motivation to exercise, and psychological need satisfaction by applying constructs from the Basic Needs Theory. This study will inform future longitudinal studies that may explore these constructs through use of mediation to clarify mechanisms of action. The proposed conceptual model, described below, will detail how weight stigma may be undermining motivation to exercise by thwarting fulfillment of competence, autonomy, and relatedness (conceptual model visually depicted in Figure 2).

Autonomy. The need for autonomy refers to the innate need or desire to engage in activities and behaviors that are personally directed and endorsed (Deci \& Ryan, 2002; Edmunds et al., 2006). In other words, people must feel as though they have a choice in their actions. Importantly, individuals can engage in behaviors that others have requested or encouraged and still have a sense of autonomy as long as they also personally endorse that behavior (Deci \& Ryan, 2002). As proposed by the Basic Needs Theory and supported by empirical studies, satisfaction of this need has been shown to promote selfdetermined exercise motivation (Ng et al., 2012). Additionally, studies have demonstrated positive associations between satisfaction of autonomy and moderate and strenuous exercise behavior (Weman-Josefsson et al., 2015). According to Ryan and colleagues (2008), a number of factors influence psychological need satisfaction, particularly the need for autonomy, including environmental (e.g., autonomy supportive vs. controlling) and personality factors. Environments that are autonomy supportive have been shown to be positively associated with psychological need satisfaction and selfdetermined motivation (Edmunds et al., 2006). Using health care as an example, an autonomy supportive climate would be one wherein the health care provider 
demonstrates respect for the patient's choice, even if that choice is against the medical recommendation (Ng et al., 2012).

Individuals who experience weight stigma directly related to exercise and health behaviors may feel as though their choices are not respected. As previously discussed, physicians engage in less patient-centered communication and spend less time discussing treatment options with overweight and obese patients (Phelan et al., 2015). Therefore, it is quite probable that a health care provider may prescribe or recommend a specific exercise regimen for the patient without addressing patient concerns or incorporating important feedback about patient preference, which can undermine patient autonomy. As an additional example, it is not unlikely that when overweight and obese persons attempt to exercise, friends, family, and even personal trainers may assume that the person does not know how to properly exercise due to the negative stereotypes they harbor. This may lead these people to feel compelled to "educate" the overweight or obese person and dictate the exercise session with little regard for that person's choice. While there are numerous situations in which one could hypothesize how experienced weight stigma may thwart satisfaction of autonomy, this has yet to be explored in the empirical literature.

Competence. The need for competence refers to feeling effective and confident in navigating one's environment in an effort to produce desired outcomes (Deci \& Ryan, 2002; Edmunds et al., 2006). To support the need for competence, it is important for the person to both possess skills and have access to the resources necessary to experience mastery and overcome any barriers that should arise (Ryan et al., 2008). According to the SDT, developing a feeling of competence is facilitated by autonomy-when an individual personally endorses a behavior they are more inclined to learn and persevere (Ryan et al., 
2008). In a systematic literature review examining exercise and physical activity in the context of the SDT, competence satisfaction was cited as the most frequently explored need in the empirical literature, with findings consistently demonstrating a positive association with exercise motivation and behavior (Teixeira, Carraça, Markland, Silva, \& Ryan, 2012a).

The proposed conceptual model suggests that both experiencing frequent weight stigma related to exercising, as well as internalizing negative beliefs and stereotypes about overweight and obese person's ability to effectively exercise will undermine competence in this domain. As Vartanian and Shaprow (2008) and Vartanian and Novak (2011) found, experienced and internalized weight stigma may lead individuals to avoid engaging in exercise, which means that these individuals will have limited opportunities to develop skills and mastery in this context. While this has yet to be explored in regards to weight stigma, research exploring the negative effects of race-based stigma have found that perceived racial discrimination can lead to decreased levels of mastery and increased psychological distress (Broman, Mavaddat, \& Hsu, 2000). As of yet, few studies have specifically incorporated perceived competence within the domain of weight stigma research (i.e., Schmalz, 2010); findings support the assertion that awareness of weight stigma (i.e., stigma consciousness) negatively impacts perceived competence to engage in physical activity and exercise. Importantly, this relationship was mediated by bodyesteem, which could be conceptualized as a potential indicator of internalized weight stigma. This is similar to other studies examining how stigma consciousness can negatively affect outcomes. For example, Brown and Pinel (2003) found that stigma consciousness moderated the effect of gender stereotypes on math performance in a 
sample of women. Specifically, those high in stigma consciousness performed worse when experiencing stereotype threat. Additional studies have demonstrated how stereotype threat can undermine motivation. For example, Fogliati and Bussey (2013) found that women exposed to stereotype threat related to math performance not only performed more poorly than non-stereotyped women but were also less motivated to improve. Applying these results to weight-related stereotype threat, if exposure to stereotypes can negatively affect motivation to engage in exercise or improve in this domain, this would also limit the person's perceived competence.

As noted, findings from Seacat and Mickelson (2009) suggest that experiencing weight-related stereotype threat can undermine motivation to exercise. In this study, exercise self-efficacy was found to partially mediate this relationship. Self-efficacy, a concept proposed by Bandura (1977), is conceptualized as the belief that one can successfully accomplish a task, even in the presence of barriers. Arguably self-efficacy is related to perceived competence as defined by the SDT such that it involves feeling confident in one's ability to successfully complete a desired behavior. Therefore, it is possible that weight-related stereotype threat undermines motivation to exercise by negatively impacting self-efficacy, mastery, and thus competence.

Relatedness. The need for relatedness refers to feeling as though one belongs, is socially connected, cared for, and respected by others (Edmunds et al., 2006; Ryan et al., 2008). This is possibly the most face valid assertion of the propose model, as it is clear that experiencing weight stigma through rude comments and discriminatory behavior can impact a person's sense of feeling respected. Qualitative studies have identified commonly endorsed weight stigma experiences of overweight and obese persons that can 
undermine exercise motivation and subsequent behavior (Lewis et al., 2011a; Lewis, Thomas, Hyde, Castle, \& Komesaroff, 2011b). For example, participants reported being laughed at or verbally degraded when exercising and feeling unwilling to engage in exercise due to the expectation and fear that they would be laughed at, stared at, abused and ridiculed (Lewis et al., 2011a). Further, obese persons have reported feeling socially withdrawn and disconnected due to experiences with weight stigma beyond the context of exercise. Specifically, these persons reported feeling "lonely", "rejected", "excluded" and “isolated" (Lewis et al., 2011a). In a qualitative study exploring these perceptions in obese men, some even reported feeling as though they could not be considered a good role model for their children (Lewis et al., 2011b). These findings support the empirical evidence indicating negative affect, lowered self-esteem, and social withdrawal as common reactions to discrimination, rejection, and stigmatization (Smart Richman \& Leary, 2009). While there are no quantitative empirical studies that have formally examined the impact of weight stigma on relatedness, the quantitative data in addition to patterns seen in other stigmatized groups suggests that this is a reasonable hypothesis.

\section{Summary}

The Basic Needs Theory posits that satisfaction of three innate needs, autonomy, competence, and relatedness, are necessary to promote successful motivational processes. This research proposes that this theory may be applied to the current weight stigmaexercise literature to help conceptualize underlying mechanisms of action, something that has yet to be explained. Specifically, it is proposed that weight stigma can undermine motivation to exercise by thwarting satisfaction of these three needs. However, due to the novelty of this model, it has yet to be tested empirically. The present study aims to serve 
as the first step in considering the proposed conceptual model by exploring unique associations among experienced weight stigma, exercise motivation and psychological need satisfaction. Future studies may expand upon this research to consider the role of internalized weight stigma and examine mechanisms of action through use of longitudinal study designs.

\section{Purpose of the Present Study}

The present study aims to further explore associations between experienced weight stigma and motivation to exercise in a diverse community sample of women. Very few studies have examined these relationships and preliminary investigations have a variety of limitations. For example, some studies failed to incorporate theoretically and empirically supported measures of motivation and exercise behavior. The purpose of the present study is to (a) explore relationships between experienced weight stigma and exercise motivation and behavior using theoretically informed measures (b) explore how experienced weight stigma might differ based on important factors such as body weight and demographic variables such as age and (c) explore unique associations among experienced weight stigma, exercise motivation and psychological need satisfaction, as outlined by the Basic Needs Theory.

The majority of previous studies examining weight stigma have been limited to women and the few studies examining gender differences in experience, internalization, and coping with weight-based stigma have had mixed findings (Papadopoulos \& Brennan, 2015; Puhl \& Brownell, 2006). Additionally, studies have shown that women tend to be less physically active overall and exercise less than their male counterparts (Nomaguchi \& Bianchi, 2004; Troiano et al., 2008; World Health Organization, 2016b). Moreover, there appears to be differences in motivation to exercise, with some studies 
suggesting that women are more extrinsically motivated while men endorse more intrinsic motivations (Egli, Bland, Melton, \& Czech, 2011; Lauderdale, Yli-Piipari, Irwin, \& Layne, 2015). Relatedly, studies have suggested that women are more likely to exercise for weight control when compared to men (McDonald \& Thompson, 1992), which could possibly be connected with experiences and coping with weight stigma. Presently, the experienced weight stigma and exercise literature is in its infancy and therefore associations have not been well studied. Given the lack of clarity with the role of gender in experience of weight stigma as well as established differences in exercise motivation and behavior by gender, the present study aims to explore and clarify these associations in a female-only sample.

\section{Research Questions and Hypotheses}

\section{1a. How does experience with weight stigma relate to BMI status?}

\section{1b. Does experience with weight stigma differ by BMI status?}

Hypothesis: Previous studies report positive associations between BMI and experience with weight stigma (Pearl et al., 2015b; Pearl et al., 2015c; Vartanian \& Shaprow, 2008). Therefore, it is predicted BMI will be positively associated with experienced weight stigma, as measured by the Stigmatizing Situations Inventory, such that those with higher BMI will endorse more frequent experience with weight stigma. Pearson's correlations will be used to examine the relationship between experienced weight stigma and BMI. Further, a One-Way ANOVA will be completed to compare mean scores on the Stigmatizing Situations Inventory by BMI classification.

\section{How does experienced weight stigma relate to exercise motivation?}


Hypothesis: At present, the literature is mixed with regard to the relationship between experienced weight stigma and exercise motivation. As previously described, mixed findings may be in part due to the methodological and conceptual limitations regarding exercise motivation in previous studies. In the weight stigma literature, several coping strategies for dealing with experienced weight stigma have been identified that do not promote health outcomes including avoidance of potentially stigmatizing situations, negative self-talk, and eating more (Puhl \& Brownell, 2006). Additionally, some studies found negative associations between experienced weight stigma and motivation to avoid exercise. Therefore, it is predicted that those with more frequent experiences with weight stigma will also endorse less intention to exercise. In other words, I would expect individuals with high motivation to avoid exercise to also endorse low intention to exercise. Additionally, previous studies described positive associations between experienced weight stigma and controlled motivation style (Pearl et al., 2015b); therefore, it is predicted that a positive association will also emerge in the present study. Pearson's correlation analyses and regression analyses will be utilized to assess these hypotheses.

\section{How does experienced weight stigma relate to exercise behavior?}

Hypothesis: As previously described, studies exploring the relationship between experienced weight stigma and exercise behavior have mixed findings. However, given that exercise motivation can be used to predict behavior, it is hypothesized that more frequent experiences with weight stigma will be associated with less intention to exercise and therefore less engagement in exercise behavior. Pearson's correlation analyses will be completed to explore this relationship. 


\section{How does experienced weight stigma relate to psychological need satisfaction?}

Hypothesis: Experienced weight stigma has yet to be thoroughly examined within the context of the Basic Needs Theory. However, as previously described, it is possible that experienced weight stigma could be negatively associated with satisfaction of autonomy, competence, and relatedness. Pearson's analyses will be completed to explore (a) if experienced weight stigma is significantly associated with any of the three psychological needs and (b) the direction of any observed associations.

\section{How is experienced weight stigma and psychological need satisfaction uniquely associated with exercise motivation?}

Hypothesis: As previously described, the literature is currently lacking an explanation of how experienced weight stigma may undermine motivation to exercise. The proposed model (see Figure 2) suggests that experience with weight stigma may thwart psychological need satisfaction. Though this has yet to be explored previously, it is hypothesized that psychological need satisfaction, particularly the needs of competence and relatedness, will emerge as partial mediators in the experienced weight stigma/motivation relationship. See Figure 3 for a visual depiction of the proposed mediational model.

The present cross-sectional study will complete preliminary hierarchical regression analyses for testing the proposed conceptual model. Specifically, unique associations will be explored among experienced weight stigma, psychological need satisfaction and exercise motivation. Due to the cross-sectional design of the present study, mediation will not be tested (Maxwell \& Cole, 2007). It is hypothesized that experienced weight stigma will be uniquely and negatively associated with exercise 
motivation. It is also hypothesized that psychological needs, particularly competence and relatedness, will also emerge as uniquely and positively associated with exercise motivation. 


\section{METHODS}

\section{Participants}

Participants were adult females recruited through online social media and web platforms such as Facebook and Craigslist, posted flyers throughout the community, as well as the Douglass Loop Farmer's Market in Louisville, Kentucky. Inclusion criteria were as follows: Participants must (a) be between the ages of 21 and 64 (b) be able to provide written informed consent and (c) have adequate spoken and written English proficiency. Given that recruitment was completed through online means and in a public setting, formal screening for cognitive and psychological impairments was not formally completed. No participants demonstrated significant cognitive or psychological impairment at the time of in-person recruitment. Additional exclusion criteria included self-reported: (a) significant physical, psychological or medical disability/impairment that has limited ability to exercise in the last three months and/or (b) cardiac arrest or myocardial infarction within the past six months (c) are currently pregnant or breastfeeding and (d) unable to complete the online questionnaire due to lack of computer access or other cognitive or physical impairment. Additionally, while they were not excluded at the point of recruitment, participants with BMI qualifying as Underweight (< 18.5) were excluded from statistical analysis. 


\section{Procedure}

It was initially proposed that ethnically diverse female participants would be recruited from local community settings such as health fairs, hair salons and stores frequented by adult female shoppers in Kentucky and Southern Indiana, with the goal of achieving a participant sample representative of the Louisville area. However, limited sites granted permission for study recruitment. Therefore, recruitment efforts were expanded to allow for online recruitment and study participation. Ultimately, female participants were recruited through online social media and web platforms such as Facebook and Craigslist, posted flyers throughout the community, as well as the Douglass Loop Farmer's Market in Louisville, Kentucky. A \$100 gift card lottery was used as an incentive for study participation and completion.

With regard to procedures for online and flyer recruitment, interested individuals who proceeded to the online survey were first presented with a preamble describing study purpose and procedures. Participants who agreed to take part in the study could then proceed to the brief eligibility screen. Eligible participants were directed to move forward in the survey to complete study questionnaires. Participants who completed the survey were presented with the option to provide their email address to be entered into the gift card lottery. Ineligible participants received a message thanking them for their interest and advising they did not meet eligibility criteria.

With regard to procedures for farmer's market recruitment, trained study personnel staffed a table with a posted study sign and invited interested individuals to learn about a research study assessing experiences with weight stigma. An overview of 
study purpose and procedures were reviewed and informed consent (preamble; verbal assent) was obtained. Consented individuals then completed a brief screening to assess eligibility. Ineligible participants were thanked for their interest in the study and advised they did not meet eligibility criteria. Participant weight was discreetly measured following consent procedures, using a portable calibrated digital scale. All eligible participants provided their email address to allow researchers to email a study link to access the online questionnaire. Participants were asked to complete the questionnaire within two weeks following the time of recruitment. Participants had the option to be entered into the gift card lottery after study completion. Each participant was assigned a unique ID number with which to complete the online questionnaire. This ID number was used in place of participant name on all subsequent forms and databases.

\section{Measures}

Please reference Appendix A for measure abbreviations, as needed.

Background and demographics measure. Participants completed a brief demographic questionnaire assessing demographic information such as age, gender, ethnicity, income level, years of education, current occupation, and marital status. Health comorbidities were assessed using the Self-Administered Comorbidity Questionnaire (SACQ), a brief measure assessing self-reported diagnosis of 13 common medical conditions including heart disease, cancer, back pain and diabetes (Sangha, Stucki, Liang, Fossel, \& Katz, 2003). Participants are asked to rate whether they currently have the problem, if they receive treatment for it, and if it limits their activities. A total sum score was calculated (1 point if medical condition endorsed, 1 point if treatment received, and 1 point if the medical condition limits functioning; total possible score of 39). This measure has demonstrated strong psychometrics, including a test-retest reliability of 0.81 as 
calculated by the Spearman correlation coefficient. Further, this measure correlated well with the Charlson Index- a widely used measure for chart review (Sangha et al., 2003).

Body mass index. Height (in inches) and weight (in pounds) was obtained to calculate body mass index (BMI) using the international BMI classifications (World Health Organization, 2016a): Underweight <18.50, Normal 18.50-24.99, Overweight 25.00-29.99, Obese Class I 30.00-34.99, Obese Class II 35.00-39.99, Obese Class III $\geq 40.00$. Self-reported height and weight was utilized for feasibility purposes; however, efforts were made to obtain objective weight data. Participants who were recruited inperson at the Farmer's Market were discreetly weighed by study staff (objective weight). Self-reported weight was obtained through the online survey. Participants who were recruited through online efforts were not only asked to report their weight, but also weigh themselves and upload a photo of their scale reading (objective weight). As additional indicators for self-reported weight accuracy, participants were also asked to provide details such as "when did you weigh yourself (date)" and "where did you weigh yourself." Participants were asked to indicated if they guessed their weight (i.e., "I was unable to weigh myself, so I just guessed my weight" answered with yes or no response).

Weight stigma experience. Experienced weight stigma was assessed using The Stigmatizing Situations Inventory (SSI; Myers \& Rosen, 1999). This widely-used validated measure comprises 50 items examining experiences with 11 types of weight stigmatizing situations including: comments from children, others making negative assumptions about you, physical barriers, being stared at, inappropriate comments from doctors, rude comments from family, rude comments from others, being avoided, excluded, and ignored, loved ones embarrassed by your size, job discrimination, and 
being physically attacked. Responses are provided using a 10-point ordinal scale assessing the frequency with which participants experience such stigmatization $(0=$ never, $1=$ once in your life, $2=$ several times in your life, $3=$ about once/year, $4=$ several times/year, $5=$ about once a month, $6=$ several times/month, $7=$ about once/week, $8=$ several times/week, $9=$ daily). This measure has demonstrated strong psychometric properties, including high internal consistency, convergent and divergent validity $(\alpha=.95$; Myers $\&$ Rosen, 1999).

Internalized weight stigma. The degree to which participants evaluate themselves based on their weight as well as apply weight-based stereotypes to themselves was assessed using the modified version of the Weight Bias Internalization Scale (WBISM). This measure was recently modified by Pearl and Puhl (2014) so that it could be applicable across body weight categories and was found to demonstrate high internal consistency as well as strong construct validity $(\alpha=.94$, Eigenvalue $=7.19$, all factor loadings $\geq .50 ;$ Pearl \& Puhl, 2014). Additionally, this measure was found to have good convergent and discriminant validity (Pearl \& Puhl, 2014). This brief 11-item measure includes items such as "I hate myself for my weight" and "I am less attractive than most other people because of my weight." Responses are provided on a 7-point scale ranging from "strongly disagree" to "strongly agree." Items 1 and 9 were reversed scored. A total mean score was computed across the 11 items.

Physical activity and exercise behavior. To assess if participants are meeting CDC guidelines for physical activity (moderate intensity physical activity for a total of 150 minutes per week), participants completed the Rapid Assessment of Physical Activity (RAPA) measure (University of Washington Health Promotion Research Center, 
2006). This scale was originally developed for use in primary care settings to quickly assess adult's physical activity engagement; however, it has demonstrated strong psychometric properties, change sensitivity, and compares well to more extensive measures of physical activity (Glasgow et al., 2005; Topolski et al., 2006). This measure comprises nine dichotomous yes/no items assessing both level and intensity of physical activity as well as engagement in strength and flexibility training. A cumulative total score of 6 or greater indicates adherence to CDC/ACSM physical activity guidelines.

To assess exercise behavior participants completed the Godin Leisure-Time Exercise Questionnaire (GLTQ-E; Godin \& Shephard, 1985). This brief measure assesses frequency of engagement in strenuous (e.g., running, jogging, and basketball), moderate (e.g., fast walking, easy bicycling, easy swimming), and light (e.g., yoga, golf, easy walking) exercise behavior in a typical week. Total leisure activity scores were computed as follows: ( 9 x Strenuous $)+(5 \mathrm{x}$ Moderate) . Scores of 23 or less suggest insufficient activity to achieve substantial health benefits. Scores of 24 or higher suggest sufficiently activity levels which are associated with substantial health benefits. Light activity was not included in the total activity score as these exercises are not associated with health benefits (Godin \& Shephard, 1985). Numerous reliability and validity studies assessing this measure have demonstrated good psychometric properties (Godin \& Shephard, 1997). Additionally, this measure has been utilized in many of the preliminary studies assessing weight stigma and exercise behavior (Pearl, Dovidio, \& Puhl, 2015a; Pearl et al., 2015b; Vartanian \& Novak, 2011).

Exercise motivation. Behavioral intention is often assessed as an indicator of motivation for a variety of behaviors including exercise (Courneya et al., 1999). Ajzen 
(2006) published specific instructions for creating Theory of Planned Behavior measures, including measures of behavioral intention. Previous studies have utilized brief measures assessing behavioral intentions, adapting the behavioral intention content as necessary; these measures have yielded moderate correlations with self-reported physical activity ( $\mathrm{r}$ $=.47-.48$, Blanchard, Courneya, Rodgers, Daub, \& Knapik, 2002; r = .34, Høie, Moan, \& Rise, 2010).

The present study adapted the behavioral intention measure utilized by Høie and colleagues (2010), to assess intention to exercise $(\alpha=.92)$. The first item read: "I plan to exercise for 30 accumulated minutes at a moderate intensity, 3 to 5 times per week, in the next 2 weeks." The remaining three items read: "I will try...", "I intend to...", and "I expect to..." Responses were provided on a 7-point scale ranging from "Strongly Disagree" to "Strongly Agree." The four items were averaged to obtain a behavioral intention score, with higher scores suggesting greater intention.

As previously described, the Self-Determination Theory (SDT) provides a conceptually sound model of motivation (see Figure 1 for a visual depiction of the SDT continuum of motivation). To assess participant's motivation to exercise, specifically where they are on the continuum of motivation, participants completed the Treatment Self-Regulation Questionnaire-Exercise (TSRQ-E) measure (Levesque et al., 2007). This measure comprises 15 -items that describe different reasons for starting or continuing to exercise regularly such as "because I personally believe it is the best thing for me" and "because I feel pressure from others to do so." Responses are provided on a 7-point scale ranging from "not at all true" to "very true." There are three subscales to this measure including: Autonomous Regulatory Style, Controlled Regulatory Style and Amotivation. 
Mean scores were calculated for each subscale. Previous research has found positive associations between autonomous regulatory style, the most self-determined form of motivation, and important outcomes such as increased physical activity and exercise behavior (Levesque et al., 2007; Williams, Ryan, \& Deci, 2016). The TSRQ has shown acceptable internal consistency ( $\alpha>$.73; Levesque et al., 2007).

Participants also completed the Exercise-Avoidance Motivation Scale to allow for comparison to the existing weight stigma-exercise motivation literature, as this measure has been utilized in preliminary experienced weight stigma and exercise motivation studies (Vartanian \& Shaprow, 2008). This measure comprises 8 items that reflect reactions to experiencing negative situations related to body weight such as "I feel uncomfortable going to a gym where there are a lot of mirrors" and "If I go to the gym, there are some exercises or pieces of equipment that I avoid." Responses are provided on a 7-point scale ranging from "not at all true" to "completely true." Higher scores suggest greater exercise avoidance motivation $(\alpha>.83$; Vartanian \& Shaprow, 2008)

Basic psychological needs. To assess participants' satisfaction of autonomy, competence, and relatedness in the domain of exercise, participants completed the Psychological Need Satisfaction in Exercise Scale (PNSE; Wilson, Rogers, Rodgers, \& Wild, 2006). This 18-item measure examines Perceived Competence (e.g., "I feel that I am able to complete exercises that are personally challenging"), Perceived Autonomy (e.g., "I feel free to choose which exercises I participate in"), and Perceived Relatedness (e.g., "I feel connected to the people who I interact with while we exercise together") in the context of exercising. Responses are provided on a 6-point scale (i.e., $1=$ false, $6=$ true). Average scores for each subscale are computed, with higher scores suggesting 
stronger need satisfaction. This measure has demonstrated strong psychometric properties including strong construct validity and high internal consistency $(\alpha>.90$; Wilson et al., 2006).

To assess participants' satisfaction of the three basic needs (autonomy, competency, and relatedness) in general, they completed the Balanced Measure of Psychological Needs (BMPN; Sheldon \& Hilpert, 2012). This 18-item assessment comprises 3 balanced subscales (Relatedness, Competence, and Autonomy), with each subscale consisting of items assessing satisfaction and dissatisfaction. For example, on the Relatedness subscale, items include "I feel close and connected with other people who are important to me" and "I feel unappreciated by one or more important people." Responses are provided on a 5-point scale (e.g., $1=$ no agreement, $3=$ some agreement, 5 $=$ much agreement). Three aggregate scores for each subscale were computed by subtracting the dissatisfaction score from the satisfaction score (Sheldon \& Hilpert, 2012).

This domain general measure has demonstrated strong psychometric properties including good convergent and discriminant validity, improved construct validity and predictive power when compared to previous measures such as the Basic Psychological Needs Scale, and adequate internal consistency ( $\alpha$ ranging from .78 - .79; Sheldon \& Hilpert, 2012).

\section{Statistical Approach and Data Analytic Plan}

Analysis decisions. Data analyses were completed using SPSS v25.0 (IBM Corporation, 2017). Preliminary analyses and exploration of data were completed to assess for missing data, outliers, normality, and statistical test assumptions. Visual inspection of histograms and boxplots revealed non-normally distributed data for multiple 
variables; therefore, median and interquartile range (IQR) are reported rather than mean and standard deviation. Nonparametric test alternatives and data transformation approaches were utilized as warranted.

Table 1 provides a visual depiction of decisions for participant removal from data analysis. All participants with missing self-reported weight and height data $(n=51)$ were excluded from data analysis given the importance of considering weight and BMI in this study. The majority of participants with missing self-reported weight data are actually study drop-outs, such that they dropped out of the survey well before the weight questions (weight questions were presented last in the survey). Descriptive information for those removed due to missing self-reported weight data are provided in Tables 2-3 There was a high rate of missing objective weight data (i.e., scale photo upload) for participants recruited online (64.1\% missing). Participants with underweight BMI were removed from data analysis, as it is possible their weight stigma experiences and perceptions are different from those of greater weight. Participants who indicated they guessed their weight and also did not provide any supporting information (i.e., when did you weigh yourself, where did you weigh yourself) were excluded from data analysis. Participants who indicated they guessed their weight but also provided supporting information $(n=18)$ were included. Both self-reported and objective weight data were examined in the context of descriptive and planned analyses.

Missing Value Analysis was conducted for each primary study variable with the final sample $(N=144)$ to assess for missing data patterns (see Table 4; Measure reliability can also be found in Table 4). Little's missing completely at random (MCAR) tests, an omnibus test of patterns in missing data, revealed that the data were missing 
completely at random for all measures except for the Weight Bias Internalization Scalemodified (Little, 1988). When data are missing completely at random and only a small proportion of data are missing, imputation approaches can then be applied accordingly. Missing values were replaced with predicted values for all measures (except for the WBIS-M) using the expectation-maximization (EM) algorithm (Enders, 2001). Given that data was not missing completely at random and there was minimal missing data for WBIS-M (less than $2 \%$ for each item), individuals with missing data points were excluded (rather than using a multiple imputation approach) only from analyses that included this measure.

One extreme outlier was detected for experienced weight stigma scores, as measured by the Stigmatizing Situations Inventory. As experienced weight stigma is a primary study and predictor variable, a winsorizing data approach was applied such that the extreme value was replaced with the next-highest, non-extreme outlier score (Field, 2013). Three extreme outliers were also detected for weight (1 self-report, 2 objective); these values were left unchanged as they are considered a valid representation of participant weight.

Descriptive analyses are presented for each sub-sample, as well as for data pooled from both recruitment sites ( $N=144$; 66 Farmer's Market; 78 Online). Regression analyses were completed with data pooled from each sub-sample. Participant recruitment method/site (farmer's market or online) was entered as a control variable for all regression analyses.

Descriptive analyses. Descriptive statistics were used to describe: (1) demographic characteristics, (2) BMI characteristics including frequencies for each BMI classification 
group, (3) weight stigma characteristics (e.g., scores on experienced and internalized weight stigma measures), (4) exercise motivation characteristics (e.g., exercise intention, amotivation, autonomous and controlled motivation style scores), (5) physical activity and exercise behavior characteristics and (6) basic psychological needs characteristics (e.g., scores for autonomy, relatedness, and competence in both the exercise setting as well as in general). Mann-Whitney $\mathrm{U}$ and Kruskal-Wallis $\mathrm{H}$ analyses were used to compare mean scores across groups in light of non-normal data distributions. Chi-Square test of independence analyses were utilized to assess for group differences, as appropriate. Spearman's rank-order correlations were used to assess associations between continuous variables. Correlational analyses were completed on various demographic variables to determine if it was necessary to control for variables statistically within the regression models. Alpha levels of .05 or less was considered to be statistically significant.

\section{Data Analysis Decisions for Hypothesis Testing.}

\section{1a. How does experience with weight stigma relate to BMI status?}

Hypothesis 1a: It is predicted that BMI will be positively associated with experienced weight stigma as measured by the Stigmatizing Situations Inventory (SSI).

Exploration of BMI and experienced weight stigma variables revealed nonnormal data distributions, therefore, a Spearman's rank-order correlation was completed as an alternative to Pearson's correlation. Preliminary analysis showed the relationship between BMI and experienced weight stigma to be monotonic, as assessed by visual inspection of a scatterplot.

\section{1b. Does experience with weight stigma differ by BMI status?}


Hypothesis 1b: It is predicted that experienced weight stigma scores, as measured by the Stigmatizing Situations Inventory (SSI), will differ significantly by BMI classification. Specifically, it is predicted that participants with overweight and obese BMI will have higher experienced weight stigma scores than those of healthy weight.

A Kruskal-Wallis $\mathrm{H}$ test was completed as an alternative to One-Way ANOVA in light of violations of normality and homogeneity of variances. A linear regression analysis was also completed to consider the association between experienced weight stigma and BMI as a continuous variable, rather than categorical. All relevant assumptions for use of simple regression analyses were tested. There was linearity as assessed by partial regression plots and a plot of studentized residuals against the predicted values. There was independence of residuals, as assessed by a Durbin-Watson statistic of 1.71 . There was no evidence of multicollinearity, as assessed by tolerance values greater than 0.1 . There were no leverage values greater than 0.2 and no values for Cook's distance above 1. Heteroscedasticity was detected, as assessed by visual inspection of a plot of studentized residuals versus unstandardized predicted values. There was one significant outlier as assessed by Casewise Diagnostics. Of note, a square root transformation was applied to the experienced weight stigma variable (SSI mean score) in light of severe positive skew to allow for improved normality of residuals, as assessed by Q-Q Plot (Field, 2013). Given violations of homoscedasticity and outliers, results should be interpreted with caution.

\section{How does experienced weight stigma relate to exercise motivation?}

Hypothesis 2: It is predicted that those with more frequent experiences with weight stigma (SSI) will endorse less intention to exercise and higher controlled motivation style (TSRQ-E). It is also predicted that experienced weight stigma will be negatively 
associated with exercise intention and emerge as a significant independent variable in a regression model.

In light of non-normal data distributions, Spearman's rank-order correlations were completed, rather than Pearson's. Preliminary analyses showed all relationships to be monotonic, as assessed by visual inspection of scatterplots.

Additionally, a linear regression was completed to examine the association between experienced weight stigma and exercise intention. Post hoc power analyses demonstrated adequate power (.98) to achieve a medium effect size of .15 (G*Power; Faul, Erdfelder, Lang, \& Buchner, 2007). Assumptions of homoscedasticity and normality of residuals were violated; therefore, data transformation approaches were utilized to allow for all assumptions to be appropriately met. Specifically, a square root transformation was applied to the experienced weight stigma variable in light of severe positive skew (SSI mean score) and a log transformation was applied to the exercise intention variable after reverse scoring in light of severe negative skew (Field, 2013).

All relevant assumptions for use of hierarchical regression analyses were tested. There was linearity as assessed by partial regression plots and a plot of studentized residuals against the predicted values. There was independence of residuals, as assessed by a Durbin-Watson statistic of 1.90 . There was no evidence of multicollinearity, as assessed by tolerance values greater than 0.1 . There were no leverage values greater than 0.2 and no values for Cook's distance above 1. There was homoscedasticity, as assessed by visual inspection of a plot of studentized residuals versus unstandardized predicted values. There were no significant outliers as assessed by Casewise Diagnostics. The assumption of normality of residuals was met, as assessed by Q-Q Plot. 


\section{How does experienced weight stigma relate to exercise behavior?}

Hypothesis 3: It is predicted that more frequent experiences with weight stigma (SSI) will be associated with less engagement in exercise behavior (GLTQ-E).

Due to non-normal data distributions, a Spearman's rank-order correlation was utilized, rather than Pearson's. Preliminary analyses revealed a monotonic relationship, as assessed by visual inspection of a scatterplot.

\section{How does experienced weight stigma relate to psychological need satisfaction?}

Hypothesis 4: It is predicted that frequency of experienced weight stigma (SSI) will be negatively associated with psychological need satisfaction.

Due to non-normal data distributions, a Spearman's rank-order correlation was utilized, rather than Pearson's. Correlation analyses were completed for all three psychological needs in the domain of exercise (PNSE) as well as in general (BMPN). Preliminary analyses revealed a monotonic relationship, as assessed by visual inspection of a scatterplot.

\section{What are the unique associations between psychological need satisfaction} variables and exercise motivation when accounting for experienced weight stigma?

Hypothesis 5: It is predicted that psychological need satisfaction variables will be uniquely and significantly associated with exercise motivation when accounting for experienced weight stigma.

Research Question 5 was assessed using a hierarchical multiple regression model. Data transformation approaches were applied to some variables to allow test assumptions to be met. Specifically, a square root transformation was applied to the experienced weight stigma variable in light of severe positive skew (mean score SSI), a log transformation was applied to the exercise intention variable after reverse scoring in light 
of severe negative skew, and a square root transformation was applied to the exercise autonomy variable (PNSE autonomy subscale mean score) after reverse scoring in light of negative skew (Field, 2013). All other variables remained untransformed. Post hoc power analyses demonstrated adequate power (.91) to achieve a medium effect size of .15 (G*Power; Faul et al., 2007).

All relevant assumptions for use of hierarchical regression analyses were tested. There was linearity as assessed by partial regression plots and a plot of studentized residuals against the predicted values. There was independence of residuals, as assessed by a Durbin-Watson statistic of 2.20. There was no evidence of multicollinearity, as assessed by tolerance values greater than 0.1 . There were no leverage values greater than 0.2 and no values for Cook's distance above 1. There was homoscedasticity, as assessed by visual inspection of a plot of studentized residuals versus unstandardized predicted values. There were no significant outliers as assessed by Casewise Diagnostics. The assumption of normality of residuals was met, as assessed by Q-Q Plot.

\section{Statistical Power Analyses}

A priori power analyses using $G^{*}$ Power (Faul et al., 2007) suggested that a minimum of 159 participants would be necessary to achieve $80 \%$ power for the detection of a medium effect size (0.25) at a significance level of .05 to complete the One-way ANOVA exploring weight stigma scores across BMI groups. Ultimately, a KruskalWallis test was used rather than One-way ANOVA in light of non-normal data distributions. This non-parametric test has been shown to achieve higher power when compared to the One-way ANOVA in the setting of non-symmetric data distributions (Hecke, 2012). A priori power analyses suggested that fewer participants were required 
to complete the hierarchical regression analyses (114 participants for regression including up to 9 predictors for $80 \%$ power and medium effect of 0.15 ), t-tests, and correlational analyses described. Post hoc power analyses revealed that the achieved power for regression analyses $(N=144)$ with 9 independent variables was 90.8 . 


\section{RESULTS}

\section{Participants Characteristics}

Enrollment and response rates. A total of 263 individuals were enrolled in this study across recruitment sites (119 Farmer's Market; 144 Online). Table 5 depicts specific recruitment information, including eligibility details. 208 eligible participants (72 Farmer's Market; 136 Online) partially or fully completed the online survey. There was a $65 \%$ response rate for individuals recruited at the Farmer's Market.

Sample demographics. Participant demographic characteristics are reported in Table 6 for both the total sample as well as each sub-sample. Participants were predominantly non-Hispanic White (90.3\%), never married (43.8\%), employed full-time (63.9\%), well-educated (83.4\% Bachelor's Degree or above), with household incomes below $\$ 50,000(63 \%)$. Participants were older in the Farmer's Market sample $(M d n=42)$ when compared to the Online sample $(M d n=31), U=3485.5, z=3.66, p<.001$. As might be expected, state of residence for participants differed by recruitment method/site,

$\chi^{2}(3, N=144)=48.12, p<.001$. The expected cell count assumption was violated for the Chi-Square test (37.5\% had expected count for state of residence of less than 5); results should be interpreted with caution. No significant differences were observed across other demographic characteristics. 
Health status. Health-related characteristics for the total sample as well as each sub-sample are presented in Table 7. Participants were predominantly Overweight or Obese (59\% according to self-report weight and $63 \%$ according to objective weight data). Most participants had no smoking history (75.7\%). The most frequently endorsed medical problems included back pain (25.7\%), depression (20.1\%), other medical problems (18.8\%) and high blood pressure (10.4\%). No statistically significant differences were detected for health status characteristics by participant sub-sample.

\section{Primary Study Variables}

Associations among primary study variables were assessed using Spearman's rank-order correlations. A matrix of these associations is presented in Table 8.

Weight stigma characteristics. A descriptive portrayal of participants'

experiences with weight stigma may be seen in Tables 9-10. The majority of participants have personally encountered negative weight-related situations such as being stared at and rude or inappropriate comments from strangers, family, children and doctors at least once in their lifetime. Experienced weight stigma scores were not statistically significantly different for the online sample $(M d n=.42)$ when compared to the farmer's market sample $(M d n=.24), U=2200.50, z=-1.50, p=.134$. Significant differences were detected by participant sub-sample for experience with physical barriers $(U=$ 2010.00, $z=-2.49, p=.013)$ and loved ones being embarrassed by participant size $(U=$ 2056.50, $z=-2.48, p=.013$ ), with the online sample endorsing higher frequency of experiences. 
Internalized weight bias was also assessed to allow for supplemental and exploratory analyses $(M d n=2.82, I Q R=2.68)$. Internalized weight bias scores did not statistically significantly differ between the online sample $(M d n=2.86)$ and farmer's market sample $(M d n=2.82), U=2137.50, z=-.78, p=.434, N=137$. A strong positive association between experienced weight stigma and internalized weight bias was detected, $r_{s}=.69, p<.001$.

Physical activity and exercise characteristics. Table 11 presents descriptive information for each measure of physical activity and exercise motivation and behavior described below. Correlation results are presented in Table 8 .

Exercise motivation. Overall, participant's motivation to exercise, as measured by exercise intention, was high. No statistically significant differences were found by participant recruitment site/method $(p=.859)$. Exercise intention was not statistically significantly associated with BMI derived from self-reported weight $(p=.071)$ or objective weight $(p=.067)$.

Participants endorsed high levels of autonomous exercise motivation, moderate levels of controlled exercise motivation, and low levels of exercise amotivation. Controlled exercise motivation scores were statistically significantly higher for participants in the online sample when compared to the farmer's market sample $(U=$ $1880.50, z=-2.79, p=.005)$. No statistically significant differences emerged by subsample for autonomous exercise motivation $(p=.278)$ or amotivation $(p=.764)$. No significant associations were detected for controlled exercise motivation and BMI derived from self-report $\left(r_{s}=.05, p=.530\right)$ or objective $\left(r_{s}<-.01, p=.968\right)$ weight. No significant association were detected for amotivation and BMI derived from self-report 
$\left(r_{s}=.07, p=.423\right)$ or objective $\left(r_{s}=.14, p=.184\right)$ weight. A significant negative association was found between autonomous exercise motivation and objective BMI $\left(r_{s}=\right.$ $-.29, p=.005)$, but not self-reported weight derived BMI $\left(r_{s}=-.13, p=.111\right)$.

Overall, participants had low levels of motivation to avoid exercise. Positive associations were found between exercise avoidance motivation and BMI (self-report: $r_{s}$ $=.47, p<.001$; objective: $\left.r_{s}=.56, p<.001\right)$.

Physical activity and exercise behavior. The majority of participants met CDC guidelines for physical activity and could be considered active based on their engagement in moderate and vigorous exercise. No differences were detected for physical activity (RAPA: $p=.596$ ) or exercise behavior (GLTE: $p=.300$ ) by participant sub-sample. Exercise behavior was negatively associated with BMI derived from both self-reported and objective weight $(p=.002)$.

Basic needs characteristics. Table 12 presents descriptive information for each psychological need, both generally and in the domain of exercise.

Psychological need satisfaction. Overall, participants endorsed high levels of psychological need satisfaction and low to moderate levels of psychological need dissatisfaction (see Table 12). No statistically significant differences were detected by participant sub-sample for relatedness $(p=.777)$, competence $(p=.783)$, and autonomy ( $p=.618)$ aggregate scores. Additionally, no significant differences were found by participant sub-sample for psychological need satisfaction and dissatisfaction scores $(p>$ .05). Negative associations were detected for relatedness and BMI (self-report and objective; $p \leq .01)$ as well as autonomy and objective BMI ( $p=.021)$. 
Exercise psychological need satisfaction. Overall, participants had high levels of exercise autonomy and moderate levels of exercise competence and relatedness. No statistically significant differences were detected by participant sub-sample for relatedness $(p=.194)$, competence $(p=.763)$ and autonomy $(p=.105)$. Statistically significant negative associations were detected between exercise competence and BMI (self-report and objective; $p<.001)$ and exercise autonomy and BMI $(p<.05)$. A significant negative association was found between exercise relatedness and objective $\operatorname{BMI}(p=.045)$, but not self-reported weight derived BMI $(p=.250)$.

\section{Research Questions and Hypothesis Testing}

Question 1a: How does experience with weight stigma relate to BMI status?

Hypothesis 1a: It is predicted that BMI will be positively associated with experienced weight stigma as measured by the Stigmatizing Situations Inventory.

Hypothesis 1a was supported, with strong positive associations found between BMI derived from self-reported weight and experienced weight stigma $\left(r_{s}=.59, p<\right.$ $.001)$, as well as BMI derived from objective weight and experienced weight stigma $\left(r_{s}=\right.$ $.60, p<.001)$.

\section{Question 1b: Does experience with weight stigma differ by BMI status?}

Hypothesis 1b: It is predicted that experienced weight stigma scores, as measured by the Stigmatizing Situations Inventory, will differ significantly by BMI classification. Specifically, it is predicted that participants with overweight and obese BMI will have higher experienced weight stigma scores than those of healthy weight.

Median experienced weight stigma scores were statistically different between BMI categories derived from self-report weight data $\left(\chi^{2}(4)=55.48, p<.001\right)$ and BMI 
categories derived from objective weight data $\left(\chi^{2}(4)=36.78, p<.001\right)$. Table 13

provides a summary of statistically significant pairwise comparisons performed using Dunn's (1964) procedure with a Bonferroni correction for multiple comparisons.

Adjusted p-values are presented. Values are mean ranks unless otherwise stated. Figure 4 presents experienced weight stigma mean rank scores by BMI group.

BMI derived from self-report weight data was statistically significantly associated with experienced weight stigma $(\beta=.54, p<.001 ; F(1,142)=57.03, p<.001)$. BMI accounted for $28.7 \%$ of the explained variance in experienced weight stigma. Similar results were detected for BMI derived from objective weight data $(\beta=.58, p<.001 ; F(1$, $90)=42.57, p<.001 ; 32.1 \%$ of variance $)$.

\section{Question 2: How does experienced weight stigma relate to exercise}

\section{motivation?}

Hypothesis 2: It is predicted that those with more frequent experiences with weight stigma will endorse less intention to exercise and higher controlled motivation style.

Exercise intention. Hypothesis 2 was not supported, as no statistically significant association was detected for experienced weight stigma and exercise intention, $r_{\mathrm{s}}=-.11$, $p=.195$.

Correlational analyses revealed no statistically significant association between experienced weight stigma and exercise intention, however, due to the exploratory nature of this study, a linear regression was performed as proposed. Participant sub-sample (Online and Farmer's Market) and health status as measured by the SACQ were included 
as control variables in the first block. The experienced weight stigma variable was included in the second block. Exercise intention was included as the dependent variable.

Table 14 provides a summary of regression details. The model including health status and sample (Model 1) was statistically significant $(F(2,141)=3.06, p=0.50)$; health status was statistically significantly associated with exercise intention $(\beta=.21, p=$ .015 ). The addition of experienced weight stigma (Model 2; $\beta=.06, p=.507$ ) did not statistically significantly increase $R^{2}(F(3,140)=2.18, p=.093)$. Health status was the only independent variable to remain statistically significantly associated with exercise intention in the final model $(\beta=.20, p=.022)$; as health status increased by one unit, indicating more health conditions and related impairment, exercise intention decreased by 0.20 units.

SDT exercise motivation. Experienced weight stigma was found to be positively associated with controlled motivational style $\left(r_{s}=.23, p=.006\right)$ and negatively associated with autonomous motivational style $\left(r_{s}=-.20, p=.015\right)$. No statistically significant association was detected between experienced weight stigma and amotivation $\left(r_{s}=.14, p=.085\right)$.

Motivation to avoid exercise. Experienced weight stigma was found to be positively associated with motivation to avoid exercise, $r_{s}=.62, p<.001$.

Question 3: How does experienced weight stigma relate to exercise behavior?

Hypothesis 3: It is predicted that more frequent experiences with weight stigma will be associated with less engagement in exercise behavior. 
A small statistically significant negative association was found between experienced weight stigma and exercise behavior $\left(r_{s}=-.18, p=.045\right)$, supporting Hypothesis 3.

Question 4: How does experienced weight stigma relate to psychological need satisfaction?

Hypothesis 4: It is predicted that frequency of experienced weight stigma will be negatively associated with psychological need satisfaction.

Psychological Need Satisfaction in Exercise. Statistically significant negative associations were found between experienced weight stigma and two exercise-based psychological needs, exercise competence $\left(r_{s}=-.37, p<.001\right)$ and exercise autonomy $\left(r_{s}\right.$ $=-.27, p=.001)$. No statistically significant association was detected between experienced weight stigma and exercise relatedness, $r_{s}=-.14, p=.091$.

Overall Psychological Need Satisfaction. Statistically significant negative associations were detected between experienced weight stigma and all three psychological needs (competence $r_{s}=-.44, p<.001$; autonomy $r_{s}=-.44, p<.001$; relatedness $\left.r_{s}=-.41, p<.001\right)$.

Question 5: What are the unique associations between psychological need satisfaction variables and exercise motivation when accounting for experienced weight stigma?

Hypothesis 5: It is predicted that psychological need satisfaction variables will be uniquely and significantly associated with exercise motivation when accounting for experienced weight stigma. 
Sample and health status were included as control variables in the first block, followed by the experienced weight stigma variable in the second block, and three psychological needs variables in general (BMPN) as well as three psychological needs in the domain of exercise (PNSE) were added to the final block. Exercise intention was included as the dependent variable.

Table 15 provides a summary of regression details. Models 1 and 2 were consistent with those detailed in the regression results for Research Question 2. With the addition of all six psychological needs variables in the final model (Model 3), there was a total of $22.3 \%$ of variation accounted for in exercise intention, $F(9,134)=4.27 p<.001$. The only variable to emerge as a statistically significantly associated with exercise intention in the final model was exercise competence $(\beta=-.30, p=.003)$; as exercise competence increases by one unit, exercise intention increases by 0.30 units.

\section{Supplemental Analyses}

Internalized weight bias. As previously described, experienced weight stigma was not statistically significantly associated with exercise intention. However, internalized weight bias did emerge as significantly and negatively associated with exercise intention. Therefore, a supplemental hierarchical regression analysis was completed $(N=137)$. Specifically, this hierarchical regression was structured the same as the regression completed for Research Question 5, however, internalized weight bias was also included as an independent variable. Data transformation approaches were applied to some variables to allow test assumptions to be met. Specifically, a square root transformation was applied to the experienced weight stigma variable in light of severe positive skew (mean score SSI), a log transformation was applied to the exercise 
intention variable after reverse scoring in light of severe negative skew, and a square root transformation was applied to the exercise autonomy variable (PNSE autonomy subscale mean score) after reverse scoring in light of negative skew (Field, 2013). All other variables remained untransformed.

Sample and health status were included in the first block, followed by experienced weight stigma and internalized weight bias in the second block, and all six psychological needs (generally and in the domain of exercise) in the third block. Exercise intention was included as the dependent variable. Post hoc power analyses demonstrated adequate power (.87) to achieve a medium effect size of .15 (G*Power; Faul et al., 2007). All relevant assumptions for use of hierarchical regression analyses were tested. There was linearity as assessed by partial regression plots and a plot of studentized residuals against the predicted values. There was independence of residuals, as assessed by a Durbin-Watson statistic of 2.06. There was no evidence of multicollinearity, as assessed by tolerance values greater than 0.1 . There were no leverage values greater than 0.2 and no values for Cook's distance above 1 . There was homoscedasticity, as assessed by visual inspection of a plot of studentized residuals versus unstandardized predicted values. There were no significant outliers as assessed by Casewise Diagnostics. The assumption of normality of residuals was met, as assessed by Q-Q Plot.

Table 16 provides a summary of regression details. Model 1 (control variables), accounted for $4.3 \%$ of the variation in exercise intention, $F(2,134)=2.98, p=.054$. Health status was statistically significantly negatively associated with exercise intention $(\beta=.21, p=.017)$. The inclusion of experienced weight stigma and internalized weight bias in Model 2 explained an additional $1.4 \%$ of the variance in exercise intention, $F(4$, 
$132)=1.99, p=.100$. The change in $\mathrm{R}^{2}$ was not significant and internalized weight bias $(\beta=.09, p=.478)$ and experienced weight stigma $(\beta=-.15, p=.222)$ did not significantly contribute to the model. Finally, adding all six psychological need variables to the regression model explained an additional $18.4 \%$ of the variance in exercise intention, $R^{2}=.24, F(10,126)=3.99, p<.001$. When all variables were included in the final model, only exercise competence $(\beta=-.30, p=.004)$ remained statistically significantly associated with exercise intention. Given that exercise intention was reverse scored for transformation, results indicate positive associations for exercise competence with the dependent variable exercise intention. 


\section{DISCUSSION}

The purpose of this study was to (1) explore the relationship between experienced weight stigma and exercise motivation and behavior using theoretically-supported measures (2) assess how experienced weight stigma might differ based on factors such as body weight and demographic variables and (3) consider unique associations among experienced weight stigma, exercise motivation and psychological need satisfaction as outlined by the Basic Needs Theory. As noted in the introduction, The Basic Needs Theory posits that satisfaction of three innate psychological needs (competence, autonomy, and relatedness) promotes optimal self-motivation, and environments that undermine fulfillment of these needs, such as discriminatory and prejudiced environments, will negatively affect motivation. As described, the proposed conceptual model (see Figure 2) suggests that this theory may be applied to help conceptualize underlying mechanisms of action in the weight stigma-exercise motivation relationship. The present cross-sectional study serves as the first step in assessing this model by exploring unique associations among constructs of interest.

Broadly, it was predicted that frequency of experienced weight stigma would be negatively associated with exercise motivation (as assessed by exercise intention) and behavior and positively associated with controlled (extrinsically-driven) exercise motivational style. It was predicted that individuals of higher BMI would endorse experiencing more frequent weight stigma situations. It was hypothesized that more 
frequent experiences with weight stigma would be associated with less satisfaction of psychological needs, both in general as well as in the domain of exercise. Further, it was hypothesized that (a) experienced weight stigma would explain a significant proportion of variance in exercise intention within a regression model and (b) psychological need satisfaction variables would be uniquely and positively associated with exercise intention and account for a significant portion of variance in exercise intention, above and beyond the effects of experienced weight stigma.

An overview of salient study findings and how these findings align with proposed research questions and hypotheses will be detailed in the following sections.

\section{Experienced Weight Stigma Associations}

Health status. Frequency of experienced weight stigma was positively associated with participant health status, such that individuals who endorsed more health conditions and related impairment also endorsed more frequent personal experiences with weight-related stigmatizing situations. It is possible this association is driven by participant weight status, as individuals with higher BMI in this sample endorsed more health co-morbidities. This finding is consistent with the established literature that individuals of higher body weight are more likely to have co-morbid health conditions (Azarbad \& Gonder-Frederick, 2010; Khaodhiar, McCowen, \& Blackburn, 1999) and more frequent experienced weight stigma (Papadopoulos \& Brennan, 2015). However, this finding may also support growing empirical evidence that experienced weight stigma itself has a negative impact on physical health. Self-reported experienced discrimination due to weight has been associated with worse diabetes control, even when controlling for BMI (Potter et al., 2015). Further, in a longitudinal study completed by Schafer and 
Ferraro (2011), perceived weight-based discrimination was found to be associated with worse functional disability regardless of body weight. Additionally, Hunger and Major (2015) demonstrated that perceived weight-related discrimination and stigma mediated the relationship between BMI and self-reported health. Lastly, as previously described in the introduction, weight stigma has been shown to impact quality and utilization of medical care, which can also contribute to poor health status and management of chronic health conditions.

These findings are consistent with race-based discrimination literature, such that the stress associated with discrimination contributes to poorer health outcomes (Berger \& Sarnyai, 2015; Williams, Neighbors, \& Jackson, 2003). Experienced weight stigma may impact health status by acting upon physiological processes associated with stress. For example, stress processes, including those occurring in the context of social threats, can trigger hypothalamic-pituitary-adrenocortical (HPA) axis activation and hypercortisolism, which is associated with overeating, increased adiposity, and health conditions such as type 2 diabetes and cardiovascular disease (Tomiyama et al., 2014). Preliminary research in this domain has demonstrated significant relationships among weight stigma and markers of HPA activation and oxidative stress, even when controlling for adiposity, which supports the notion that personal encounters with weight-based stigma impacts physiology that not only contributes to poor health outcomes, but also contributes to underlying mechanisms associated with overweight and obesity (Tomiyama et al., 2014).

Body mass index. Hypotheses 1a and $1 \mathrm{~b}$ were supported. Self-reported and objective BMI was found to be strongly and positively associated with frequency of 
experienced weight stigma, which is consistent with the existing weight stigma literature (Papadopoulos \& Brennan, 2015). BMI accounted for a significant portion of the variance in frequency of experienced weight stigma (self-reported BMI: 28.7\%; objective BMI: $32.1 \%$ ) Additionally, frequency of personally encountered weight stigma experiences differed by BMI category. Overall, differences emerged between the obesity classes and the healthy weight and overweight groups, with those of higher weight endorsing more frequent experiences with weight stigma. Findings suggest that those with more apparent heavier weight, who are already at higher risk for poor psychological and physical health outcomes, are more likely to experience weight-related discrimination and prejudiced behavior and encounters. No differences emerged between healthy weight and overweight groups, suggesting that healthy weight and overweight individuals have similar rates of personally experienced weight stigma. This finding is consistent with the literature, in that women experience weight-related discrimination and stigma even at objectively lower body weight (Azarbad \& Gonder-Frederick, 2010; Major et al., 2014).

Overall, the frequency with which participants endorsed weight stigma experiences in this study was lower than what was reported in studies with obese treatment-seeking adults (Friedman et al., 2005; Myers \& Rosen, 1999; Puhl \& Brownell, 2006) and comparable to what was endorsed in a study that included female undergraduates of predominantly healthy weight (Vartanian \& Shaprow, 2008). However, when examining obese participants alone (29.8\% of sample when utilizing BMI derived from self-reported weight), experienced weight stigma scores align well with what was endorsed in other samples of obese adults. Overall, this pattern of results 
suggests that individuals with objectively high weight - obesity classes I-III - experience weight stigma at significantly higher rates than those of healthy and overweight.

Exercise motivation. Hypothesis 2 was partially supported. Contrary to what was hypothesized, frequency of experienced weight stigma was not statistically significantly associated with intention to exercise. Very few studies have considered associations with experienced weight stigma and motivation to exercise, rather than motivation to avoid exercise. The studies that have explored motivation to exercise are mixed, with some suggesting that weight stigma may promote exercise intention and behavior (Pearl et al., 2015b) while others suggest the opposite (Seacat \& Mickelson, 2009). Frequency of experienced weight stigma was strongly and positively associated with motivation to avoid exercise, which is consistent with the literature (Vartanian \& Novak, 2011; Vartanian \& Shaprow, 2008). Social influences may be driving this association, as the Exercise Avoidance Motivation Scale includes items targeting avoidance due to weight stigma (e.g., "I avoid going out in public places because I am afraid that people will make comments about my size"). Furthermore, most of the scale items inherently address avoidance due to body and weight-related concerns. With scale content in mind, the strong association between exercise avoidance and frequency of experienced weight is unsurprising.

Of note, participants endorsed high levels of exercise intention and relatively low levels of motivation to avoid exercise overall. Additionally, while exercise intention was not associated with BMI, those with higher BMI endorsed more motivation to avoid exercise. These findings suggest that frequency of personally encountered weight-related stigma may not thwart individuals' intentions to exercise regularly. However, it may 
make people, particularly those of heavier body weight, less apt to exercise in public settings that could be perceived as threatening (such as the gym). Future studies could further explore the specific situations in which people are more likely to avoid exercising, along with their perspectives on why they are avoiding, and how this relates to experiences with weight-based stigma.

While frequency of experienced weight stigma was not significantly associated with exercise intention, a weak though statistically significant negative association was found for internalized weight bias and exercise intention. This finding suggests that, in terms of motivation to exercise, internalization rather than frequency of experienced weight-related stigma may be more prudent to consider. Previous work has demonstrated that internalized societal attitudes of attractiveness and anti-fat bias moderated the impact of experienced weight stigma on exercise avoidance, such that individuals with higher levels of internalization were more affected by personal encounters with weight stigma situations when compared to those with low levels of internalization (Vartanian \& Novak, 2011). Perhaps these findings could be extrapolated to motivation to exercise, in addition to exercise avoidance.

As expected, individuals who endorsed more frequent weight-related stigma experiences endorsed higher levels of controlled (extrinsic) exercise motivation and lower levels of autonomous (intrinsic) exercise motivation. Additionally, internalized weight bias was also positively associated with controlled exercise motivation. It is important to note that participants recruited from the online sample had higher levels of controlled exercise motivation when compared to those recruited from the farmer's market. This discrepancy is relatively unsurprising, as one might expect that those who 
attend a farmer's market would be more likely to personally value and ascribe to a healthful lifestyle. As proposed by the SDT, when exercise behavior is controlled, it is regulated by an external force, such that an individual feels pressured to engage in the behavior, which is not ideal for promoting lasting motivation (Edmunds et al., 2006). Additionally, more controlled motivational style is often seen when individuals engage in a behavior to avoid negative affective states such as shame or guilt (Edmunds et al., 2006). Therefore, these findings suggest that individuals who both experience more frequent weight stigma encounters and have higher levels of internalized weight bias may be motivated to engage in exercise because of perceived pressure from others or in an attempt to cope with the negative emotional and affective states often associated with stigma. This assertion is supported by recent research completed by Himmelstein, Puhl and Quinn (2018) which demonstrated that most frequently endorsed weight stigma coping responses included engaging in healthy lifestyle behavior, such as exercise, as well as negative affect (i.e., feeling sad, depressed, angry or badly about one's body). Notably, avoidance of exercise also emerged as a frequent coping response behind engaging in healthful behavior and negative affect, which is consistent with the present study's findings. Of course, coping by engaging in healthy behavior is vastly different than coping through negative affect and avoidance of exercise. Therefore, future work would benefit from further exploration of associations among weight stigma and coping responses with particular focus on understanding when and which individuals engage in particular coping strategies.

Exercise behavior. Hypothesis 3 was supported; individuals who endorsed more frequent experiences with weight-related stigma also endorsed less engagement in 
moderate and vigorous exercise. Specifically, and consistent with the Theory of Planned Behavior, it was proposed that experienced weight stigma would be negatively associated with exercise intention, which would then suggest a negative association with exercise behavior. However, experienced weight stigma was not significantly associated with exercise intention in this study. Not surprisingly, higher levels of motivation to avoid exercise (primarily within a public setting), was associated with less engagement in exercise behavior, regardless of setting. Therefore, it is possible to surmise that while experienced weight stigma may not affect intention to exercise, it may interfere with successful initiation and/or maintenance of exercise behavior, as individuals may be motivated to avoid exercise because of perceived psychosocial risks (i.e., weight stigma).

It is important to note that the weight stigma and exercise behavior literature is mixed, with some studies detecting a positive association (overweight and obese sample; Pearl et al., 2015c) and others detecting no association (primarily healthy weight sample; Vartanian \& Shaprow, 2008). Furthermore, Schvey and colleagues (2017) found that in a sample of overweight and obese adults experienced weight stigma at the gym was unrelated to self-reported frequency of gym use but was related to negative feelings toward the gym. As previously described, it has been posited that individuals may engage in compensatory behavior to combat negative stereotypes, such that overweight and obese adults might engage in regular exercise to cope with experienced weight stigma (Himmelstein et al., 2018; Pearl et al., 2015c; Puhl \& Brownell, 2003). However, it has also been demonstrated that individuals may cope with weight stigma through avoidance of exercise (Himmelstein et al., 2018). Therefore, additional studies, particularly those of longitudinal design, are required to further elucidate the relationship 
between weight stigma and exercise behavior. As aforementioned, it may prove useful to consider engagement in and avoidance of exercise as it relates to a coping response with weight stigma.

\section{Psychological need satisfaction.}

Overall psychological need satisfaction. Higher rates of experienced weight stigma were associated with less satisfaction of all three psychological needs (autonomy, competence, and relatedness), which supports Hypothesis 4. As previously described, psychological need satisfaction, as proposed by the Basic Needs Theory, is imperative for facilitating self-determined and optimal motivation. Consistent with the theory, exercise intention was positively associated with satisfaction of all three of the basic psychological needs constructs assessed in this study. These findings lend partial support for the proposed conceptual model that more frequent, personally experienced weight-based stigmatizing situations may thwart satisfaction of psychological needs. Specifically, experienced weight stigma could lead people to feel socially excluded and disrespected (relatedness), unable to successfully navigate their environment and achieve desired outcomes (competence) and that they have limited choice in their actions (autonomy). While causal inferences cannot be made due to the use of correlation and the crosssectional nature of this study, future research utilizing modeling approaches and longitudinal study designs may further elucidate the effects of experienced weight stigma on psychological need satisfaction. Researchers could employ use of experimental study design such as random assignment to a stigma vs. control condition or naturalistic design wherein participants track naturally occurring weight stigma experiences over time. 
Psychological need satisfaction in exercise. Higher rates of experienced weight stigma were associated with less satisfaction of exercise competence and autonomy, but not exercise relatedness, partially supporting Hypothesis 4. Given that experienced weight stigma was associated with more avoidance of exercise and less exercise behavior, it would be understandable that such individuals may have less opportunity to develop competence and mastery with regard to exercise. Further, weight stigma may foster autonomy-controlling environments, rather than autonomy-supportive, which could limit an individual's sense that they may engage in personally endorsed behavior. For example, friends, family, fitness staff, and medical providers may try to push their exercise-related recommendations on a person with overweight or obesity because of the negative stereotypes or assumptions they harbor towards them (e.g., this person does not know how to properly exercise because of their body weight).

Surprisingly and contrary to what was hypothesized, frequency of experienced weight stigma was not related to satisfaction of perceived exercise relatedness. Perhaps individuals with more frequent weight stigma experiences are (1) exercising alone and/or (2) not exercising enough to either agree or disagree with the relatedness subscale items on the Psychological Need Satisfaction in Exercise scale (PNSE). As previously described, individuals with more frequent personal experiences with weight stigma endorsed greater exercise avoidance, particularly with regard to public/gym settings. Therefore, individuals may be more apt to exercise privately. Additionally, individuals who endorsed higher levels of experienced weight stigma also endorsed less engagement in exercise behavior. Many items on the PNSE relatedness subscale specifically consider "exercise companions" which would not be relevant for those who exercise alone or not 
very often. Future studies might consider adapting this measure or utilizing additional measures, such as The Gym Survey Scale (Schvey et al., 2017) to further characterize weight-related stigma experiences and relatedness perceptions in the domain of exercise. For example, The Gym Survey Scale includes items such as, "I feel negatively judged at my gym" and "people stare or give me dirty looks at my gym." Researchers might consider adapting items to read "when I exercise" rather than "at my gym," depending on the sample, to be more inclusive of other exercise settings.

\section{Support for Proposed Conceptual Model}

Recall that the present study aimed to serve as the first step in testing the proposed conceptual model (see Figure 2) which posits that weight stigma may undermine motivation to exercise by thwarting fulfillment of three innate psychological needs: autonomy, competence, and relatedness. Specifically, the present study conducted cross-sectional association analyses (correlational and regression) to explore unique associations among experienced weight stigma, psychological need satisfaction and exercise motivation.

As described in previous discussion sections, bivariate analyses revealed a negative association between frequency of experienced weight stigma and all three psychological needs in general and exercise competence and autonomy in the domain of exercise. These findings lend partial support for the proposed conceptual model such that experienced weight stigma may impact psychological need satisfaction. Again, causal inferences cannot be made at this time in light of use of correlation analyses and crosssectional study design. Multivariate analyses allowed for a more sophisticated picture of the unique associations among experienced weight stigma, psychological need 
satisfaction, and exercise motivation. Contrary to what was hypothesized, though consistent with the present study's correlational findings, frequency of experienced weight stigma did not significantly contribute to the regression model. With all six psychological need variables included in the final block ( 3 overall psychological need variables and 3 exercise-specific psychological need variables), only satisfaction of exercise competence significantly contributed to the model $(\beta=.30, p<.01)$; the final model accounted for $22.3 \%$ of the variance in motivation to exercise. Importantly, these findings remained when both experienced weight stigma and internalized weight bias were included in the model (see Supplemental Analyses and Tables 15-16). Altogether, findings suggest that perceived competence in the domain of exercise may be most important with regard to motivation to exercise which is consistent with the SDT and Basic Needs Theory literature. For example, satisfaction of competence is consistently positively associated with exercise (Teixeira et al., 2012a) and has been shown to explain a greater proportion of the variance in health outcomes, even above that which is explained by autonomous motivation (Ng et al., 2012). These findings hold important clinical implications, as previous empirical studies have demonstrated that healthy lifestyle interventions can facilitate satisfaction of exercise competence (Hsu et al., 2013). As an additional way to consider multivariate findings, it is also possible that experienced weight stigma and/or internalized weight bias may have an indirect effect on exercise intention through satisfaction of psychological needs, which would lend support for the proposed conceptual model even with no significant association detected between experienced weight stigma and intention to exercise (see Hayes, 2009). Future studies utilizing longitudinal study design and path modeling could provide clarity regarding the 
magnitude and significance of proposed causal connections as well as direct and indirect effects between weight stigma, psychological need satisfaction and exercise motivation.

In sum, findings from the present study lend partial support for the proposed conceptual model, however, replication and utilization of longitudinal study design and path analyses would be helpful for assessing proposed associations and mechanisms of action.

\section{Study Characteristics Influencing Participation}

It is important to consider self-selection bias and how this may have influenced study participation and sample demographics. Participants were aware that the present study was examining women's experiences with weight and health. Further, study flyers read, "we are interested in learning more about how social factors, such as people making comments about your weight, may influence health behavior." Therefore, it is possible that individuals who were more open to considering weight-related concerns and experiences were more likely to participate. It is also possible that participants who were more open to considering health behavior, such as diet and exercise, were more inclined to participate.

Participants were recruited primarily through online platforms, such a Facebook, and a farmer's market located within an affluent region of Louisville. Participants who were recruited online were much more likely to drop out of the survey and have missing objective weight data (i.e., scale photo upload). It is possible that participants recruited through online efforts had less insight into study purpose and time commitment, as they may have read the preamble too quickly and did not have study staff as readily available to answer questions. Additionally, it possible that online participants were not as compelled to finish the survey given that they were not personally recruited by study 
staff. Participants recruited through online efforts were asked to weigh themselves and upload a scale photo into the survey. This method of obtaining objective weight information may have posed too many barriers to promote follow-through for most participants. For example, participants may not have had a scale at home and may not have been inclined to travel to a different location where they could access a scale. It is also possible that participants who were less tech-savvy did not possess the knowledge or skillset to navigate the photo upload process. Additionally, it is possible that some participants did not feel comfortable weighing themselves. Perhaps some participants chose not to weigh themselves to avoid negative affect that may be associated with knowing one's weight (Pacanowski, Linde, \& Neumark-Sztainer, 2015).

Regarding recruitment at the farmer's market, it seemed that participants who were attending with family, especially young children, were less apt to engage with study staff. This is understandable given that they may be preoccupied with navigating the large crowds and tending to their children. Therefore, it is likely that mothers with young children were under-represented in this sample. Furthermore, individuals who were attending the farmer's market with friends or family may have felt less comfortable publicly expressing interest in a study about women's experiences with body weight and health.

Participants who were recruited from the farmer's market were weighed on-site. Although study staff did so as discreetly as possible, this may have deterred some from study participation. In fact, it may be possible that individuals with more frequent personal encounters with weight stigma and/or higher levels of internalized weight bias 
may not have expressed interest in study participation in an effort to avoid further stigmatization or activation of negative affect from being weighed.

Participation in the present study required access to the internet, as the survey was administered online. Therefore, the online method of participation may have deterred individuals with unreliable internet access. Individuals of lower social economic status, particularly with regard to education, were under-represented in this sample, which may be partially explained by the online method of participation.

Community recruitment efforts within the greater Louisville area yielded limited site participation. While study staff approached various sites across the community such as a local foodbank, libraries, churches, storefronts, and farmer's markets that attract more ethnically and socially diverse community members, only one farmer's market consented to allow data collection. Further, there are numerous barriers for recruiting an ethnically diverse sample through online methods, particularly with regard to African Americans, such as distrust stemming from a longstanding history of injustice, as well as lack of understanding of both the importance and process of research (Watson, Robinson, Harker, \& Arriola, 2016). Therefore, recruitment of a heterogeneous community sample as originally proposed was limited.

It is important to recall that individuals recruited from online methods, rather than the local farmer's market, were more likely to reside in a state outside of the Kentuckiana region. While the two samples were largely similar in numerous respects and study sample did not emerge as a significant contributor to the regression models, it seems appropriate to assume that there are, at the very least, cultural differences by state of residence that are important to consider. 


\section{Participant Characteristics with Potential Influence on Outcomes}

It is important to consider participant characteristics that may have influenced study outcomes. Firstly, the homogeneity of sample characteristics likely limits the generalizability of the present study's findings. In particular, participation in the present study was limited to women only, therefore, we do not have an understanding of how these associations may differ by gender. Additionally, the overall sample was largely composed of non-Hispanic White participants which limits our ability to understand how ethnicity may influence outcomes. The lack of ethnic diversity in the present sample and weight stigma literature as a whole is problematic as we have limited understanding of (1) the ways in which ethnic minorities experience and internalize weight stigma and (2) how this may intersect with other race-based discrimination and prejudice and (3) differences among ethno-racial groups. Recommendations for addressing these concerns are described below in the Implications and Recommendations section.

Participants in this sample were well-educated which may partially explain the relatively high levels of exercise intention and behavior observed in the present sample, as individuals with higher education tend to be more active (Shaw \& Spokane, 2008). Furthermore, while leisure-time physical activity has been found to be lower for African American and Hispanic individuals when compared to non-Hispanic White, education has been shown to account for nearly all observed ethno-racial differences (He \& Baker, 2005). These findings highlight the importance of education for facilitating engagement in health behavior.

It is also possible that individuals in this sample over-reported exercise intention and behavior, a pattern that has been well-documented in the exercise literature (Brenner \& DeLamater, 2014), which may have influenced study findings. Similar to Schvey and 
colleagues (2017) conceptualization, it is also possible that individuals over-endorsed their intention to exercise and engagement in exercise behavior in an attempt to defy negative stereotypes about overweight and obese persons. If in fact exercise intention scores are inflated, this may partially explain the lack of association in this study between frequency of experienced weight stigma and exercise intention.

Approximately $25 \%$ of participants in the present study endorsed experiencing back pain. Further, a proportion of participants endorsed having other health conditions such as osteoarthritis/degenerative arthritis (6.3\%) and rheumatoid arthritis (4.2\%) which are often associated with pain. Chronic pain is a common comorbidity for individuals with obesity due to a variety of reasons such as inflammation and mechanical stresses on the body, however, pain can also cause obesity as those suffering from pain may avoid physical activity in an effort to reduce pain (McVinnie, 2013). Functional impairment in the context of obesity can often be explained by medical comorbidities (Heo, Pietrobelli, Wang, Heymsfield, \& Faith, 2010). As seen in the present study, participant health status was negatively associated with exercise intention and behavior and positively associated with exercise avoidance motivation. Given this association, health status was entered as a control variable in the regression analyses. Future studies should include specific indices of health and obesity-related functional impairment as covariates given these identified associations and potential to influence findings.

Overall, participants in the present sample endorsed relatively high rates of depression (20.1\%) on the Self-Administered Comorbidity Questionnaire (single item: Do you have depression: yes or no). It is possible that individuals over-endorsed this item. While the question asks if individuals currently have this condition, perhaps those 
with history of depression, even without current symptoms, endorsed it anyway. For example, often Major Depressive Disorder is carried throughout one's lifetime with specifiers indicating either current, in partial remission, or in remission. It is also possible that individuals with self-diagnosed depression endorsed this item, who may in fact fall below the diagnostic threshold as put forth by the Diagnostic and Statistical Manual of Mental Disorders. It is also possible that participants misunderstood the question and endorsed health conditions whether past or present.

Regardless, it is important to consider that individuals with depression are typically less active (Roshanaei-Moghaddam, Katon, \& Russo, 2009) and may be more susceptible to perceiving judgement from others and may be more vulnerable to internalized weight bias as a result of the maladaptive thought process inherent with depression. Further, studies have found that weight stigma is associated with mood disturbance and diagnosis of anxiety, depressive and substance use disorders (Papadopoulos \& Brennan, 2015). Taken together, weight stigma may contribute to depression, and depression may influence perception and internalization of weight stigma. Future work might benefit from comparing the proposed associations between experienced weight stigma, exercise motivation and psychological need satisfaction by mental health diagnosis, or lack thereof. Future studies should employ well-validated measures for depression and other mental health disorders, as the present study did not employ specific indices of mental health disorders (such as the Patient Health Questionnaire; Kroenke, Spitzer, \& Williams, 2001).

\section{Strengths and Limitations}

Strengths. The present study provides a significant contribution to the literature and has numerous strengths worth noting. The present study is one of very few that have 
considered motivation to exercise, rather than simply motivation to avoid exercise, with regard to weight stigma. Given that the present study included well-validated and theoretically informed measures of exercise motivation, such as those derived from the Theory of Planned Behavior and SDT, additional insight was gleaned into the specific association between frequency of personally-encountered experiences with weight-based stigma and motivation to engage in regular exercise.

To my knowledge, this is the first study to consider unique associations between experienced weight stigma, psychological need satisfaction (both in general and in the domain of exercise), and exercise motivation. Importantly, findings from the present study set the stage for future work. In particular, the present study can inform future studies, particularly those of longitudinal design, that may examine proposed mechanisms of action in the weight stigma-exercise motivation relationship, such as those detailed in the proposed conceptual model (see Figure 2).

Additional strengths of the present study include: (a) well-powered analyses, which allowed for reduced probability of type II error (b) use of online data collection, which allowed for an easily employable and convenient method of completing study questionnaires and (c) the inclusion of objective weight data, in addition to self-reported weight data, as possible.

Limitations. There are numerous limitations to the present study. First, in-person community recruitment was limited to one site, a farmer's market located within an affluent area of Louisville. Study flyers were also posted throughout Louisville, however, very few participants were gained from this approach. Due to these limitations, methods were expanded to allow for online recruitment. While the online and farmer's market 
samples did not differ on many characteristics, there were significant differences observed with regard to age, state of residence and controlled (extrinsic) motivational style. It is also possible that these two samples are inherently different in other unknown ways. Therefore, due to recruitment barriers and the decision to pool samples, it may be difficult to extrapolate these current findings to the larger population. Additionally, the overall sample is predominantly non-Hispanic White and well-educated, which further limits generalizability.

The present study did not consider contextual factors, such as community environment (e.g., access to affordable healthy food and safe environments for physical activity) and cultural influences related to physical activity behavior and eating habits, a notable limitation given the importance of these factors in the domain of body weight and health.

One salient limitation of the present study is the reliance on self-report measures. Accuracy of responses on self-report measures may be influenced by social desirability bias, recall bias and memory errors, to name a few. Some suggest that the widely-held concerns regarding the validity of self-report data are exaggerated (Chan, 2009). Regardless, it is important to note that some of the primary constructs assessed in this study are known to be susceptible to biased reporting, such as exercise behavior, height and weight data. Specifically, self-reported exercise motivation and behavior may be more likely to be over-reported (Brenner \& DeLamater, 2014), weight may be more likely to be under-reported, and height may be more likely to be over-reported (Gorber, Tremblay, Moher, \& Gorber, 2007). While objective weight data was obtained for all participants recruited in-person, the majority of participants recruited online failed to 
provide objective weight information. Further, all height data was obtained through selfreport. Notably, analyses were completed with use of BMI derived from both selfreported and objective weight data to assess if differences emerged, however, none were detected. Be that as it may, it seems unlikely that differences would emerge between use of objective and self-reported weight in this study given that individuals who provided both were informed by their objective scale reading.

An additional limitation of the present study was the high percentage of missing weight data, though the majority of participants with missing weight data can be considered study drop-outs (see Table 1). The weight questions were presented at the end of the questionnaire in an effort to minimize priming effects, which may partially explain the high rates of missing values. Future studies should consider questionnaire order randomization to limit the impact of study drop-out on particular question sets while also providing the opportunity to assess potential priming.

Another important limitation of the present study was that most study variables were not normally distributed. To address this concern, non-parametric test alternatives and data transformation approaches were utilized, therefore, findings should be interpreted with caution. Relatedly, medians and interquartile range were reported rather than means and standard deviations, which may make it more difficult to compare findings from the present study to those described in the extant literature.

The cross-sectional design of the present study is a salient limitation. Firstly, the proposed mediation model (see Figure 3) could not be assessed, as mediation comprises causal processes that unfold across time which would require use of longitudinal models. In this regard, cross-sectional approaches to mediation have been shown to provide 
biased estimates, as they do not offer the temporal information that is required to draw accurate conclusions. (Maxwell \& Cole, 2007)

\section{Implications and Recommendations}

Clinical implications and recommendations. Findings from the present study, and weight stigma literature as a whole, highlight the complexity of the association between weight stigma and health. As the weight stigma-exercise literature is in its infancy, the ways in which experienced and/or internalized weight stigma impact exercise motivation and behavior remain unclear. Further research is needed to clarify associations and mechanisms of action between weight stigma and exercise motivation and behavior, however, available empirical evidence can be used to inform clinical intervention and research.

Consistent with the literature, findings from the present study suggest that more frequent personal encounters with weight-stigmatizing situations may lead people to avoid exercising, particularly in public settings. As detailed by Himmelstein and colleagues (2018), individuals cope with weight stigma in a variety of ways, both healthy and unhealthy (i.e., engaging in healthy behavior, negative affect, avoidance of exercise). It may be beneficial for lifestyle interventions and/or weight management programs to (1) specifically address weight stigma encounters in the curriculum and (2) incorporate cognitive and behavioral strategies to facilitate use of adaptive coping strategies and reduce engagement in unhealthful coping. When first employed, it may be useful to have individuals track their experiences and associated thoughts and behavioral reactions to foster insight into when they were more apt to engage in healthy vs. unhealthy coping. This strategy is consistent with Cognitive-Behavioral Therapy approaches (Beck, 2016). 
This newfound awareness may allow for improved decision-making when met with weight-related stigma experiences in the future.

Consistent with the SDT and Basic Needs Theory, satisfaction of psychological needs was associated with higher levels of intention to exercise and more autonomous (intrinsic) exercise motivation. In particular, findings from the present study suggest that perceived exercise competence may be most important to consider, above and beyond autonomy and relatedness, for promoting intention to exercise. This finding supports the well-documented assertion that interventions that promote need satisfaction, particularly exercise competence, may prove useful for facilitating motivation (Edmunds et al., 2006; Teixeira et al., 2012a). Notably, frequency of experienced weight stigma was associated with less psychological need satisfaction; therefore, future work would benefit from exploring interventions that not only promote need satisfaction, but also bolster coping in a way that protects from the effects of future weight-stigmatizing experiences.

Findings from the present study suggest that internalized weight bias may be more salient than experienced weight stigma with regard to intention to exercise. In other words, individuals who self-direct weight stigma and personally endorse negative weightbased stereotypes may be more vulnerable for poor psychological and physical health outcomes. This finding has significant clinical implications, as interventions can be developed for reducing internalized weight bias. Brief weight bias interventions that emphasize the complexity of obesity, including factors beyond a person's control such as biological and environmental, have shown promising results for individuals in the health care field (Diedrichs \& Barlow, 2011; Poustchi, Saks, Piasecki, Hahn, \& Ferrante, 2013). Additional weight bias interventions have attempted to (1) increase likeability and 
acceptance of persons with obesity and (2) manipulate perceptions regarding the broader populations acceptance of obesity (Grosko, 2010; Lee, 2014; Puhl, 2005). Additional intervention research is needed, particularly with samples of overweight and obese adults who may self-direct weight stigma.

Strategies from already established weight bias interventions could also be integrated with self-compassion interventions to reduce weight bias, self-directed stigma and associated negative outcomes for overweight and obese adults. Self-compassion comprises three main elements: self-kindness, common humanity (i.e., perceiving one's experience as shared with larger human experience), and mindfulness (i.e., balanced awareness of painful internal experiences, rather than over-identification; see Neff, 2003). Self-compassion interventions have been effective for reducing body dissatisfaction, shame and self-worth based on appearance (Albertson, Neff, \& DillShackleford, 2015). Therefore, it is possible that interventions that address general stereotypes and perceptions of persons with overweight and obesity and provide strategies for reducing self-criticism and judgment may be especially helpful. Additional research is needed to explore these assertions.

\section{Empirical recommendations.}

Measurement. The present study utilized the Stigmatizing Situations Inventory to assess frequency of experienced weight stigma, as this well-validated measure is employed most often in the weight stigma literature. This measure requires individuals to estimate the frequency (use of a 10-point response scale; $0=$ never, $9=$ daily) with which they have experienced different weight-stigmatizing situations across their lifetime. However, it has been demonstrated that respondents may have difficulty estimating frequency of weight-stigmatizing encounters with use of the 10-point response scale; 
therefore, some have proposed modifying the response scale (4-point response scale; $0=$ never, 3 = multiple times), which may improve response accuracy (Puhl \& Brownell, 2006; Puhl, Moss-Racusin, \& Schwartz, 2007). Additionally, the length of the Stigmatizing Situations Inventory (50 items) may be too burdensome for participants. Future studies might consider utilizing the Stigmatizing Situations Inventory-Brief (SSIB, 10 items; Vartanian, 2015) measure, which has demonstrated strong psychometric properties, along with the modified response scale.

Schvey and colleagues (2017) recently developed two self-report measures that consider weight-related experiences, perceptions, and preferences at the gym. The Gym Survey (13 items; $\alpha=.91$ ) comprises three sub-scales: Self-Consciousness at the Gym, Negative Attitudes Toward the Gym, Stigma at the Gym (weight-related). The Gym Preferences measure (17 items; $\alpha=.91)$ comprises three subscales: Specialization for Members with Overweight, Shame Free Environment, Gym Offerings. Future studies exploring weight stigma in the context of exercise motivation and behavior should consider utilizing this measure to gain additional insight into gym-specific weight-based stigma perceptions and experiences.

Future studies would benefit from exploring associations among weight stigma and more specific subtypes of extrinsic motivation as proposed by the SDT (i.e., external, introjected, identified and integrated forms of motivation; see Figure 1) to obtain more specificity for the degree of internalization of external motives. Specifically, future studies could incorporate measures such as the Exercise Motivation Scale (Li, 1999), which consists of 31 items and eight subscales: amotivation, external regulation, introjected regulation, identified regulation, integrated regulation, intrinsic regulation to 
learn, accomplish task, and experience sensations (Li, 1999; Wininger, 2007). This measure has demonstrated sound psychometric properties (Wininger, 2007). Given that exercise motivational style can change across time (Edmunds, Ntoumanis, \& Duda, 2007), it may be most beneficial to utilize the Exercise Motivation Scale in conjunction with longitudinal study design.

The present study utilized exercise intention, as informed by the Theory of Planned Behavior, to assess motivation to exercise. It is important to note there are several ways to conceptualize exercise motivation and measurement of this construct differs greatly depending on theory. Future studies should consider including multiple validated measures of exercise motivation simultaneously to provide a more holistic perspective of the relationship between weight stigma and motivation to exercise.

Sample. Future studies should explore and expand upon the present study's hypotheses by recruiting a more heterogenous, diverse sample. Firstly, by recruiting both men and women, comparisons of key associations can be made by gender. Some studies have suggested that men and women may experience comparable rates of weight-related stigmatizing situations (Friedman et al., 2005; Puhl \& Brownell, 2006). Further, some studies have found no gender differences in coping strategies employed with regard to weight stigma (Puhl \& Brownell, 2006). Future work could benefit from specifically exploring gender differences in the weight stigma-exercise relationship. Additionally, it will be important for future studies to include a more ethnically diverse sample to explore differences by ethno-racial group. Recent research found that the negative impact of weight-related discrimination on psychological well-being was greater for Hispanic women when compared to White women (Ciciurkaite \& Perry, 2018). Further, weight- 
related discrimination was not associated with mental health outcomes for African American women (Ciciurkaite \& Perry, 2018). These findings highlight the importance of examining weight stigma in ethnically diverse samples. Future work would benefit from considering the proposed associations with regard to weight stigma, exercise motivation and psychological need satisfaction by ethnicity. Future studies would benefit from employing recommendations described by Watson and colleagues (2016) for recruiting a more ethnically diverse sample, particularly with regard to African Americans.

The present study included participants across the weight continuum, ranging from healthy weight to obese. Consistent with the weight stigma literature, obese participants endorsed more frequent personal encounters with weight stigma situations. It seems plausible that the relationships between experienced weight stigma, psychological need satisfaction, and exercise intention are different (perhaps stronger) for individuals who are subjected to weight-related stigma more often; therefore, future studies should consider exploring proposed association in an obese-only sample.

Alternative methods and statistical analysis. Future studies should utilize inperson recruitment strategies whenever possible to obtain objective weight and height data. As seen with the present study, it is difficult to obtain objective weight data with online questionnaires when participants are recruited through online methods.

Researchers should consider incentivizing participants to upload scale photos, perhaps by offering an opportunity to be entered into a separate gift card lottery associated with the photo upload. Additionally, researchers could offer an additional incentive item for scale photo upload, such as a gift certificate. It may also be helpful for study staff to reach out 
to individuals with missing objective weight data in an effort to problem-solve and emphasize the importance of providing that information.

Given the positive associations found between experienced weight stigma and exercise avoidance as well as controlled (extrinsic) motivational style, future work should consider multivariate analyses. Inclusion of exercise avoidance and controlled motivation as outcome variables, rather than exercise intention, would extend the approach of the present study. This would provide further insight into unique associations and mechanisms of action for the experienced weight stigma-exercise motivation relationship.

Additional construct exploration. Thorough consideration of internalized weight bias in the context of the proposed associations was outside the scope of the present study. However, the present findings, in conjunction with the empirical weight stigma literature, suggest that internalized weight bias is important to consider with regard to exercise motivation. Therefore, future studies should include measures of internalized weight bias to further assess its relationship with psychological need satisfaction and motivation to exercise. Future research directions may also include exploration of the potential moderating or mediating role of internalized weight bias on the relationship between experienced weight stigma and exercise motivation. The construct of internalized weight bias has been conceptualized and measured in several different ways throughout the literature. For example, researchers have included measures such as the Anti-fat Attitudes Questionnaire (Crandall, 1994), Fat Phobia Scale- short form (Bacon, Scheltema, \& Robinson, 2001), Weight Bias Internalization Scale (Durso \& Latner, 2008), and Attitudes toward Obese Persons Scale (Allison, Basile, \& Yuker, 1991). 
Future work would benefit from further consideration of discriminant and convergent validity of these measures. Additionally, it would be beneficial for researchers to establish a more universal conceptualization of the construct of internalized weight bias to guide future research.

\section{Summary of Conclusions}

The present study examined associations with frequency of experienced weight stigma and participant characteristics, exercise motivation and behavior, and psychological need satisfaction as described by the Basic Needs Theory. Findings suggest that individuals of heavier body weight, particularly obese persons, experience more frequent weight stigma situations. Further, findings suggest that individuals who experience more frequent personal encounters with weight-related stigma are more likely to avoid exercise, engage in less exercise behavior, endorse higher levels of controlled (extrinsic) and lower levels of autonomous (intrinsic) exercise motivation, and have less satisfaction of psychological needs. Multivariate findings indicate that perceived exercise competence may be most influential with regard to exercise intention. Contrary to study hypotheses, frequency of experienced weight stigma was not associated with intention to exercise. Future studies of longitudinal design should assess both direct and indirect associations among experienced weight stigma and exercise intention, with particular focus on identifying underlying mechanisms of action. While the present study was exploratory and relied on cross-sectional self-report data, the observed results lend partial support for the proposed conceptual model (see Figure 2) which suggests that weight stigma may undermine motivation to exercise by thwarting satisfaction of three psychological needs known to be important for facilitating motivational processes. This research highlights the pervasiveness of weight-based stigmatization and its negative 
effects on exercise motivation and behavior. Further, findings from the present study can inform clinical interventions and future research to promote exercise motivation and behavior, facilitate adaptive coping in the setting of weight stigma, and reduce internalized weight bias. 


\section{REFERENCES}

Ahmed, S. M., Lemkau, J. P., \& Birt, S. L. (2002). Toward sensitive treatment of obese patients. Fam Pract Manag, 9(1), 25-28.

Ajzen, I. (1991). The theory of planned behavior. Organizational behavior and human decision processes, 50(2), 179-211.

Ajzen, I. (2006). Constructing a theory of planned behavior questionnaire. Retrieved from https://people.umass.edu/aizen/pdf/tpb.measurement.pdf

Ajzen, I. (2011). The theory of planned behaviour: reactions and reflections. Psychology \& Health, 26(9), 1113-1127.

Albertson, E. R., Neff, K. D., \& Dill-Shackleford, K. E. (2015). Self-compassion and body dissatisfaction in women: A randomized controlled trial of a brief meditation intervention. Mindfulness, 6(3), 444-454.

Alegria Drury, C. A., \& Louis, M. (2002). Exploring the Association Between Body Weight, Stigma of Obesity, and Health Care Avoidance. Journal of the American Academy of Nurse Practitioners, 14(12), 554-561. doi:10.1111/j.17457599.2002.tb00089.x

Allison, D. B., Basile, V. C., \& Yuker, H. E. (1991). The measurement of attitudes toward and beliefs about obese persons. International Journal of Eating Disorders, 10(5), 599-607.

Andreyeva, T., Puhl, R., \& Brownell, K. (2008). Changes in Perceived Weight Discrimination Among Americans, 1995-1996 Through 2004-2006. Obesity, 16(5), 1129-1134. doi:doi:10.1038/oby.2008.35 
Azarbad, L., \& Gonder-Frederick, L. (2010). Obesity in women. Psychiatric Clinics, 33(2), 423-440.

Bacon, J. G., Scheltema, K. E., \& Robinson, B. E. (2001). Fat phobia scale revisited: the short form. International Journal of Obesity, 25(2), 252.

Bandura, A. (1977). Self-efficacy: toward a unifying theory of behavioral change. Psychological Review, 84(2), 191.

Beck, A. T. (2016). Cognitive therapy: Nature and relation to behavior therapy. Behavior Therapy, 47(6), 776-784. doi:10.1016/j.beth.2016.11.003

Berger, M., \& Sarnyai, Z. (2015). 'More than skin deep': Stress neurobiology and mental health consequences of racial discrimination. Stress: The International Journal on the Biology of Stress, 18(1), 1-10. doi:10.3109/10253890.2014.989204

Blanchard, C. M., Courneya, K. S., Rodgers, W. M., Daub, B., \& Knapik, G. (2002). Determinants of exercise intention and behavior during and after phase 2 cardiac rehabilitation: An application of the theory of planned behavior. Rehabilitation Psychology, 47(3), 308.

Brenner, P. S., \& DeLamater, J. D. (2014). Social desirability bias in self-reports of physical activity: is an exercise identity the culprit? Social Indicators Research, 117(2), 489-504.

Broman, C. L., Mavaddat, R., \& Hsu, S.-y. (2000). The experience and consequences of perceived racial discrimination: A study of African Americans. Journal of Black Psychology, 26(2), 165-180. doi:10.1177/0095798400026002003 
Brown, R. P., \& Pinel, E. C. (2003). Stigma on my mind: Individual differences in the experience of stereotype threat. Journal of Experimental Social Psychology, 39(6), 626-633. doi:http://dx.doi.org/10.1016/S0022-1031(03)00039-8

Carels, R. A., Young, K. M., Wott, C. B., Harper, J., Gumble, A., Oehlof, M. W., et al. (2009). Weight bias and weight loss treatment outcomes in treatment-seeking adults. Annals of Behavioral Medicine, 37(3), 350-355. doi:10.1007/s12160-0099109-4

Centers for Disease Control and Prevention. (2011). Adding physical activity to your life: Overcoming barriers to physical activity. Retrieved from http://www.cdc.gov/physicalactivity/basics/adding-pa/barriers.html

Centers for Disease Control and Prevention. (2014). Facts about physical activity. Retrieved from https://www.cdc.gov/physicalactivity/data/facts.htm

Centers for Disease Control and Prevention. (2015a). Adult obesity causes \& consequences. Retrieved from http://www.cdc.gov/obesity/adult/causes.html

Centers for Disease Control and Prevention. (2015b). Physical activity and health: The benefits of physical activity. Retrieved from http://www.cdc.gov/physicalactivity/basics/pa-health/

Chan, D. (2009). So why ask me? Are self-report data really that bad. Statistical and methodological myths and urban legends: Doctrine, verity and fable in the organizational and social sciences, 309-336.

Ciciurkaite, G., \& Perry, B. L. (2018). Body weight, perceived weight stigma and mental health among women at the intersection of race/ethnicity and socioeconomic 
status: Insights from the modified labelling approach. Sociology of Health \& Illness, 40(1), 18-37. doi:10.1111/1467-9566.12619

Committee on Accelerating Progress in Obesity Prevention. (2012). Accelerating progress in obesity prevention: solving the weight of the nation: National Academies Press.

Courneya, K. S., Friedenreich, C. M., Arthur, K., \& Bobick, T. M. (1999). Understanding exercise motivation in colorectal cancer patients: A prospective study using the theory of planned behavior. Rehabilitation Psychology, 44(1), 68.

Crandall, C. S. (1994). Prejudice against fat people: ideology and self-interest. Journal of Personality and Social Psychology, 66(5), 882.

Deci, E. L., Eghrari, H., Patrick, B. C., \& Leone, D. R. (1994). Facilitating internalization: The self-determination theory perspective. Journal of personality, 62(1), 119-142.

Deci, E. L., \& Ryan, R. (2002). Overview of self-determination theory: An organismic dialectical perspective. Handbook of self-determination research, 3-33.

Diedrichs, P. C., \& Barlow, F. K. (2011). How to lose weight bias fast! Evaluating a brief anti-weight bias intervention. British Journal of Health Psychology, 16(4), 846861.

Dunn, O. J. (1964). Multiple comparisons using rank sums. Technometrics, 6(3), 241252.

Durso, L. E., \& Latner, J. D. (2008). Understanding self-directed stigma: development of the weight bias internalization scale. Obesity (Silver Spring), 16 Suppl 2, S80-86. doi:10.1038/oby.2008.448 
Ebben, W., \& Brudzynski, L. (2008). Motivations and barriers to exercise among college students. Journal of Exercise Physiology Online, 11(5), 1-11.

Edmunds, J., Ntoumanis, N., \& Duda, J. L. (2006). A Test of Self-Determination Theory in the Exercise Domain. Journal of Applied Social Psychology, 36(9), 2240-2265. doi:10.1111/j.0021-9029.2006.00102.x

Edmunds, J., Ntoumanis, N., \& Duda, J. L. (2007). Adherence and well-being in overweight and obese patients referred to an exercise on prescription scheme: A self-determination theory perspective. Psychology of Sport and Exercise, 8(5), 722-740.

Egli, T., Bland, H. W., Melton, B. F., \& Czech, D. R. (2011). Influence of Age, Sex, and Race on College Students' Exercise Motivation of Physical Activity. Journal of American College Health, 59(5), 399-406. doi:10.1080/07448481.2010.513074

Ekkekakis, P., \& Lind, E. (2005). Exercise does not feel the same when you are overweight: the impact of self-selected and imposed intensity on affect and exertion. Int J Obes, 30(4), 652-660.

Ekkekakis, P., Lind, E., \& Vazou, S. (2010). Affective Responses to Increasing Levels of Exercise Intensity in Normal-weight, Overweight, and Obese Middle-aged Women. Obesity, 18(1), 79-85. doi:10.1038/oby.2009.204

Enders, C. K. (2001). A Primer on Maximum Likelihood Algorithms Available for Use With Missing Data. Structural Equation Modeling: A Multidisciplinary Journal, 8(1), 128-141. doi:10.1207/S15328007SEM0801_7 
Epel, E. S., McEwen, B., Seeman, T., Matthews, K., Castellazzo, G., Brownell, K. D., et al. (2000). Stress and body shape: stress-induced cortisol secretion is consistently greater among women with central fat. Psychosomatic Medicine, 62(5), 623-632.

Ervin, R. B. (2009). Prevalence of metabolic syndrome among adults 20 years of age and over, by sex, age, race and ethnicity, and body mass index: United States. National health statistics reports, 13, 1-8.

Faul, F., Erdfelder, E., Lang, A.-G., \& Buchner, A. (2007). G* Power 3: A flexible statistical power analysis program for the social, behavioral, and biomedical sciences. Behavior research methods, 39(2), 175-191.

Field, A. (2013). Discovering statistics using IBM SPSS statistics: sage.

Fogliati, V. J., \& Bussey, K. (2013). Stereotype Threat Reduces Motivation to Improve: Effects of Stereotype Threat and Feedback on Women's Intentions to Improve Mathematical Ability. Psychology of Women Quarterly. doi:10.1177/0361684313480045

Foster, G. D., Makris, A. P., \& Bailer, B. A. (2005). Behavioral treatment of obesity. The American Journal of Clinical Nutrition, 82(1), 230S-235S.

Friedman, K. E., Reichmann, S. K., Costanzo, P. R., Zelli, A., Ashmore, J. A., \& Musante, G. J. (2005). Weight stigmatization and ideological beliefs: relation to psychological functioning in obese adults. Obesity, 13(5), 907-916.

Glasgow, R. E., Ory, M. G., Klesges, L. M., Cifuentes, M., Fernald, D. H., \& Green, L. A. (2005). Practical and Relevant Self-Report Measures of Patient Health Behaviors for Primary Care Research. The Annals of Family Medicine, 3(1), 7381. doi:10.1370/afm.261 
Godin, G., \& Shephard, R. (1985). A simple method to assess exercise behavior in the community. Canadian journal of applied sport sciences. Journal canadien des sciences appliquees au sport, 10(3), 141-146.

Godin, G., \& Shephard, R. (1997). Godin leisure-time exercise questionnaire. Med Sci Sports Exerc, 29(6), 36-38.

Gorber, S. C., Tremblay, M., Moher, D., \& Gorber, B. (2007). A comparison of direct vs. self-report measures for assessing height, weight and body mass index: a systematic review. Obesity Reviews, 8(4), 307-326.

Grosko, T. A. (2010). Obesity stigma reduction. (70), ProQuest Information \& Learning, US. Retrieved from https://search.ebscohost.com/login.aspx?direct=true $\& d b=p s y h \& A N=2010-99020-$ $\underline{316 \& \text { site=ehost-live Available from EBSCOhost psyh database. }}$

Hagger, M., \& Chatzisarantis, N. (2008). Self-determination theory and the psychology of exercise. International review of sport and exercise psychology, 1(1), 79-103.

Hainer, V., Toplak, H., \& Stich, V. (2009). Fat or Fit: What Is More Important? Diabetes Care, 32(Suppl 2), S392-S397. doi:10.2337/dc09-S346

Hayes, A. F. (2009). Beyond Baron and Kenny: Statistical mediation analysis in the new millennium. Communication monographs, 76(4), 408-420.

He, X. Z., \& Baker, D. W. (2005). Differences in leisure-time, household, and workrelated physical activity by race, ethnicity, and education. Journal of General Internal Medicine, 20(3), 259-266.

Hecke, T. V. (2012). Power study of anova versus Kruskal-Wallis test. Journal of Statistics and Management Systems, 15(2-3), 241-247. 
Heo, M., Pietrobelli, A., Wang, D., Heymsfield, S. B., \& Faith, M. S. (2010). Obesity and functional impairment: influence of comorbidity, joint pain, and mental health. Obesity, 18(10), 2030-2038.

Himmelstein, M. S., Puhl, R. M., \& Quinn, D. M. (2018). Weight stigma and health: The mediating role of coping responses. Health Psychology, 37(2), 139-147.

Høie, M., Moan, I. S., \& Rise, J. (2010). An extended version of the theory of planned behavour: Prediction of intentions to quit smoking using past behaviour as moderator. Addiction Research \& Theory, 18(5), 572-585.

Hsu, Y.-T., Buckworth, J., Focht, B. C., \& O'Connell, A. A. (2013). Feasibility of a SelfDetermination Theory-based exercise intervention promoting Healthy at Every Size with sedentary overweight women: Project CHANGE. Psychology of Sport and Exercise, 14(2), 283-292.

Hulens, M., Vansant, G., Lysens, R., Claessens, A. L., \& Muls, E. (2001). Exercise capacity in lean versus obese women. Scandinavian Journal of Medicine \& Science in Sports, 11(5), 305-309. doi:10.1034/j.1600-0838.2001.110509.x

Hunger, J. M., \& Major, B. (2015). Weight stigma mediates the association between BMI and self-reported health. Health Psychology, 34(2), 172.

IBM Corporation. (2017). IBM SPSS Statistics for Windows Version 25.0. Armonk NY: IBM Corp. In.

Jakicic, J. M., Clark, K., Coleman, E., Donnelly, J. E., Foreyt, J., Melanson, E., et al. (2001). American College of Sports Medicine position stand. Appropriate intervention strategies for weight loss and prevention of weight regain for adults. Medicine and science in sports and exercise, 33(12), 2145-2156. 
Karvinen, K. H., Courneya, K. S., Campbell, K. L., Pearcey, R. G., Dundas, G., Capstick, V., et al. (2007). Correlates of exercise motivation and behavior in a populationbased sample of endometrial cancer survivors: an application of the Theory of Planned Behavior. International Journal of Behavioral Nutrition and Physical Activity, 4(1), 21.

Khaodhiar, L., McCowen, K. C., \& Blackburn, G. L. (1999). Obesity and its comorbid conditions. Clin Cornerstone, 2(3), 17-31.

Kroenke, K., Spitzer, R. L., \& Williams, J. B. (2001). The PHQ-9: validity of a brief depression severity measure. Journal of General Internal Medicine, 16(9), 606613.

Kushner, R. F. (2012). Clinical Assessment and Management of Adult Obesity. Circulation, 126(24), 2870-2877. doi:10.1161/circulationaha.111.075424

Lauderdale, M. E., Yli-Piipari, S., Irwin, C. C., \& Layne, T. E. (2015). Gender Differences Regarding Motivation for Physical Activity Among College Students: A Self-Determination Approach. Physical Educator, 72, 153-172.

LeBlanc, E. S., O'Connor, E., Whitlock, E. P., Patnode, C. D., \& Kapka, T. (2011). Effectiveness of primary care-relevant treatments for obesity in adults: a systematic evidence review for the US Preventive Services Task Force. Annals of Internal Medicine, 155(7), 434-447.

Lee, M. (2014). Malleability of weight-biased attitudes and beliefs: A meta-analysis of weight bias reduction interventions. Body image, 11(3), 251-259. 
Leone, L. A., \& Ward, D. S. (2013). A mixed methods comparison of perceived benefits and barriers to exercise between obese and nonobese women. Journal of Physical Activity \& Health, 10(4), 461-469.

Levesque, C. S., Williams, G. C., Elliot, D., Pickering, M. A., Bodenhamer, B., \& Finley, P. J. (2007). Validating the theoretical structure of the Treatment Self-Regulation Questionnaire (TSRQ) across three different health behaviors. Health Educ Res, 22(5), 691-702. doi:10.1093/her/cyl148

Levy, R. L., Finch, E. A., Crowell, M. D., Talley, N. J., \& Jeffery, R. W. (2007). Behavioral intervention for the treatment of obesity: strategies and effectiveness data. The American journal of gastroenterology, 102(10), 2314-2321.

Lewis, S., Thomas, S. L., Blood, R. W., Castle, D. J., Hyde, J., \& Komesaroff, P. A. (2011a). How do obese individuals perceive and respond to the different types of obesity stigma that they encounter in their daily lives? A qualitative study. Social Science \& Medicine, 73(9), 1349-1356. doi:http://dx.doi.org/10.1016/j.socscimed.2011.08.021

Lewis, S., Thomas, S. L., Hyde, J., Castle, D. J., \& Komesaroff, P. A. (2011b). A qualitative investigation of obese men's experiences with their weight. American Journal of Health Behavior, 35(4), 458-469.

Li, F. (1999). The exercise motivation scale: Its multifaceted structure and construct validity. Journal of Applied Sport Psychology, 11(1), 97-115.

Little, R. J. A. (1988). A Test of Missing Completely at Random for Multivariate Data with Missing Values. Journal of the American Statistical Association, 83(404), 1198-1202. doi:10.1080/01621459.1988.10478722 
Luppino, F. S., de Wit, L. M., Bouvy, P. F., Stijnen, T., Cuijpers, P., Penninx, B. W., et al. (2010). Overweight, obesity, and depression: a systematic review and metaanalysis of longitudinal studies. Arch Gen Psychiatry, 67(3), 220-229. doi:10.1001/archgenpsychiatry.2010.2

MacLean, L., Edwards, N., Garrard, M., Sims-Jones, N., Clinton, K., \& Ashley, L. (2009). Obesity, stigma and public health planning. Health Promotion International, 24(1), 88-93. doi:10.1093/heapro/dan041

Major, B., Hunger, J. M., Bunyan, D. P., \& Miller, C. T. (2014). The ironic effects of weight stigma. Journal of Experimental Social Psychology, 51, 74-80. doi:10.1016/j.jesp.2013.11.009

Maloney, E. M., Boneva, R. S., Lin, J. M., \& Reeves, W. C. (2010). Chronic fatigue syndrome is associated with metabolic syndrome: results from a case-control study in Georgia. Metabolism, 59(9), 1351-1357.

doi:10.1016/j.metabol.2009.12.019

Malterud, K., \& Ulriksen, K. (2011). Obesity, stigma, and responsibility in health care: A synthesis of qualitative studies. International Journal of Qualitative Studies on Health and Well-being, 6(4), 1-11. doi:10.3402/qhw.v6i4.8404

Maxwell, S. E., \& Cole, D. A. (2007). Bias in cross-sectional analyses of longitudinal mediation. Psychological methods, 12(1), 23.

Mayo Clinic. (2015). Diseases and conditions: Obesity. Retrieved from http://www.mayoclinic.org/diseases-conditions/obesity/basics/definition/con$\underline{20014834}$ 
McAuley, E. (1992). The role of efficacy cognitions in the prediction of exercise behavior in middle-aged adults. Journal of Behavioral Medicine, 15(1), 65-88.

McDonald, K., \& Thompson, J. K. (1992). Eating Disturbance, Body Image Dissatisfaction, and Reasons for Exercising: Gender Differences and Correlational Findings. International Journal of Eating Disorders, 11(3), 289292.

McVinnie, D. S. (2013). Obesity and pain. British journal of pain, 7(4), 163-170.

Myers, A., \& Rosen, J. C. (1999). Obesity stigmatization and coping: relation to mental health symptoms, body image, and self-esteem. International Journal of Obesity, 23(3), 221-230.

National Institute of Diabetes and Digestive and Kidney Diseases. (2012). Overweight and obesity statistics. Retrieved from http://www.niddk.nih.gov/healthinformation/health-statistics/Pages/overweight-obesity-statistics.aspx

National Institute on Aging. (2016). Exercise and physical activity: Your everday guide from the national institute on aging. Retrieved from https://www.nia.nih.gov/health/publication/exercise-physical-activity/introduction

Neff, K. (2003). Self-compassion: An alternative conceptualization of a healthy attitude toward oneself. Self and identity, 2(2), 85-101.

Ng, J. Y., Ntoumanis, N., Thøgersen-Ntoumani, C., Deci, E. L., Ryan, R. M., Duda, J. L., et al. (2012). Self-determination theory applied to health contexts a meta-analysis. Perspectives on Psychological Science, 7(4), 325-340.

NHLBI Obesity Education Initiative Expert. (1998). Clinical guidelines on the identification, evaluation, and treatment of overweight and obesity in adults. 
Retrieved from

https://www.nhlbi.nih.gov/health/educational/wecan/portion/documents/CORESE

$\underline{\text { T1.pdf }}$

Nomaguchi, K. M., \& Bianchi, S. M. (2004). Exercise time: Gender differences in the effects of marriage, parenthood, and employment. Journal of Marriage and Family, 66(2), 413-430. doi:10.1111/j.1741-3737.2004.00029.x

Pacanowski, C. R., Linde, J. A., \& Neumark-Sztainer, D. (2015). Self-weighing: Helpful or harmful for psychological well-being? A review of the literature. Current Obesity Reports, 4(1), 65-72.

Papadopoulos, S., \& Brennan, L. (2015). Correlates of weight stigma in adults with overweight and obesity: A systematic literature review. Obesity, 23(9), 17431760. doi:10.1002/oby.21187

Pearl, R. L., Dovidio, J. F., \& Puhl, R. M. (2015a). Visual portrayals of obesity in health media: Promoting exercise without perpetuating weight bias. Health Education Research, 30(4), 580-590. doi:10.1093/her/cyv025

Pearl, R. L., Dovidio, J. F., Puhl, R. M., \& Brownell, K. D. (2015b). Exposure to weightstigmatizing media: Effects on exercise intentions, motivation, and behavior. Journal of Health Communication, 20(9), 1004-1013. doi:10.1080/10810730.2015.1018601

Pearl, R. L., \& Puhl, R. M. (2014). Measuring internalized weight attitudes across body weight categories: Validation of the Modified Weight Bias Internalization Scale. Body image, 11(1), 89-92. 
Pearl, R. L., Puhl, R. M., \& Dovidio, J. F. (2015c). Differential effects of weight bias experiences and internalization on exercise among women with overweight and obesity. Journal of Health Psychology, 20(12), 1626-1632. doi:10.1177/1359105313520338

Phelan, S., Burgess, D., Yeazel, M., Hellerstedt, W., Griffin, J., \& Ryn, M. (2015). Impact of weight bias and stigma on quality of care and outcomes for patients with obesity. Obesity Reviews, 16(4), 319-326.

Potter, L., Wallston, K., Trief, P., Ulbrecht, J., Juth, V., \& Smyth, J. (2015). Attributing discrimination to weight: Associations with well-being, self-care, and disease status in patients with type 2 diabetes mellitus. Journal of Behavioral Medicine, 38(6), 863-875. doi:10.1007/s10865-015-9655-0

Poustchi, Y., Saks, N. S., Piasecki, A. K., Hahn, K. A., \& Ferrante, J. M. (2013). Brief intervention effective in reducing weight bias in medical students. Family medicine, 45(5), 345 .

Puhl, R., \& Brownell, K. D. (2003). Ways of coping with obesity stigma: review and conceptual analysis. Eating Behaviors, 4(1), 53-78.

Puhl, R., \& Heuer, C. A. (2010). Obesity stigma: Important considerations for public health. American Journal of Public Health, 100(6), 1019-1028. doi:10.2105/ajph.2009.159491

Puhl, R., \& Suh, Y. (2015). Health Consequences of Weight Stigma: Implications for Obesity Prevention and Treatment. Current Obesity Reports, 1-9.

Puhl, R. M. (2005). Impact of Perceived Consensus on Stereotypes About Obese People: A New Approach for Reducing Bias. Health Psychology, 24(5), 517-525. 
Puhl, R. M., Andreyeva, T., \& Brownell, K. D. (2008). Perceptions of weight discrimination: prevalence and comparison to race and gender discrimination in America. International Journal of Obesity, 32(6), 992.

Puhl, R. M., \& Brownell, K. D. (2006). Confronting and coping with weight stigma: an investigation of overweight and obese adults. Obesity, 14(10), 1802-1815.

Puhl, R. M., Moss-Racusin, C. A., \& Schwartz, M. B. (2007). Internalization of weight bias: implications for binge eating and emotional well-being. Obesity, 15(1), 1923.

Roshanaei-Moghaddam, B., Katon, W. J., \& Russo, J. (2009). The longitudinal effects of depression on physical activity. General hospital psychiatry, 31(4), 306-315.

Ryan, R. M., \& Deci, E. L. (2000). Self-determination theory and the facilitation of intrinsic motivation, social development, and well-being. American psychologist, $55(1), 68$.

Ryan, R. M., Patrick, H., Deci, E. L., \& Williams, G. C. (2008). Facilitating health behaviour change and its maintenance: Interventions based on self-determination theory. European Health Psychologist, 10(1), 2-5.

Sallis, J., Hovell, M., Hofstetter, C. R., Elder, J., Faucher, P., Spry, V., et al. (1990). Lifetime history of relapse from exercise. Addictive behaviors, 15(6), 573-579.

Sangha, O., Stucki, G., Liang, M. H., Fossel, A. H., \& Katz, J. N. (2003). The selfadministered comorbidity questionnaire: A new method to assess comorbidity for clinical and health services research. Arthritis Care \& Research, 49(2), 156-163. 
Schafer, M. H., \& Ferraro, K. F. (2011). The stigma of obesity: does perceived weight discrimination affect identity and physical health? Social Psychology Quarterly, 74(1), 76-97.

Schmalz, D. L. (2010). 'I Feel Fat': Weight-Related Stigma, Body Esteem, and BMI as Predictors of Perceived Competence in Physical Activity. Obesity Facts, 3(1), $15-$ 21.

Schvey, N. A., Sbrocco, T., Bakalar, J., Ress, R., Barmine, M., Gorlick, J., et al. (2017). The experience of weight stigma among gym members with overweight and obesity. Stigma and Health, 2(4), 292-306.

Schwartz, M. B., Chambliss, H. O. N., Brownell, K. D., Blair, S. N., \& Billington, C. (2003). Weight bias among health professionals specializing in obesity. Obesity Research, 11(9), 1033-1039.

Seacat, J. D., \& Mickelson, K. D. (2009). Stereotype Threat and the Exercise/ Dietary Health Intentions of Overweight Women. Journal of Health Psychology, 14(4), 556-567. doi:10.1177/1359105309103575

Shaw, B. A., \& Spokane, L. S. (2008). Examining the association between education level and physical activity changes during early old age. Journal of Aging and Health, 20(7), 767-787.

Sheldon, K. M., \& Hilpert, J. C. (2012). The balanced measure of psychological needs (BMPN) scale: An alternative domain general measure of need satisfaction. Motivation and Emotion, 36(4), 439-451.

Silva, M., Vieira, P., Coutinho, S., Minderico, C., Matos, M., Sardinha, L., et al. (2010a). Using self-determination theory to promote physical activity and weight control: a 
randomized controlled trial in women. Journal of Behavioral Medicine, 33(2), 110-122. doi:10.1007/s10865-009-9239-y

Silva, M. N., Markland, D., Vieira, P. N., Coutinho, S. R., Carraça, E. V., Palmeira, A. L., et al. (2010b). Helping overweight women become more active: need support and motivational regulations for different forms of physical activity. Psychology of Sport and Exercise, 11(6), 591-601.

Smart Richman, L., \& Leary, M. R. (2009). Reactions to discrimination, stigmatization, ostracism, and other forms of interpersonal rejection: A multimotive model. Psychological Review, 116(2), 365-383. doi:10.1037/a0015250

Spees, C. K., Scott, J. M., \& Taylor, C. A. (2012). Differences in the Amounts and Types of Physical Activity by Obesity Status in US Adults. American Journal of Health Behavior, 36(1), 56-65.

Steele, C. M., \& Aronson, J. (1995). Stereotype threat and the intellectual test performance of African Americans. Journal of Personality and Social Psychology, 69(5), 797.

Sutin, A. R., \& Terracciano, A. (2013). Perceived Weight Discrimination and Obesity. PLoS ONE, 8(7), e70048. doi:10.1371/journal.pone.0070048

Teixeira, P. J., Carraça, E. V., Markland, D., Silva, M. N., \& Ryan, R. M. (2012a). Exercise, physical activity, and self-determination theory: a systematic review. Int J Behav Nutr Phys Act, 9(1), 78.

Teixeira, P. J., Silva, M. N., Mata, J., Palmeira, A. L., \& Markland, D. (2012b). Motivation, self-determination, and long-term weight control. Int J Behav Nutr Phys Act, 9(1), 22. 
The National Institute of Diabetes and Digestive and Kidney Disease. (2017).

Overweight and obesity statistics. Retrieved from

https://www.niddk.nih.gov/health-information/health-statistics/overweight-

obesity

Thøgersen-Ntoumani, C., \& Ntoumanis, N. (2006). The role of self-determined motivation in the understanding of exercise-related behaviours, cognitions and physical self-evaluations. Journal of sports sciences, 24(4), 393-404.

Thompson, W. G., Cook, D. A., Clark, M. M., Bardia, A., \& Levine, J. A. (2007).

Treatment of obesity. Paper presented at the Mayo Clinic Proceedings.

Tomiyama, A. J., Epel, E. S., McClatchey, T. M., Poelke, G., Kemeny, M. E., McCoy, S. K., et al. (2014). Associations of weight stigma with cortisol and oxidative stress independent of adiposity. Health Psychology, 33(8), 862-867.

doi:10.1037/hea0000107

Topolski, T. D., LoGerfo, J., Patrick, D. L., Williams, B., Walwick, J., \& Patrick, M. M. B. (2006). Peer reviewed: the Rapid Assessment of Physical Activity (RAPA) among older adults. Preventing Chronic Disease, 3(4).

Troiano, R. P., Berrigan, D., Dodd, K. W., Masse, L. C., Tilert, T., \& McDowell, M. (2008). Physical activity in the United States measured by accelerometer. Medicine and science in sports and exercise, 40(1), 181.

U.S. Department of Health and Human Services Health Resources and Services Administration. (2012). Diabetes HbA1c. Retrieved from http://www.hrsa.gov/quality/toolbox/508pdfs/diabetesmodule.pdf 
University of Washington Health Promotion Research Center. (2006). Rapid Assessment of Physical Activity (RAPA). Retrieved from http://depts.washington.edu/hprc/rapa

Vartanian, L. R. (2015). Development and validation of a brief version of the Stigmatizing Situations Inventory. Obesity Science \& Practice, 1(2), 119-125. doi:10.1002/osp4.11

Vartanian, L. R., \& Novak, S. A. (2011). Internalized societal attitudes moderate the impact of weight stigma on avoidance of exercise. Obesity, 19(4), 757-762. doi:10.1038/oby.2010.234

Vartanian, L. R., \& Shaprow, J. G. (2008). Effects of Weight Stigma on Exercise Motivation and Behavior: A Preliminary Investigation among College-aged Females. Journal of Health Psychology, 13, 131-138.

doi: $10.1177 / 1359105307084318$

Wang, S. S., Brownell, K. D., \& Wadden, T. (2004). The influence of the stigma of obesity on overweight individuals. International Journal of Obesity, 28(10), 1333-1337.

Watson, B., Robinson, D. H., Harker, L., \& Arriola, K. R. J. (2016). The inclusion of African-American study participants in web-based research studies. Journal of medical Internet research, 18(6).

Weman-Josefsson, K., Lindwall, M., \& Ivarsson, A. (2015). Need satisfaction, motivational regulations and exercise: Moderation and mediation effects. The International Journal of Behavioral Nutrition and Physical Activity, 12. 
Williams, D. R., Neighbors, H. W., \& Jackson, J. S. (2003). Racial/ethnic discrimination and health: findings from community studies. American Journal of Public Health, 93(2), 200-208.

Williams, G. C., Grow, V. M., Freedman, Z. R., Ryan, R. M., \& Deci, E. L. (1996). Motivational predictors of weight loss and weight-loss maintenance. Journal of Personality and Social Psychology, 70(1), 115.

Williams, G. C., Ryan, M., \& Deci, E. L. (2016). Self-Determination Theory Questionnaires. Retrieved from http://selfdeterminationtheory.org/

Wilson, P. M., Mack, D. E., \& Grattan, K. P. (2008). Understanding motivation for exercise: a self-determination theory perspective. Canadian Psychology/Psychologie Canadienne, 49(3), 250.

Wilson, P. M., Rogers, W. T., Rodgers, W. M., \& Wild, T. C. (2006). The psychological need satisfaction in exercise scale. Journal of Sport and Exercise Psychology, $28(3), 231$.

Wininger, S. R. (2007). Self-determination theory and exercise behavior: An examination of the psychometric properties of the exercise motivation scale. Journal of Applied Sport Psychology, 19(4), 471-486.

World Health Organization. (2016a). BMI classification. Retrieved from http://apps.who.int/bmi/index.jsp?introPage=intro_3.html

World Health Organization. (2016b). Physical Activity and Women. Retrieved from http://www.who.int/dietphysicalactivity/factsheet_women/en/ 
Wott, C. B., \& Carels, R. A. (2010). Overt Weight Stigma, Psychological Distress and Weight Loss Treatment Outcomes. Journal of Health Psychology, 15(4), 608-614. doi: $10.1177 / 1359105309355339$

Wright, S. M., \& Aronne, L. J. (2012). Causes of obesity. Abdominal Imaging, 37(5), 730-732. doi:10.1007/s00261-012-9862-x 
Appendix A

SACQ: Self-Administered Comorbidity Questionnaire (health status)

SSI: Stigmatizing Situations Inventory (frequency of experienced weight stigma)

WBIS-M: Weight Bias Internalization Scale-modified (internalized weight bias)

RAPA: Rapid Assessment of Physical Activity (CDC guidelines for physical activity)

GLTQ-E: Godin Leisure-Time Exercise Questionnaire (exercise behavior)

TSRQ-E: Treatment Self-Regulation Questionnaire-Exercise (SDT exercise motivational style)

Exercise-Avoidance: Exercise-Avoidance Motivation Scale (exercise avoidance motivation)

PNSE: Psychological Need Satisfaction in Exercise Scale (psychological needs in exercise)

BMPN: Balanced Measure of Psychological Needs (psychological needs in general) 


\section{Table 1}

Participants Removed from Data Analysis

\begin{tabular}{|c|c|}
\hline Reason for Removal & $\mathrm{N}$ \\
\hline Underweight BMI & 5 \\
\hline No Weight Data & 49 \\
\hline Dropped Out Before Weight Questions & 39 \\
\hline Dropped Out at Weight Questions & 9 \\
\hline Skipped Weight Question & 1 \\
\hline No Height Data & 2 \\
\hline Guessed Weight $^{*}$ & 5 \\
\hline Dropped Out at Demographic Questionnaire & 1 \\
\hline Significant Pattern of Missing Data & 1 \\
\hline Did Not Complete Stigmatizing Situations Inventory & 1 \\
\hline Total & 64 \\
\hline
\end{tabular}

Note. All participants who dropped out before weight questions are also missing data for the Stigmatizing Situations Inventory, a primary study measure. Therefore, these participants can be considered study drop-outs.

*Participant indicated that they guessed their weight with no supporting details (i.e., no scale photo, no data for when did you weigh yourself/where did you weigh yourself). 
Table 2

Demographic Characteristics of Participants who Dropped Out Before Weight Question

\begin{tabular}{|c|c|c|c|c|}
\hline Characteristic & $\mathrm{N}$ & $\%$ & $\mathrm{M}(\mathrm{SD})$ & Median(IQR) \\
\hline Age & 39 & 100 & $35.15(11.13)$ & $29.00(21.00)$ \\
\hline \multicolumn{5}{|l|}{ Ethnicity } \\
\hline White (non-Hispanic) & 31 & 79.5 & & \\
\hline Black or African American & 3 & 7.7 & & \\
\hline Hispanic & 3 & 7.7 & & \\
\hline Asian & 1 & 2.6 & & \\
\hline More than One & 1 & 2.6 & & \\
\hline \multicolumn{5}{|l|}{ Marital Status } \\
\hline Never Married & 17 & 43.6 & & \\
\hline Married & 17 & 43.6 & & \\
\hline Separated & 1 & 2.6 & & \\
\hline Divorced & 4 & 10.3 & & \\
\hline \multicolumn{5}{|l|}{ Employment Status } \\
\hline Full-time & 26 & 66.7 & & \\
\hline Part-time & 4 & 10.3 & & \\
\hline Unemployed & 4 & 10.3 & & \\
\hline Student & 8 & 20.5 & & \\
\hline Disabled & 0 & 0 & & \\
\hline \multicolumn{5}{|l|}{ Income } \\
\hline $0-9,999$ & 5 & 12.8 & & \\
\hline $10,000-19,000$ & 2 & 5.1 & & \\
\hline $20,000-29,999$ & 5 & 12.8 & & \\
\hline $30,000-39,999$ & 1 & 2.6 & & \\
\hline $40,000-49,999$ & 8 & 20.5 & & \\
\hline $50,000-59,999$ & 7 & 17.9 & & \\
\hline $60,000-69,999$ & 3 & 7.7 & & \\
\hline $70,000-79,999$ & 6 & 15.4 & & \\
\hline 80,000 or more & 2 & 5.1 & & \\
\hline \multicolumn{5}{|l|}{ Education } \\
\hline High School / GED & 5 & 12.8 & & \\
\hline Some College & 6 & 15.4 & & \\
\hline Associate Degree & 3 & 7.7 & & \\
\hline Bachelor's Degree & 10 & 25.6 & & \\
\hline Master's Degree & 13 & 33.3 & & \\
\hline Professional Degree & 0 & 0 & & \\
\hline Doctorate & 2 & 5.1 & & \\
\hline \multicolumn{5}{|l|}{ State of Residence } \\
\hline Kentucky & 19 & 48.7 & & \\
\hline Indiana & 2 & 5.1 & & \\
\hline
\end{tabular}




$\begin{array}{ccc}\text { Ohio } & 1 & 2.6 \\ \text { Other } & 16 & 41.0\end{array}$


Table 3

Demographic Characteristics of Participants who Dropped Out at the Weight Question

\begin{tabular}{|c|c|c|c|c|}
\hline Characteristic & $\mathrm{N}$ & $\%$ & $\mathrm{M}(\mathrm{SD})$ & Median (IQR) \\
\hline Age & 9 & 100 & $38.11(15.78)$ & $29.00(29.50)$ \\
\hline \multicolumn{5}{|l|}{ Ethnicity } \\
\hline White (non-Hispanic) & 8 & 88.9 & & \\
\hline More than One & 1 & 11.1 & & \\
\hline \multicolumn{5}{|l|}{ Marital Status } \\
\hline Never Married & 2 & 22.2 & & \\
\hline Married & 5 & 55.6 & & \\
\hline Divorced & 2 & 22.2 & & \\
\hline \multicolumn{5}{|l|}{ Employment Status } \\
\hline Full-time & 5 & 55.6 & & \\
\hline Part-time & 2 & 22.2 & & \\
\hline Unemployed & 2 & 22.2 & & \\
\hline \multicolumn{5}{|l|}{ Income } \\
\hline $0-9,999$ & 2 & 22.2 & & \\
\hline $20,000-29,999$ & 1 & 11.1 & & \\
\hline $30,000-39,999$ & 1 & 11.1 & & \\
\hline $40,000-49,999$ & 3 & 33.3 & & \\
\hline $70,000-79,999$ & 2 & 22.2 & & \\
\hline \multicolumn{5}{|l|}{ Education } \\
\hline High School / GED & 1 & 11.1 & & \\
\hline Some College & 2 & 22.2 & & \\
\hline Bachelor's Degree & 2 & 22.2 & & \\
\hline Master's Degree & 4 & 44.4 & & \\
\hline \multicolumn{5}{|l|}{ State of Residence } \\
\hline Kentucky & 6 & 66.7 & & \\
\hline Indiana & 1 & 11.1 & & \\
\hline Ohio & 0 & 0 & & \\
\hline Other & 2 & 22.2 & & \\
\hline $\begin{array}{l}\text { Stigmatizing Situations } \\
\text { Inventory Total Score }\end{array}$ & 9 & 100 & $.88(.93)$ & $.64(1.12)$ \\
\hline Exercise Intention Score & 9 & 100 & $5.67(1.60)$ & $6.0(2.38)$ \\
\hline
\end{tabular}


Table 4

Missing Value Analysis for Primary Measures

\begin{tabular}{|c|c|c|c|c|c|c|c|}
\hline Measure & Total Items & $\begin{array}{c}\text { Cases with } \\
\text { Missing Data }\end{array}$ & $\begin{array}{l}\text { Missing Data } \\
\text { Points }\end{array}$ & $\begin{array}{c}\text { Maximum \% } \\
\text { Missing by Item }\end{array}$ & Chi-Square (df) & p-value & $\begin{array}{l}\text { Cronbach's } \\
\text { alpha }\end{array}$ \\
\hline Exercise Intention & 4 & 3 & 7 & 2.1 & $2.12(3)$ & .547 & .96 \\
\hline GLTQ-E & 4 & 5 & 5 & 1.4 & $13.20(12)$ & .355 & - \\
\hline TSRQ-E & 15 & 7 & 8 & 1.4 & $56.36(83)$ & .989 & .71 \\
\hline PNSE & 18 & 8 & 11 & 1.4 & $142.33(133)$ & .274 & .92 \\
\hline RAPA* & 9 & 8 & 11 & 2.1 & - & - & - \\
\hline WBIS-M & 11 & 7 & 7 & 1.4 & $79.62(60)$ & .046 & .84 \\
\hline Exercise-Avoidance & 8 & 3 & 3 & 0.7 & $21.44(21)$ & 432 & .86 \\
\hline BMPN & 18 & 7 & 6 & 1.4 & $123.14(102)$ & .076 & .73 \\
\hline SSI & 50 & 21 & 38 & 2.1 & $829.29(864)$ & .797 & .95 \\
\hline
\end{tabular}

Note. *No Little's MACR analysis completed due to categorical variable; GLTQ-E = Godin Leisure-Time Exercise Questionnaire, TSRQ-E = Treatment Self-Regulation Questionnaire-Exercise, PNSE = Psychological Need Satisfaction in Exercise Scale, RAPA = Rapid Assessment of Physical Activity, Exercise-Avoidance $=$ Exercise-Avoidance Motivation Scale, BMPN = Balanced Measure of Psychological Needs, SSI = Stigmatizing Situations Inventory. 
Table 5

Recruitment by Data Collection Method/Site

\begin{tabular}{|c|c|c|}
\hline & Method/Site & $\mathrm{N}$ \\
\hline \multicolumn{3}{|l|}{ In-Person } \\
\hline & Farmer's Market & 119 \\
\hline & Eligible & 111 \\
\hline & Ineligible & 8 \\
\hline & Male & 0 \\
\hline & Pregnant/Breastfeeding & 2 \\
\hline & Not Age 21-64 & 3 \\
\hline & Cannot Read/Write/Understand English & 0 \\
\hline & Unable to Exercise & 3 \\
\hline & Cardiac Event & 0 \\
\hline \multicolumn{3}{|l|}{ Online } \\
\hline & Eligible & 136 \\
\hline & Facebook & 88 \\
\hline & Craigslist & 6 \\
\hline & Other Social Media & 9 \\
\hline & Referred by Friend & 17 \\
\hline & Flyer & 4 \\
\hline & Email & 4 \\
\hline & Farmer's Market & 2 \\
\hline & Other & 6 \\
\hline & Ineligible & 3 \\
\hline & Male & 0 \\
\hline & Pregnant/Breastfeeding & 1 \\
\hline & Not Age 21-64 & 0 \\
\hline
\end{tabular}


Cannot Read/Write/Understand English

Unable to Exercise 1

Cardiac Event 1 
Table 6

Demographic Characteristics of Participants Included in Study

Participant Sample

\begin{tabular}{lcccccccccccc} 
& \multicolumn{4}{c}{ Total Sample } & & \multicolumn{3}{c}{ Online } & & \multicolumn{3}{c}{ Farmer's Market } \\
\cline { 2 - 11 } Characteristic & $\mathrm{n}$ & $\%$ & Median & IRQ & $\mathrm{n}$ & $\%$ & Median & IQR & $\mathrm{n}$ & $\%$ & Median & IQR \\
\hline Age $^{*}$ & 144 & & 33.00 & 22.75 & 78 & & 31.00 & 10.25 & 66 & & 42.00 & 24.50
\end{tabular}

Ethnicity

$\begin{array}{rrrrrcc}\text { White (non-Hispanic) } & 130 & 90.3 & 69 & 88.5 & 61 & 92.4 \\ \Xi \quad \text { Black or African American } & 3 & 2.1 & 3 & 3.8 & 0 & 0 \\ \text { Hispanic } & 3 & 2.1 & 2 & 2.6 & 1 & 1.5 \\ \text { Asian } & 2 & 1.4 & 2 & 2.6 & 0 & 0 \\ \text { More than One } & 5 & 3.5 & 2 & 2.6 & 3 & 4.5 \\ \text { Other } & 1 & 0.7 & 0 & 0 & 1.5\end{array}$

Marital Status

$\begin{array}{rcccccc}\text { Never Married } & 63 & 43.8 & 35 & 44.9 & 28 & 42.4 \\ \text { Married } & 62 & 43.1 & 35 & 44.9 & 27 & 40.9 \\ \text { Divorced } & 16 & 11.1 & 6 & 7.7 & 10 & 15.2 \\ \text { Widowed } & 3 & 2.1 & 2 & 2.6 & 1 & 1.5\end{array}$

Employment Status 


\begin{tabular}{|c|c|c|c|c|}
\hline Full Time & $92 \quad 63.9$ & $51 \quad 65.4$ & 41 & 62.1 \\
\hline Part Time & $31 \quad 21.5$ & $17 \quad 21.8$ & 14 & 21.2 \\
\hline Unemployed & $11 \quad 7.6$ & $\begin{array}{ll}5 & 6.4\end{array}$ & 6 & 9.1 \\
\hline Student & $24 \quad 16.7$ & $14 \quad 17.9$ & 10 & 15.2 \\
\hline Disabled & $1 \quad 0.7$ & 0 & 1 & 1.5 \\
\hline \multicolumn{5}{|l|}{ Annual Income } \\
\hline $0-9,9999$ & $15 \quad 10.4$ & $\begin{array}{ll}7 & 9.0\end{array}$ & 8 & 12.1 \\
\hline $10,000-19,999$ & $13 \quad 9.0$ & $\begin{array}{ll}7 & 9.0\end{array}$ & 6 & 9.1 \\
\hline $20,000-29,999$ & $26 \quad 18.1$ & $14 \quad 17.9$ & 12 & 18.2 \\
\hline $30,000-39,999$ & $12 \quad 8.3$ & $\begin{array}{ll}6 & 7.7\end{array}$ & 6 & 9.1 \\
\hline $40,000-49,999$ & $24 \quad 16.7$ & $13 \quad 16.7$ & 11 & 16.7 \\
\hline $50,000-59,999$ & $10 \quad 6.9$ & $4 \quad 5.1$ & 6 & 9.1 \\
\hline 60,000-69,999 & $12 \quad 8.3$ & $8 \quad 10.3$ & 4 & 6.1 \\
\hline $70,000-79,999$ & $6 \quad 4.2$ & $4 \quad 5.1$ & 2 & 3.0 \\
\hline 80,000 or more & $25 \quad 17.4$ & $14 \quad 17.9$ & 11 & 16.7 \\
\hline \multicolumn{5}{|l|}{ Education } \\
\hline High School Diploma or GED & 2.1 & $3 \quad 3.8$ & 0 & 0 \\
\hline Some College & $14 \quad 9.7$ & $8 \quad 10.3$ & 6 & 9.1 \\
\hline Associate Degree & $7 \quad 4.9$ & $4 \quad 5.1$ & 3 & 4.5 \\
\hline Bachelor's Degree & $56 \quad 38.9$ & $28 \quad 35.9$ & 28 & 42.4 \\
\hline Master's Degree & $45 \quad 31.3$ & $23 \quad 29.5$ & 22 & 33.3 \\
\hline
\end{tabular}




$\begin{array}{rcccccc}\text { Professional Degree } & 9 & 6.3 & 4 & 5.1 & 5 & 7.6 \\ \text { Doctorate } & 10 & 6.9 & 8 & 10.3 & 2 & 3.0\end{array}$

State of Residence*

$\begin{array}{rcccccc}\text { Kentucky } & 98 & 68.1 & 34 & 43.6 & 64 & 97.0 \\ \text { Indiana } & 10 & 6.9 & 8 & 10.3 & 2 & 3.0 \\ \text { Ohio } & 8 & 5.6 & 8 & 10.3 & 0 & 0 \\ \text { Other } & 28 & 19.4 & 28 & 35.9 & 0 & 0\end{array}$

Note: * denotes significant differences detected by sample $(\mathrm{p}<.05)$ as assessed by Mann-Whitney U and Chi-Square tests. 
Table 7

Health Characteristics of Sample

Participant Sample

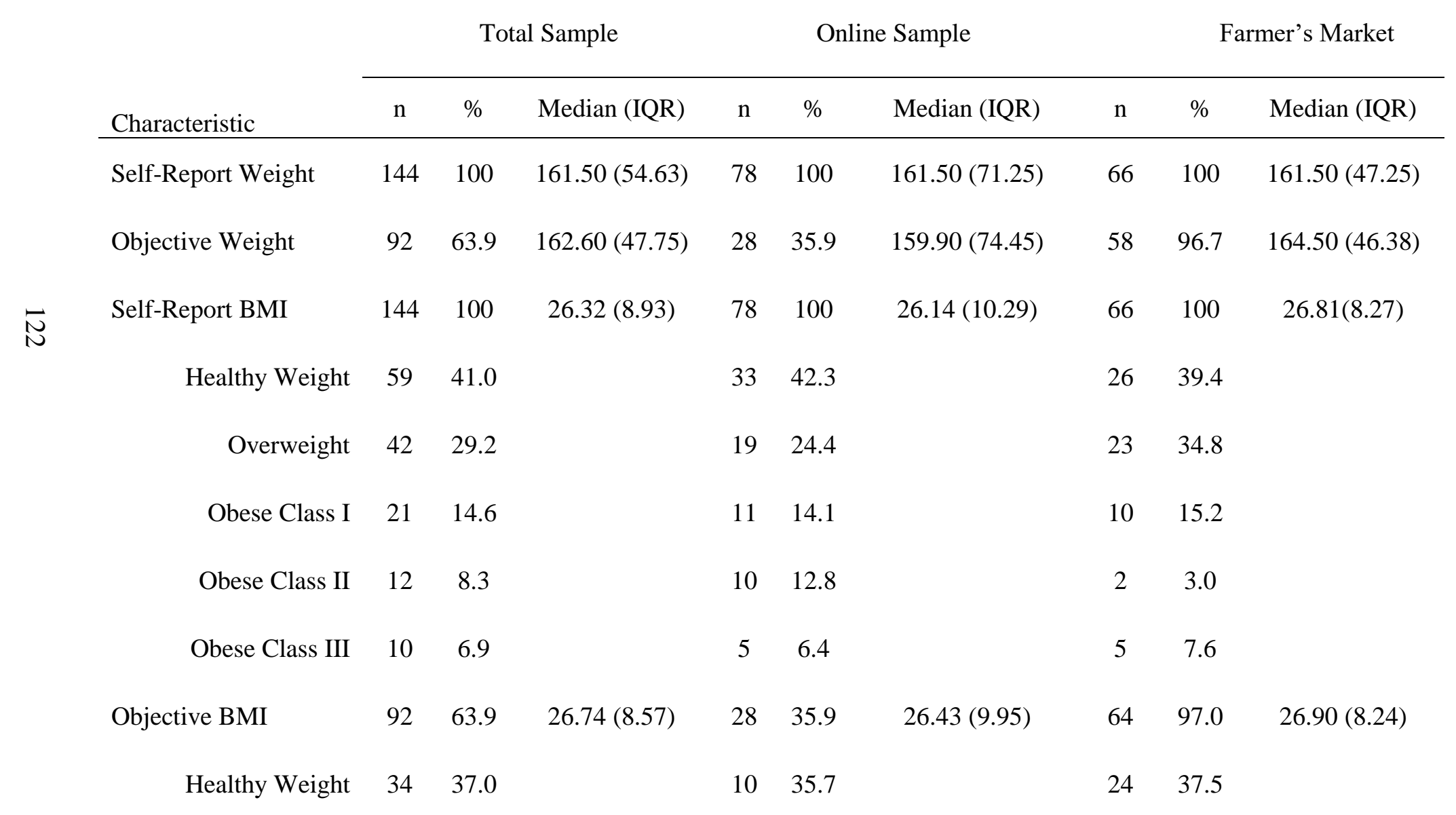




$\begin{array}{ccccccc}\text { Overweight } & 31 & 33.7 & 8 & 28.6 & 23 & 35.9 \\ \text { Obese Class I } & 14 & 15.2 & 4 & 14.3 & 10 & 15.6 \\ \text { Obese Class II } & 5 & 5.4 & 3 & 10.7 & 2 & 3.1 \\ \text { Obese Class III } & 8 & 8.7 & 3 & 10.7 & 5 & 7.8\end{array}$

Smoking Status

\begin{tabular}{|c|c|c|c|c|c|c|}
\hline Smoker & 6 & 4.2 & 4 & 5.1 & 2 & 3.0 \\
\hline Used to Smoke & 29 & 20.1 & 14 & 17.9 & 15 & 22.7 \\
\hline Never Smoked & 109 & 75.7 & 60 & 76.9 & 49 & 74.2 \\
\hline Heart Disease & 0 & 0 & 0 & 0 & 0 & 0 \\
\hline High Blood Pressure & 15 & 10.4 & 8 & 10.3 & 7 & 10.6 \\
\hline Lung Disease & 3 & 2.1 & 1 & 1.3 & 2 & 3.0 \\
\hline Diabetes & 2 & 1.4 & 1 & 1.3 & 1 & 1.5 \\
\hline $\begin{array}{l}\text { Ulcer/Stomach } \\
\text { Disease }\end{array}$ & 3 & 2.1 & 2 & 2.6 & 1 & 1.5 \\
\hline Kidney Disease & 1 & 0.7 & 0 & 0 & 1 & 1.5 \\
\hline Liver Disease & 0 & 0 & 0 & 0 & 0 & 0 \\
\hline $\begin{array}{l}\text { Anemia/Blood } \\
\text { Disease }\end{array}$ & 5 & 3.5 & 2 & 2.6 & 3 & 4.5 \\
\hline
\end{tabular}




\begin{tabular}{|c|c|c|c|c|c|c|}
\hline Cancer & 3 & 2.1 & 0 & 0 & 3 & 4.5 \\
\hline Depression & 29 & 20.1 & 14 & 17.9 & 15 & 22.7 \\
\hline $\begin{array}{l}\text { Osteoarthritis/Degener } \\
\text { ative Arthritis }\end{array}$ & 9 & 6.3 & 4 & 5.1 & 5 & 7.6 \\
\hline Back Pain & 37 & 25.7 & 21 & 26.9 & 16 & 24.2 \\
\hline Rheumatoid Arthritis & 6 & 4.2 & 3 & 3.8 & 3 & 4.5 \\
\hline $\begin{array}{l}\text { Other Medical } \\
\text { Problems }\end{array}$ & 27 & 18.8 & 12 & 15.4 & 18 & 27.3 \\
\hline
\end{tabular}


Table 8

Associations Among Demographic, Weight Stigma, Exercise, and Psychological Need Satisfaction Variables

\begin{tabular}{|c|c|c|c|c|c|c|c|c|c|c|c|c|c|c|c|c|c|c|c|}
\hline Variable & 1 & 2 & 3 & 4 & 5 & 6 & 7 & 8 & 9 & 10 & 11 & 12 & 13 & 14 & 15 & 16 & 17 & 18 & 19 \\
\hline 1 Age & - & -.05 & $.29^{* *}$ & $.20^{*}$ & .19 & -.07 & -.05 & -.06 & -.08 & $-.23^{* *}$ & .02 & $-.25^{* *}$ & -.16 & .05 & .10 & -.10 & .11 & $-.21^{* *}$ & -.14 \\
\hline 2 Ethnicity & - & - & -.08 & -.06 & -.11 & .08 & -.00 & -.06 & .03 & -.03 & -.02 & .14 & .03 & -.16 & -.01 & -.01 & -.11 & .09 & -.02 \\
\hline $3 \mathrm{SACQ}$ & - & - & - & $.27^{* *}$ & $.28^{* *}$ & $.21^{*}$ & $.28^{* *}$ & $-.22^{* *}$ & $.29^{* *}$ & $-.27^{* *}$ & -.04 & .01 & -.02 & -.07 & $-.21^{*}$ & $-.29^{* *}$ & -.17 & $-.31^{* *}$ & $-.22^{* *}$ \\
\hline 4 Self-Report BMI & - & - & - & - & $.99^{* *}$ & $.60^{* *}$ & $.60^{* *}$ & -.15 & $.47^{* *}$ & $-26^{* *}$ & -.13 & .05 & .07 & -.15 & -.12 & $-.24^{* *}$ & $-.18^{*}$ & $-.33^{* *}$ & -.10 \\
\hline 5 Objective BMI & - & - & - & - & - & $.60^{* *}$ & $.61^{* *}$ & -.19 & $.56^{* *}$ & $-.32^{* *}$ & $-.29 * *$ & -.00 & .14 & $-.24^{*}$ & -.11 & $-.27^{* *}$ & $-.21^{*}$ & $-.49 * *$ & $-.21^{*}$ \\
\hline $6 \mathrm{SSI}$ & - & - & - & - & - & - & $.69^{* *}$ & -.11 & $.62^{* *}$ & $-.17^{*}$ & $-.20^{*}$ & $.23^{* *}$ & .14 & $-.44^{* *}$ & $-.44^{* *}$ & $-.41^{* *}$ & $-.27^{* *}$ & $-.37^{* *}$ & -.14 \\
\hline 7 WBIS-M & - & - & - & - & - & - & - & $-.20^{*}$ & $.71^{* *}$ & $-.17^{*}$ & -.09 & $.44^{* *}$ & .02 & $-.45^{* *}$ & $-.44^{* *}$ & $-.46^{* *}$ & $-.23^{* *}$ & $-.33^{* *}$ & -.08 \\
\hline $\begin{array}{l}8 \text { Exercise } \\
\text { Intention }\end{array}$ & - & - & - & - & - & - & - & - & $-.21^{*}$ & $.49^{* *}$ & $.31^{* *}$ & .03 & -.10 & $.24^{* *}$ & $.19^{*}$ & $.22^{* *}$ & $.21^{*}$ & $.42^{* *}$ & $.37 * *$ \\
\hline $\begin{array}{l}9 \text { Exercise } \\
\text { Avoidance }\end{array}$ & - & - & - & - & - & - & - & - & - & $-30^{* *}$ & $-.24^{* *}$ & $.23^{* *}$ & $.18^{*}$ & $-.41^{* *}$ & $-.33^{* *}$ & $-.40^{* *}$ & $-.35^{* *}$ & $-.47^{* *}$ & $-.87^{*}$ \\
\hline 10 GLTQ-E & - & - & - & - & - & - & - & - & - & - & $.36^{* *}$ & $.16^{*}$ & $-.23^{* *}$ & $.26^{* *}$ & $.21^{* *}$ & $.17^{*}$ & $.33^{* *}$ & $.49^{* *}$ & $.31^{* *}$ \\
\hline $\begin{array}{l}11 \text { TSRQE- } \\
\text { Autonomous }\end{array}$ & - & - & - & - & - & - & - & - & - & - & - & .11 & $-.46^{* *}$ & $.35^{* *}$ & .16 & .15 & $.42^{* *}$ & $.49^{* *}$ & $.44^{* *}$ \\
\hline $\begin{array}{l}12 \text { TSRQE- } \\
\text { Controlled }\end{array}$ & - & - & - & - & - & - & - & - & - & - & - & - & -.10 & $-.30^{* *}$ & $-.24^{* *}$ & $-.18^{*}$ & $-.25^{* *}$ & .06 & .10 \\
\hline $\begin{array}{l}13 \text { TSRQE- } \\
\text { Amotivation }\end{array}$ & - & - & - & - & - & - & - & - & - & - & - & - & - & -.13 & -.02 & .04 & $-.26^{* *}$ & $-.19^{*}$ & -.14 \\
\hline $\begin{array}{l}14 \mathrm{BMPN}- \\
\text { Autonomy }\end{array}$ & - & - & - & - & - & - & - & - & - & - & - & - & - & - & $.56^{* *}$ & $.56^{* *}$ & $.41^{* *}$ & $.36^{* *}$ & $.20^{*}$ \\
\hline $\begin{array}{l}15 \text { BMPN- } \\
\text { Competence }\end{array}$ & - & - & - & - & - & - & - & - & - & - & - & - & - & - & - & $.49^{* *}$ & $.19^{*}$ & $.32^{* *}$ & $.17^{*}$ \\
\hline $\begin{array}{l}16 \text { BMPN- } \\
\text { Relatedness }\end{array}$ & - & - & - & - & - & - & - & - & - & - & - & - & - & - & - & - & $.26^{* *}$ & $.32^{* *}$ & $.20^{*}$ \\
\hline $\begin{array}{l}17 \text { PNSE- } \\
\text { Autonomy }\end{array}$ & - & - & - & - & - & - & - & - & - & - & - & - & - & - & - & - & - & $.39 * *$ & $.29^{* *}$ \\
\hline $\begin{array}{l}18 \text { PNSE- } \\
\text { Competence }\end{array}$ & - & - & - & - & - & - & - & - & - & - & - & - & - & - & - & - & - & - & $.49^{* *}$ \\
\hline $\begin{array}{l}19 \text { PNSE- } \\
\text { Relatedness }\end{array}$ & - & - & - & - & - & - & - & - & - & - & - & - & - & - & - & - & - & - & - \\
\hline
\end{tabular}

Note. Spearman's rank-order correlations; SACQ = Self-Administered Comorbidity Questionnaire, SSI = Stigmatizing Situations Inventory, WBIS-M = Weight Bias Internalization Scale-modified, Exercise Avoidance = Exercise Avoidance Motivation Scale, GLTQ-E = Godin Leisure-Time Exercise Questionnaire, TSRQE = Treatment Self-Regulation Questionnaire-Exercise (subscales), BMPN = Balanced Measure of Psychological Needs (subscales), PNSE = Psychological Need Satisfaction in Exercise Scale (subscales). ${ }^{*} p<.05 * * p .01$ 
Table 9

Stigmatizing Situations Inventory Scores by Participant Recruitment Method

\begin{tabular}{|c|c|c|c|c|}
\hline \multirow[b]{3}{*}{$\begin{array}{l}\text { Stigmatizing Situation } \\
\text { Subscale }\end{array}$} & \multicolumn{4}{|c|}{ Participant Sample } \\
\hline & \multicolumn{2}{|c|}{ Online Sample } & \multicolumn{2}{|c|}{ Farmer's Market Sample } \\
\hline & Median (IQR) & Range & Median (IQR) & Range \\
\hline Comments from Children & $.38(1.75)$ & 0 to 5.00 & $.63(1.50)$ & 0 to 5.50 \\
\hline Comments from Strangers & $.41(1.02)$ & 0 to 4.09 & $.27(.57)$ & 0 to 3.18 \\
\hline Being Stared At & $.60(1.00)$ & 0 to 3.00 & $.20(1.00)$ & 0 to 4.20 \\
\hline Comments from Family & $.43(1.04)$ & 0 to 7.14 & $.14(.71)$ & 0 to 3.14 \\
\hline Being avoided or excluded & $.00(1.50)$ & 0 to 7.00 & $.00(.50)$ & 0 to 3.00 \\
\hline $\begin{array}{l}\text { Others making negative } \\
\text { assumptions }\end{array}$ & $.00(1.33)$ & 0 to 9.00 & $.00(.67)$ & 0 to 9.00 \\
\hline Physical barriers* & $.14(.71)$ & 0 to 4.14 & $.00(.29)$ & 0 to 2.29 \\
\hline $\begin{array}{l}\text { Inappropriate comments from } \\
\text { doctors }\end{array}$ & $.25(1.00)$ & 0 to 6.75 & $.25(.75)$ & 0 to 3.00 \\
\hline Being physically attacked & $.00(.00)$ & 0 to 1.00 & $.00(.00)$ & 0 to 2.00 \\
\hline $\begin{array}{l}\text { Loved ones embarrassed by } \\
\text { your size* }\end{array}$ & $.00(.67)$ & 0 to 7.00 & $.00(.00)$ & 0 to 4.67 \\
\hline Job discriminations & $.00(.08)$ & 0 to 1.67 & $.00(.00)$ & 0 to 3.00 \\
\hline SSI Score & $.42(.81)$ & 0 to 3.22 & $.24(.45)$ & 0 to 3.22 \\
\hline
\end{tabular}

Note. SSI Score = Total Stigmatizing Situations Inventory Score; Range = range of subscale mean scores, 0 (never) to 9 (daily); MannWhitney U tests were completed to assess differences by participant sub-sample; ${ }^{*} p<.05$ 
Table 10

Descriptive Information on Stigmatizing Situations Inventory Subscales for Full Sample

\begin{tabular}{|c|c|c|c|c|}
\hline & Range & $\mathrm{M}(\mathrm{SD})$ & Median (IQR) & $\%$ \\
\hline Comments from Children & 0 to 5.50 & $.94(1.19)$ & $.50(1.50)$ & 59.7 \\
\hline Comments from Strangers & 0 to 4.09 & $.61(.72)$ & $.36(.89)$ & 79.2 \\
\hline Being Stared At & 0 to 4.20 & $.58(.74)$ & $.40(1.00)$ & 56.9 \\
\hline Comments from Family & 0 to 7.14 & $.60(.93)$ & $.29(.86)$ & 63.2 \\
\hline Being avoided or excluded & 0 to 7.00 & $.65(1.15)$ & $.00(1.00)$ & 36.1 \\
\hline Others making negative assumptions & 0 to 9.00 & $.67(1.38)$ & $.00(1.00)$ & 36.8 \\
\hline Physical barriers & 0 to 4.14 & $.36(.64)$ & $.00(.43)$ & 44.4 \\
\hline Inappropriate comments from doctors & 0 to 6.75 & $.53(.84)$ & $.25(.75)$ & 51.4 \\
\hline Being physically attacked & 0 to 2.00 & $.05(.25)$ & $.00(.00)$ & 4.2 \\
\hline Loved ones embarrassed by your size & 0 to 7.00 & $.45(.95)$ & $.00(.67)$ & 33.3 \\
\hline Job discriminations & 0 to 3.00 & $.18(.46)$ & $.00(.00)$ & 21.5 \\
\hline SSI Score & 0 to 3.22 & $.54(.62)$ & $.32(.64)$ & - \\
\hline
\end{tabular}

Note. Table format adapted from Vartanian and Shaprow (2008); Scale scores ranged from 0 (never) to 9 (daily), \% = percentage of participants who reported ever experiencing each category of stigma, SSI = Stigmatizing Situations Inventory 
Table 11

Participant's Physical Activity/Exercise Characteristics

Participant Sample

\begin{tabular}{|c|c|c|c|c|c|c|}
\hline \multirow[b]{2}{*}{ Characteristic } & \multicolumn{2}{|c|}{ Total Sample } & \multicolumn{2}{|c|}{ Online Sample } & \multicolumn{2}{|c|}{ Farmer's Market Sample } \\
\hline & $\mathrm{n}(\%)$ & Median (IQR) & $\mathrm{n}(\%)$ & Median (IQR) & $\mathrm{n}(\%)$ & Median (IQR) \\
\hline GLTQ-E Total Score & & $28.0(27.75)$ & & $29.50(28.25)$ & & $24.0(23.25)$ \\
\hline Insufficiently Active/Sedentary & $30(20.8)$ & & $15(19.2)$ & & $15(22.7)$ & \\
\hline Moderately Active & $30(20.8)$ & & $13(16.7)$ & & $17(25.8)$ & \\
\hline Active & $84(58.3)$ & & $50(64.1)$ & & $34(51.5)$ & \\
\hline RAPA & & & & & & \\
\hline Meets CDC Guidelines & $81(56.3)$ & & $45(57.7)$ & & & $36(54.6)$ \\
\hline Does Not Meet CDC Guidelines & $63(43.8)$ & & $33(42.3)$ & & & $30(45.5)$ \\
\hline
\end{tabular}

TSRQ-E

\begin{tabular}{rccc} 
Autonomous Motivation & $6.17(1.50)$ & $6.0(1.67)$ & $6.17(1.33)$ \\
Controlled Motivation & $2.83(1.50)$ & $3.25(1.83)$ & $2.67(1.33)$ \\
& $1.67(1.33)$ & $1.67(1.33)$ & $1.67(1.42)$ \\
Amotivation & $6.0(2.44)$ & $6.0(2.31)$ & $6.0(2.50)$ \\
rion & $2.13(1.84)$ & $2.31(2.38)$ & $2.06(1.38)$ \\
\hline
\end{tabular}

Note. GLTQ-E = Godin Leisure-Time Exercise Questionnaire, RAPA = Rapid Assessment of Physical Activity, TSRQ-E = Treatment Self-Regulation Questionnaire-Exercise, Exercise Avoidance = Exercise Avoidance Motivation Scale 
Table 12

Participant's Psychological Need Satisfaction Scores

\begin{tabular}{|c|c|c|c|}
\hline \multirow[b]{3}{*}{ Characteristic } & \multicolumn{3}{|c|}{ Participant Sample } \\
\hline & Total Sample & Online Sample & Farmer's Market Sample \\
\hline & Median (IQR) & Median (IQR) & Median (IQR) \\
\hline \multicolumn{4}{|l|}{ General } \\
\hline Autonomy & $2.00(1.67)$ & $1.67(1.67)$ & $2.00(1.67)$ \\
\hline Satisfaction & $4.33(1.00)$ & $4.33(1.08)$ & $4.50(1.00)$ \\
\hline Dissatisfaction & $2.33(1.25)$ & $2.33(1.08)$ & $2.33(1.08)$ \\
\hline Competence & $1.33(1.67)$ & $1.33(2.00)$ & $1.33(1.67)$ \\
\hline Satisfaction & $4.50(1.00)$ & $4.50(1.33)$ & $4.50(.75)$ \\
\hline Dissatisfaction & $3.33(1.67)$ & $3.17(1.75)$ & $3.33(1.33)$ \\
\hline Relatedness & $2.17(1.67)$ & $2.33(1.75)$ & $2.00(2.00)$ \\
\hline Satisfaction & $4.67(1.25)$ & $4.67(1.33)$ & $4.67(1.00)$ \\
\hline Dissatisfaction & $2.33(1.33)$ & $2.33(1.67)$ & $2.33(1.33)$ \\
\hline \multicolumn{4}{|l|}{ Exercise } \\
\hline Autonomy & $5.67(1.17)$ & $5.67(1.50)$ & $5.83(1.00)$ \\
\hline Competence & $4.17(1.79)$ & $4.17(1.88)$ & $4.33(1.58)$ \\
\hline Relatedness & $4.00(2.63)$ & $3.58(2.38)$ & $4.17(2.67)$ \\
\hline
\end{tabular}

Note: General Needs = Balanced Measure of Psychological Needs (BMPN); BMPN subscale scores represent aggregate scores (satisfaction score - dissatisfaction score). Exercise Needs = Psychological Need Satisfaction in Exercise Scale 


\section{Table 13}

Post Hoc Analysis Summary for Experienced Weight Stigma and BMI Associations.

\begin{tabular}{lrrr}
\hline & & Mean Ranks & P-value \\
\hline Self-Report BMI & & & $\mathrm{p}<.001$ \\
& Healthy Weight - Obese Class I & $48.26,109.00$ & $\mathrm{p}<.001$ \\
& Healthy Weight - Obese Class II & $48.26,108.46$ & $\mathrm{p}<.001$ \\
& Healthy Weight - Obese Class III & $48.26,114.20$ & $\mathrm{p}=.002$ \\
& Overweight - Obese Class I & $68.10,109.00$ & $\mathrm{p}=.031$ \\
& Overweight - Obese Class II & $68.10,108.46$ & $\mathrm{p}=.017$ \\
& Overweight - Obese Class III & $68.10,114.20$ & $\mathrm{p}<.001$ \\
& & & $\mathrm{p}=.005$ \\
& & $31.12,68.96$ & $\mathrm{p}<.001$ \\
& & $31.12,75.70$ & $\mathrm{p}=.014$ \\
& Healthy Weight - Obese Class I & $31.12,73.94$ & $\mathrm{p}=.021$
\end{tabular}

Note. Summary of Kruskal Wallace H Test post hoc analysis. 
Table 14

Regression Details for Research Question 2: How does experienced weight stigma relate to exercise motivation?

\begin{tabular}{|c|c|c|c|c|c|c|c|c|}
\hline \multirow[b]{2}{*}{ Variable } & \multicolumn{4}{|c|}{ Model 1} & \multicolumn{4}{|c|}{ Model 2} \\
\hline & $B$ & $S E B$ & $\beta$ & $\begin{array}{c}\text { Partial } \\
\text { Correlation }\end{array}$ & $B$ & $S E B$ & $\beta$ & $\begin{array}{c}\text { Partial } \\
\text { Correlation }\end{array}$ \\
\hline Sample & -.02 & .05 & -.03 & -.03 & -.01 & .05 & -.02 & -.02 \\
\hline SACQ Total Score & .03 & .01 & $.21^{*}$ & .20 & .03 & .01 & $.20 *$ & .19 \\
\hline SSI Score & & & & & .04 & .06 & .056 & .06 \\
\hline $\mathrm{R}^{2}$ & \multicolumn{4}{|c|}{.04} & \multicolumn{4}{|c|}{.05} \\
\hline $\mathrm{F}$ for change in $\mathrm{R}^{2}$ & \multicolumn{4}{|c|}{$3.06^{*}$} & \multicolumn{4}{|c|}{.44} \\
\hline
\end{tabular}

Note. SACQ = Self-Administered Comorbidity Questionnaire, SSI = Stigmatizing Situations Inventory (square root transformed); dependent variable $=$ Exercise Intention (reverse scored: high scores $=$ less exercise intention) and $\log$ transformed; $* p<.05 * * p<.01$ 
Table 15

Regression Details for Research Question 5: What are the unique associations between psychological need satisfaction variables and exercise motivation when accounting for experienced weight stigma?

\begin{tabular}{|c|c|c|c|c|c|c|c|c|c|c|c|c|}
\hline \multirow[b]{2}{*}{ Variable } & \multicolumn{4}{|c|}{ Model 1} & \multicolumn{4}{|c|}{ Model 2} & \multicolumn{4}{|c|}{ Model 3} \\
\hline & $B$ & $S E B$ & $\beta$ & $\begin{array}{c}\text { Partial } \\
\text { Correlation }\end{array}$ & $B$ & $S E B$ & $\beta$ & $\begin{array}{c}\text { Partial } \\
\text { Correlation }\end{array}$ & $B$ & $S E B$ & $\beta$ & $\begin{array}{c}\text { Partial } \\
\text { Correlation }\end{array}$ \\
\hline Sample & -.02 & .05 & -.03 & -.08 & -.01 & .05 & -.02 & -.02 & .00 & .04 & .01 & .01 \\
\hline SACQ Total Score & .03 & .01 & $.21 *$ & .20 & .03 & .01 & $.20 *$ & .19 & .01 & .01 & .07 & .07 \\
\hline SSI Score $^{+}$ & & & & & .04 & .06 & .06 & .06 & -.07 & .06 & -.11 & -.10 \\
\hline PNSE-Competence & & & & & & & & & -.07 & .02 & $-.30 * *$ & -.26 \\
\hline $\begin{array}{l}\text { PNSE-Autonomy }{ }^{+} \\
\text {(reversed) }\end{array}$ & & & & & & & & & -.00 & .04 & -.00 & -.00 \\
\hline PNSE-Relatedness & & & & & & & & & -.03 & .02 & -.15 & -.15 \\
\hline BMPN-Competence & & & & & & & & & .00 & .02 & .01 & .01 \\
\hline BMPN-Autonomy & & & & & & & & & -.04 & .03 & -.16 & -.13 \\
\hline BMPN-Relatedness & & & & & & & & & -.00 & .02 & -.02 & -.01 \\
\hline $\mathrm{R}^{2}$ & \multicolumn{4}{|c|}{.04} & \multicolumn{4}{|c|}{.05} & \multicolumn{4}{|c|}{.22} \\
\hline $\mathrm{F}$ for change in $\mathrm{R}^{2}$ & \multicolumn{4}{|c|}{$3.06^{*}$} & \multicolumn{4}{|c|}{.44} & \multicolumn{4}{|c|}{$5.12 * *$} \\
\hline
\end{tabular}

Note. ${ }^{+}$indicates transformed variable; SACQ = Self-Administered Comorbidity Questionnaire, SSI = Stigmatizing Situations Inventory (square root transformed), PNSE = Psychological Need Satisfaction in Exercise Scale (Autonomy subscale square root transformed and reverse scored: high scores = less autonomy satisfaction), BMPN = Balanced Measure of Psychological needs (subscale scores are aggregate scores: satisfaction - dissatisfaction);

dependent variable $=$ Exercise Intention (reverse scored: high scores $=$ less exercise intention) and log transformed; $* p<.05 * * p<.01$ 
Table 16

Regression Details for Supplemental Analysis: Exploring unique associations among internalized weight bias, experienced weight stigma, and psychological needs with exercise intention

\begin{tabular}{|c|c|c|c|c|c|c|c|c|c|c|c|c|}
\hline \multirow[b]{2}{*}{ Variable } & \multicolumn{4}{|c|}{ Model 1} & \multicolumn{4}{|c|}{ Model 2} & \multicolumn{4}{|c|}{ Model 3} \\
\hline & $B$ & $S E B$ & $\beta$ & $\begin{array}{c}\text { Partial } \\
\text { Correlation }\end{array}$ & $B$ & $S E B$ & $\beta$ & $\begin{array}{c}\text { Partial } \\
\text { Correlation }\end{array}$ & $B$ & $S E B$ & $\beta$ & $\begin{array}{c}\text { Partial } \\
\text { Correlation }\end{array}$ \\
\hline Sample & -.03 & .05 & -.05 & -.05 & -.02 & .05 & -.04 & -.04 & -.01 & .04 & -.02 & -.02 \\
\hline SACQ Total Score & .03 & .01 & $.21^{*}$ & .20 & .02 & .01 & .16 & .16 & .01 & .01 & .06 & .06 \\
\hline SSI Score $^{+}$ & & & & & -.02 & .08 & -.03 & -.02 & -.10 & .08 & -.15 & -.11 \\
\hline WBIS-M & & & & & .02 & .02 & .14 & .10 & .01 & .02 & .09 & .06 \\
\hline PNSE-Competence & & & & & & & & & -.07 & .02 & $-.30^{* *}$ & -.26 \\
\hline PNSE-Autonomy $^{+}$ & & & & & & & & & .01 & .04 & .02 & .01 \\
\hline \multicolumn{13}{|l|}{ (reversed) } \\
\hline PNSE-Relatedness & & & & & & & & & -.03 & .02 & -.17 & -.17 \\
\hline BMPN-Competence & & & & & & & & & -.01 & .02 & -.03 & -.02 \\
\hline BMPN-Autonomy & & & & & & & & & -.04 & .03 & -.17 & -.13 \\
\hline BMPN-Relatedness & & & & & & & & & .01 & .02 & .05 & .04 \\
\hline $\mathrm{R}^{2}$ & \multicolumn{4}{|c|}{.04} & \multicolumn{4}{|c|}{.06} & \multicolumn{4}{|c|}{.24} \\
\hline$F$ for change in $R^{2}$ & \multicolumn{4}{|c|}{2.98} & \multicolumn{4}{|c|}{.98} & \multicolumn{4}{|c|}{$5.08^{* *}$} \\
\hline
\end{tabular}

Note. ${ }^{+}$indicates transformed variable; SACQ = Self-Administered Comorbidity Questionnaire, SSI = Stigmatizing Situations Inventory (square root transformed), WBIS-M = Weight Bias Internalization Scale-modified, PNSE = Psychological Need

Satisfaction in Exercise Scale (Autonomy subscale square root transformed and reverse scored: high scores $=$ less autonomy satisfaction), BMPN = Balanced Measure of Psychological needs (subscale scores are aggregate scores: satisfaction - dissatisfaction); dependent variable $=$ Exercise Intention (reverse scored: high scores $=$ less exercise intention) and log transformed;

$* p<.05 * * p<.01$ 


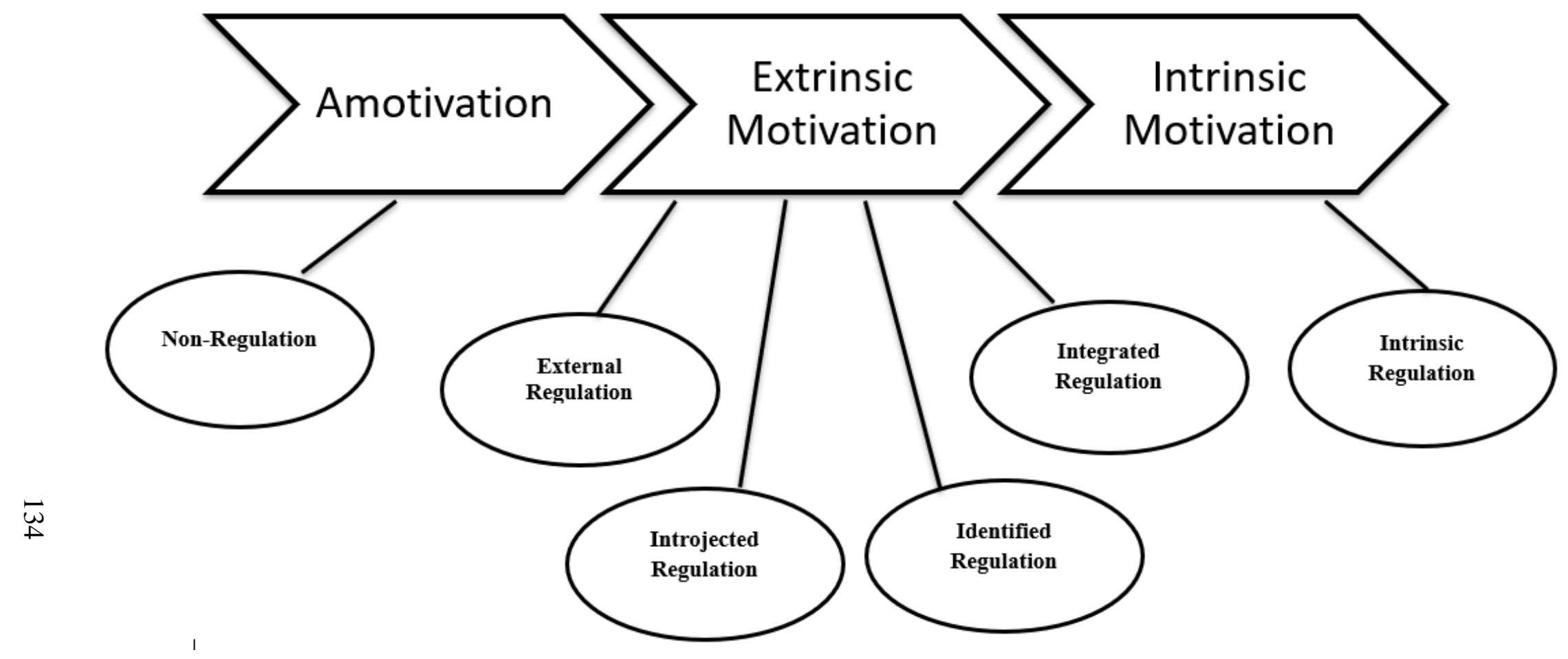

Figure 1. Continuum of Motivation (Self-Determination Theory). This figure presents constructs along the continuum of motivation as proposed by the Self-Determination Theory. This figure was adapted from Ryan, Patrick, Deci, \& Williams (2008) 


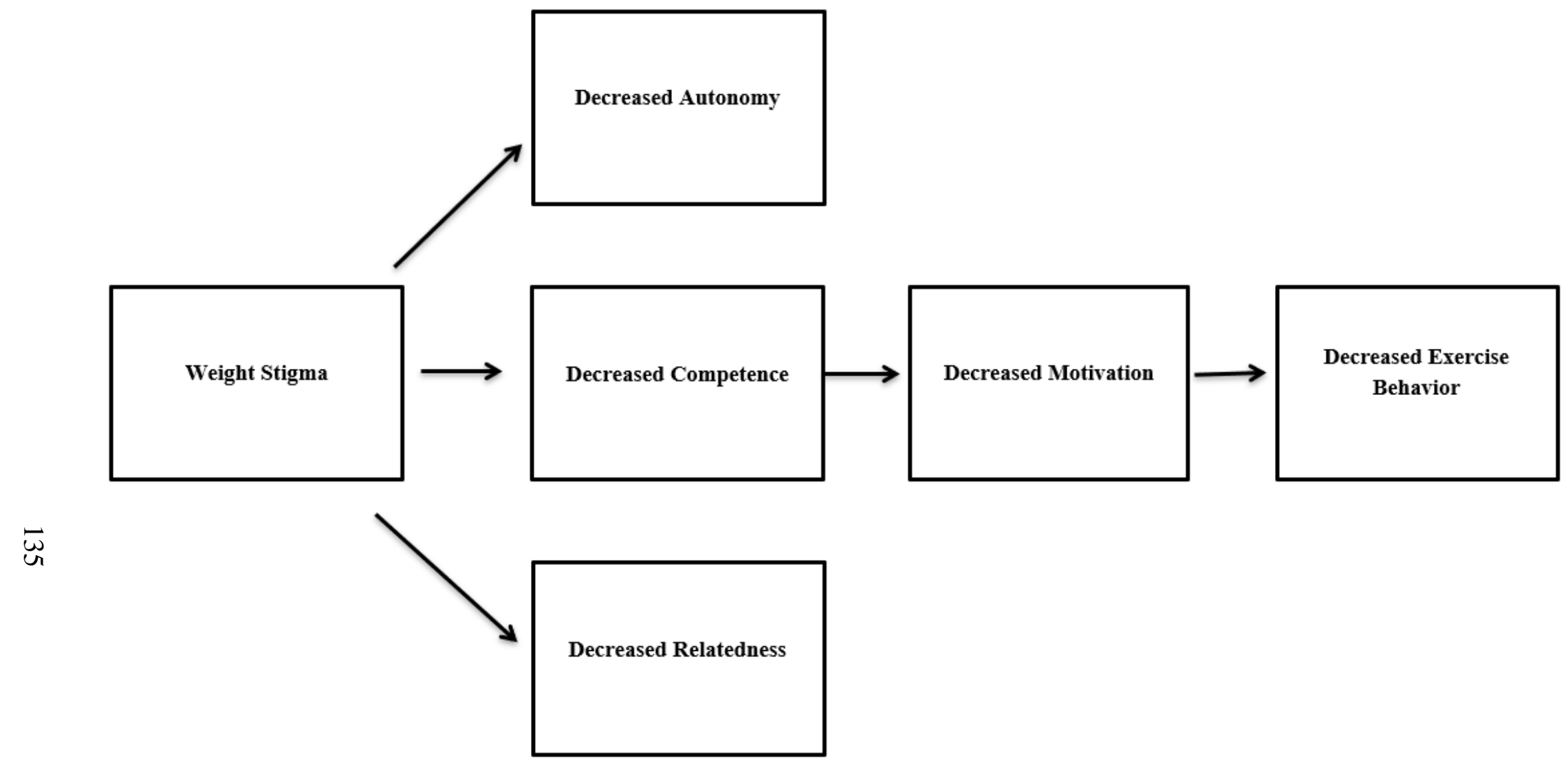

Figure 2. Proposed Conceptual Model Integrating Basic Needs Theory Constructs. This figure portrays the proposed conceptual model which suggests that weight stigma is associated with less psychological need satisfaction, exercise motivation and behavior. 


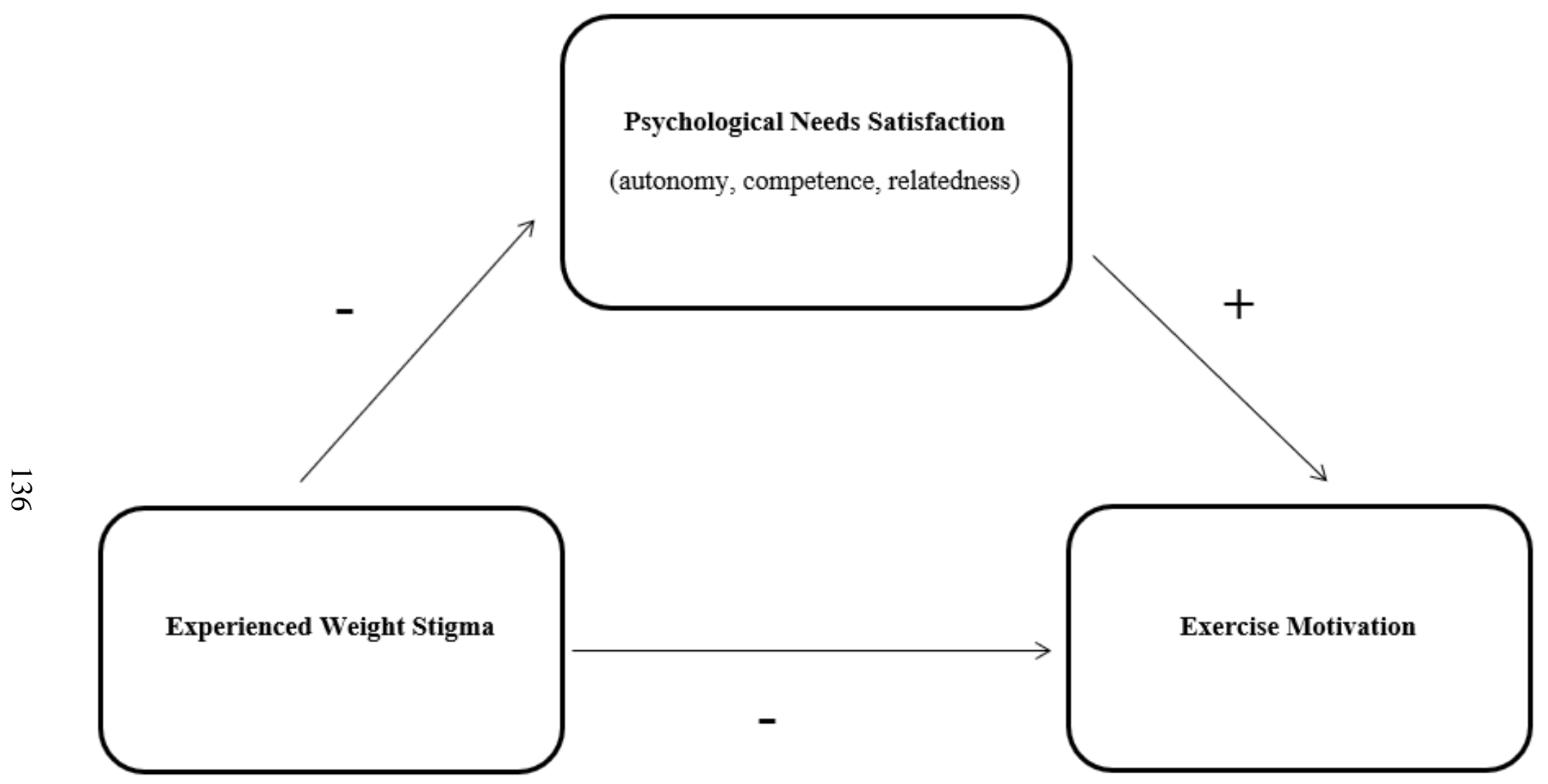

Figure 3. Proposed Mediational Model. This figure depicts the proposed mediation model which can be formally assessed in future studies of longitudinal design. 


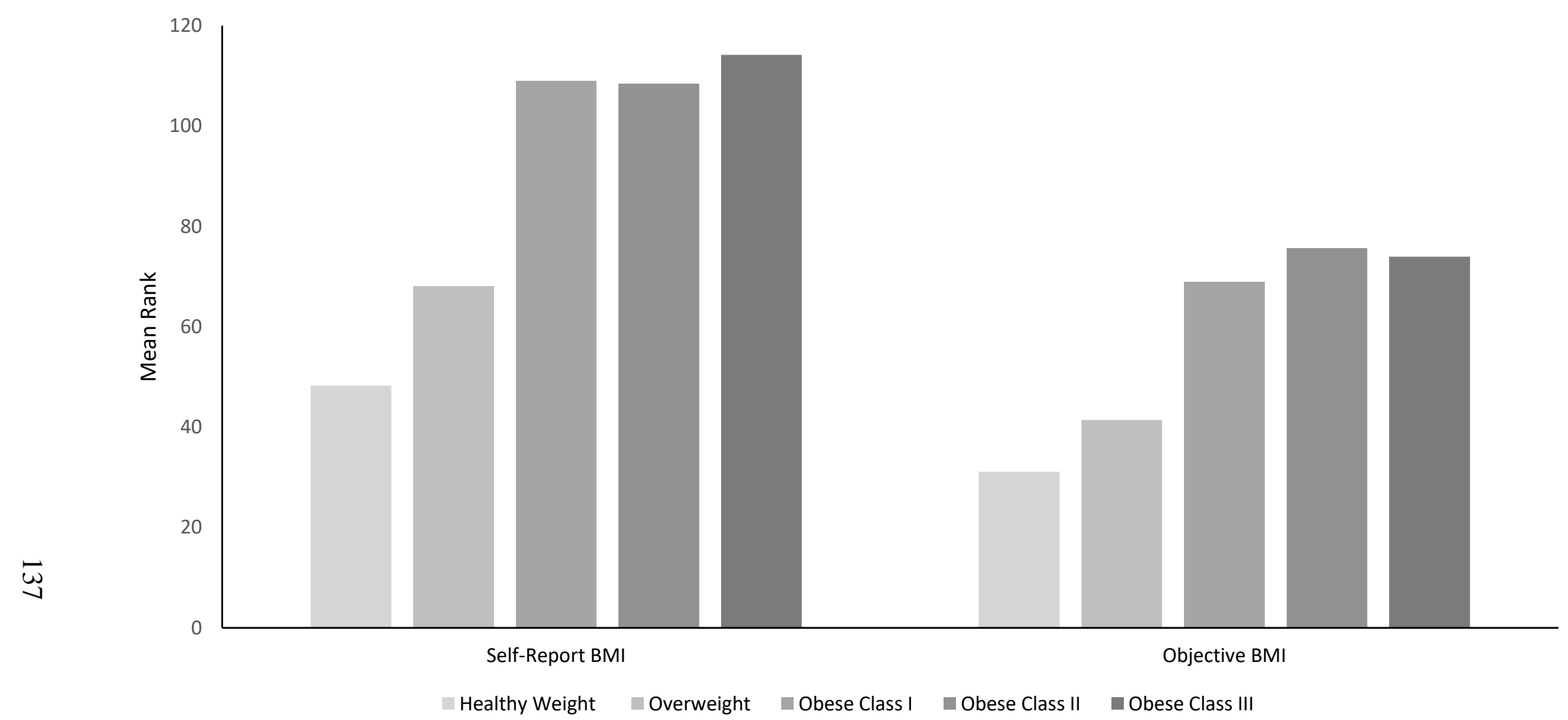

Figure 4. Kruskal-Wallis H Test: Experienced Weight Stigma Scores by BMI category. This figure presents Stigmatizing Situations Inventory mean rank scores by BMI category for both self-report and objective weight data.

Note. Self-Report BMI: Healthy Weight group significantly different from each obesity class group $(p<.001)$ and Overweight group significantly different from each obesity class group $(p<.05)$. Objective BMI: Healthy Weight group significantly different from each obesity class group $(p<.01)$ and Overweight group significantly different from Obese Class I and III groups $(p<.05)$. 


\section{CURRICULUM VITAE}

Stephanie McDonough

\section{EDUCATION}

2018

2017-2018

2015

2011
Ph.D. University of Louisville (Louisville, KY)

Clinical Psychology

Health Behavior Change Laboratory

Faculty mentor: Barbara Stetson, Ph.D.

University of Wisconsin, Dept. of Psychiatry (Madison, WI) Health Psychology Pre-Doctoral Internship

M.A. University of Louisville (Louisville, KY)

Clinical Psychology

Faculty mentor: Barbara Stetson, Ph.D.

B.S. University of Vermont (UVM; Burlington, VT)

Psychology

\section{HONORS AND AWARDS}

2016 Excellence in Clinical Work Award: Awarded one of two competitive clinical awards for outstanding clinical work at annual Department of Psychological and Brain Sciences student award reception. Nominated by faculty mentor Dr. Barbara Stetson and Director of Clinical Training Dr. Janet Woodruff-Borden

2016 Excellence in Peer Mentoring Award: Awarded for excellence in mentorship among peers at annual Department of Psychological and Brain Sciences student award reception. The winner of this award is selected following nominations and voting from fellow clinical students

2011 Heinz L. Ansbacher Award: Awarded one of four competitive Psychology Undergraduate Honors Awards for conducting outstanding research and scholarship with a humanistic element in the tradition of individual psychology 
2011 Featured Profile UVM Psychology Department Undergraduate Research: Featured on the Psychology Department webpage for undergraduates participating in and conducting independent research

2008-2011 University of Vermont Honors College Program: Maintained a minimum of 3.4 GPA, successfully completed numerous special topics seminars, proposed, completed and defended an undergraduate honors thesis

- Awarded College Honors; University Scholar Graduate

2007-2011 Dean's List: University of Vermont

\section{CLINICAL INTERESTS}

Behavioral Medicine and Clinical Psychology in Medical Settings, Psycho-Oncology, Health Behavior Change, Weight Management, Health and Pre-surgical Assessment, Integrated Primary Care, Chronic Illness, CognitiveBehavioral Therapy, Mindfulness, Acceptance and Commitment Therapy (ACT)

\section{PRE-DOCTORAL INTERNSHIP CLINICAL EXPERIENCE}

University of Wisconsin- Department of Psychiatry University of Wisconsin Hospital and Clinics (UWHC) APA Accredited Pre-doctoral Internship Placement Health Psychology Intern

\section{Primary Placement}

2017-2018 Inpatient Medical-Surgical Consultation Service (12 months) University of Wisconsin Hospital and Clinics

Provided consultation for numerous multidisciplinary services throughout the hospital such as hematology/oncology, neurology, orthopedics, transplant, burn, trauma, and hospitalist. Participated in multi-disciplinary rounds for Oncology inpatient service. Provided evaluation and brief intervention services for ethnically and economically diverse medical inpatients who presented with a wide range of medical and psychiatric conditions. Psychological, cognitive, and mental status evaluations and screenings were completed as warranted. Provided on-going psychological support and intervention for medically complex inpatients. Provided outpatient pre-transplant recipient assessment.

Supervisor: Denise Connelly, Ph.D. 


\section{Elective Rotations}

2017-2018 Cancer Psychology (12 months)

University of Wisconsin Carbone Cancer Center

Provided outpatient assessment and psychotherapy services as part of a multidisciplinary health care team for individuals and families across the cancer continuum. Provided inpatient follow-up for established patients as needed over the course of their treatment. Provided consultation, assessment and intervention services for outpatient thoracic oncology and palliative care clinics.

Supervisor: Erin Costanzo, Ph.D. and Lori Dubenske, Ph.D.

2017 Behavioral Medicine/Integrative Medicine (4 months)

UW Health-Research Park Clinic

Co-facilitated weekly outpatient pain management groups for patients presenting with a wide range of conditions associated with chronic pain. Curriculum integrated cognitive-behavioral, mindfulness-based, hypnosis, and biofeedback techniques to promote adaptive coping and effective pain management.

- Coping with Pain (6 weeks)

- Coping with Depression and Pain (6 weeks)

- Power of the Mind: Self-Hypnosis for Pain Management (6 weeks)

- Biofeedback for Pain Management (4 weeks)

Supervisor: Janice Singles, Psy.D.

\section{Outpatient Mental Health}

2017-2018 Psychiatry Outpatient Clinic (12 months)

Wisconsin Psychiatric Institute and Clinics

Provided individual psychotherapy for diverse outpatients presenting with a wide range of psychiatric conditions such as major depressive disorder, obsessive-compulsive disorder, post-traumatic stress disorder, and generalized anxiety disorder. Additional presentations included psychiatric problems and sleep disruptions secondary to chronic pain and medical comorbidities. Delivered empirically-supported treatments informed from cognitive-behavioral, acceptance and commitment, and mindfulness-based approaches. Completed on-going assessment in an effort to inform course of treatment. 
Supervisor: Greg Kolden, Ph.D.

\section{Pediatrics}

2018

Inpatient Consultation-Pediatric Service (6 months)

American Family Children's Hospital

Provided consultation to numerous multi-disciplinary services hospitalwide such as endocrinology, hematology/oncology, transplant, trauma, neonatal intensive care, and pulmonary. Provided evidence-based individual and family intervention for a wide range of presenting problems including coping and adjustment, grief/loss, terminal illness, and medical treatment non-adherence. Ongoing follow-up provided as appropriate for complex cases.

Supervisor: Jenni LeNoble, Ph.D.

\section{GRADUATE-LEVEL CLINICAL EXPERIENCE}

\section{Clinical Experience}

2016-2017 Graduate Level Therapist, Psychological Services Center Representative, Athena's Sisters, Louisville, KY

Provide psychological services and resources for Athena's Sisters, an organization of female veterans. Provide drop-in hours prior to bi-monthly organization meetings.

Supervisor: Bernadette Walter, Ph.D.

2015-2017 Graduate Clinical Assistant, Noble H. Kelley Psychological Services Center, University of Louisville

Conduct structured intake interviews for incoming clients. Develop integrative reports and initial case conceptualizations to present to specialized treatment teams. Act as first-line contact for individuals in crisis calling the clinic for treatment or assessment and refer as necessary. Act as point person managing crisis situations within the clinic. Supervise graduate students' clinical activities including intake assessments and therapy sessions. Collaborate with external agencies to provide referrals, outreach and client case management. Responsible for management of clinical operations, including chart audits, ensuring appropriate protocol followed by student therapists and supervisors, and scheduling and payment records. Entrusted with clinic key and file room and supply access. Attend weekly meetings with clinical director to discuss incoming 
clients and other clinic concerns.

2015-2017 Graduate Level Therapist, Cognitive Behavioral Therapy Clinical Team, Noble H. Kelley Psychological Services Center, University of Louisville

Implement a cognitive-behavior therapy approach to assess and treat varied psychological disorders in a diverse client population. Tailor treatment techniques to meet individual needs. Participate in weekly conceptualization-centered group supervision including support and feedback for other team members' treatment interactions. Develop and utilize individualized case conceptualizations with reference to relevant empirical literature. Receive individual supervision by licensed supervisor on regular basis.

Supervisor: Janet Woodruff-Borden, Ph.D.

2014-2015 Graduate Level Therapist, Cognitive Behavioral Therapy Clinical Team, Noble H. Kelley Psychological Services Center, University of Louisville

Implemented a cognitive-behavior therapy approach to assess and treat varied psychological disorders including depressive disorders, obsessivecompulsive disorder, trauma-related disorders, and anxiety disorders in a diverse client population. Tailored techniques to meet individual needs and implemented disorder-specific manualized treatments including: Prolonged Exposure for Posttraumatic Stress Disorder, Behavioral Activation for Depression, Acceptance-based Behavior Therapy for Generalized Anxiety Disorder and Exposure and Response Prevention for Obsessive-Compulsive Disorder. Other treatments utilized include Functional Analytic Psychotherapy, Cognitive-Behavioral Therapy for Panic Disorder and Social Anxiety. Received intensive training in multicultural considerations specific to treatment and assessment. Administered the M.I.N.I. International Neuropsychiatric Interview, DSM-5 Cultural Formulation Interview, Yale-Brown Obsessive Compulsive Scale (YBOCS-II) and Standardized Trauma Interview, as necessary. Participated in weekly conceptualization-centered group supervision including support and feedback for other team members' treatment interactions. Received individual supervision by licensed supervisor on regular basis.

Guest Lecturers:

Dr. Chad Wetterneck: Functional Analytic Psychotherapy Dr. Liz Roemer: Acceptance-based Behavior Therapy for GAD

Supervisor: Monnica Williams, Ph.D. 
2013-2014 Graduate Level Therapist, Integrated Interventions Clinical Team, Noble H. Kelley Psychological Services Center, University of Louisville

Implemented an integrated intervention therapy approach (including cognitive-behavioral therapy, interpersonal therapy, psychodynamic therapy, and narrative therapy techniques) to assess and treat varied psychological disorders in a diverse client population. Tailored techniques to meet individual's needs and goals. Participated in weekly conceptualization-centered group supervision, including support and feedback for other team members' treatment interactions. Received individual supervision by licensed supervisor on regular basis.

Supervisor: Richard Lewine, Ph.D.

2011 PACT Case Manager, Northeast Kingdom Human Services, Newport, Vermont.

Duties: Provided case management services for community adults with severe and persistent mental illness. Facilitated and coordinated treatment, rehabilitation, and support services.

Supervisor: Marcia Stricker.

\section{Assessment Experience}

2014-2017 Graduate Level Therapist, Noble H. Kelley Psychological Services Center, University of Louisville.

Adult Experience: administration of assessments and completion of integrative reports under the supervision of licensed psychologists including; administration of the WAIS-IV, Woodcock-Johnson III, WMSIV, Trail Making Test, Bender-Gestalt Test, personality assessments (MMPI-II and MCMI-III) and adult structured interviews for the assessment of cognitive functioning, learning disabilities and ADHD.

Child Experience: administration of assessments and completion of integrative reports under the supervision of licensed psychologists including; Gifted and Talented and ADHD assessment of children and adolescents for school settings (use of the WISC-IV and structured assessment interviews).

Supervisors: Bernadette Walter, Ph.D. and David Winsch, Ph.D. 


\section{External Practicum Experience}

2015-2016 Advanced Psychotherapy Practicum Student, Psychiatric Consultation Liaison and Blood and Marrow Transplant Services, University of Louisville Hospital

Site Description: Multidisciplinary team providing psychiatric consultation liaison services for patients at a tertiary care hospital in an urban center.

Implement brief CBT and Mindfulness-based interventions to medical inpatients. Provide follow-up and longer-term therapy for patients on Blood and Marrow Transplant Unit and Burn Unit. Collaborate with medical staff regarding patient care. Participate in consultation liaison psychiatry and inpatient interdisciplinary medical rounds.

Supervisors: Elizabeth Cash, Ph.D. and Jeannie Roberts, M.D.

2015 Behavioral Health Student Therapist, Interdisciplinary Head and Neck Cancer Clinic, James Graham Brown Cancer Center, University of Louisville Hospital

Site Description: Interdisciplinary cancer treatment clinic serving adult and geriatric patients with new diagnosis of head and neck cancer.

Conduct Health and Behavior Assessments with patients newly diagnosed with head and neck cancer. Perform brief behavioral health interventions including pain management, sleep hygiene, behavioral activation, relaxation techniques, and psychoeducation regarding treatment process. Administer anxiety and depression screening assessments. Collaborate with interdisciplinary team. Attend multidisciplinary treatment planning meetings and Morbidity and Mortality Conferences.

Supervisor: Elizabeth Cash, Ph.D.

\section{MULTICULTURAL AND DIVERSITY TRAINING}

2015 Department of Psychological and Brain Sciences, Noble H. Kelley Psychological Services Center, Colloquium and Professional Development Series

Microaggressions and Racial Stress and Trauma- Dr. Monnica Williams Advocacy with Military Women- Lindsay Gargotto, MSW, MFA Safe Zone Training- University of Louisville LGBT* Center 
2015 Department of Psychological and Brain Sciences, Graduate Course, Culture and Diversity in Psychology, Instructor: Dr. Monnica Williams

2015 School of Interdisciplinary \& Graduate Studies, Graduate Teaching Assistant Workshop, Diversity Issues in the Classroom

\section{RESEARCH INTERESTS}

Health Behavior Change, Health Promotion, Overweight and Obesity, Stigma, Self-Care Behavior in Chronic Illness Populations, Disease Prevention, Barriers to Healthy Diet and Regular Physical Activity, Biopsychosocial Model, Health Behavior Motivation

\section{DISSERTATION TOPIC}

"Weight Stigma and Motivation to Exercise:

Exploring Associations and Constructs from the Basic Needs Theory"

\section{RESEARCH GRANTS AND AWARDS}

$2015 \quad$ Arts and Sciences Graduate Student Union, Graduate Student Research Fund: Awarded $\$ 100$ competitive research award to fund research activities and travel to $36^{\text {th }}$ annual Society of Behavioral Medicine conference.

2014 Intramural Research and Creative Activities Grant: Awarded \$500 competitive grant to fund independent research project examining (1) risk perceptions in emerging adults who are at an increased risk for developing Type 2 diabetes and (2) the effectiveness of a health message framing intervention on intention to increase physical activity

2010 Undergraduate Research Opportunity Grant (UROP): Awarded \$300 competitive grant to support financial expenses incurred by the undergraduate honors thesis project

2010 Academic Programs for Learning and Engagement Award (APLE): Awarded $\$ 500$ competitive grant to fund the undergraduate honors thesis project

\section{RESEARCH EXPERIENCE}

2013-2017 Graduate Research Assistant, Health Behavior Change Research Program, Department of Psychological and Brain Sciences, University of Louisville, Louisville, KY 
Role: Lab Manager (2014-2017)

Supervisor: Barbara, Stetson, Ph.D.

\section{Program Objectives and Focus}

Study cognitive, behavioral and motivational domains of health-related change within a biopsychosocial model of risk prevention and health promotion. Research approaches include initial, secondary and tertiary prevention of chronic diseases to reduce illness burden in at-risk populations and improving psychosocial functioning for those already living with disease. Emphasis is placed on diabetes prevention and risk reduction through preventative measures. Additional interests include weight-management through behavioral interventions. Responsibilities include data management and analysis, laboratory management and supervision of graduate and undergraduate research assistants. Specific research projects include:

2016-2017 Women's Experiences with Weight and Health Study: University of Louisville, KY: Dissertation study designed to further explore the association between experienced weight stigma and motivation to exercise in a diverse community sample of women. Specific aims include (1) explore relationships between experienced weight stigma and exercise motivation and behavior using theoretically informed measures (2) explore how experienced weight stigma might differ based on important factors such as body weight and demographic variables such as age and (3) test the proposed model that psychological need satisfaction, as outlined by the Basic Needs Theory, may mediate the relationship between experienced weight stigma and motivation to exercise.

\section{Role: Co-Investigator}

Duties: Generated specific hypotheses informed from thorough literature review. Designed and implemented dissertation study to test hypotheses. Received Institutional Review Board approval. Created and managed study survey using REDCap survey software. Trained and supervised undergraduate research assistants on study procedures. Coordinated and implemented all study procedures and activities including community and online recruitment. Responsible for all data analysis and dissemination. Recruitment completed, currently completing data analysis.

2014-2017 Psychology and Health Risks Study: University of Louisville, Louisville, KY: Multi-phase study designed to (1) assess and characterize diabetes risk in emerging adults who have a family history of Type 2 diabetes (2) examine risk beliefs and perceptions relative to actual risk in the 
development of Type 2 diabetes (3) examine changes in intention to increase physical activity following presentation of a framed health message intervention and (4) examine initiation of physical activity followed framed health message intervention.

Role: Co-Investigator

Duties: Designed study in an effort to test specific hypotheses. Applied for and received grant funding (see Research Grants and Awards) to support study costs. Received Institutional Review Board approval. Created and managed study survey utilizing Qualtrics Survey software. Trained and supervised undergraduate and graduate research assistants on study procedures. Coordinated and implemented all study procedures and activities, including recruitment. Responsible for data management and analyses.

2013-2014 Type 2 Diabetes and Insulin Study, Joslin Diabetes Clinic, New Albany,

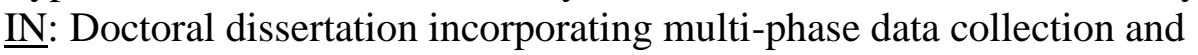
ancillary longitudinal study examining self-care behaviors, quality of life and perceptions regarding blood glucose testing in a community-based clinical sample.

Role: Graduate Research Assistant

Duties: Coordinated all recruitment activities including approach and consent of eligible patients at fasting blood-draw appointment. Collected medical chart data for review. Created and maintained database utilized to ensure study task completion (i.e. filing of HIPAA and Informed Consent documents). Maintained necessary relationships with clinic staff to ensure continued study progress. Trained and supervised all research assistants and recruitment staff on recruitment procedures.

2013 Research Assistant, University of Vermont Health Behavior Research Center, Burlington, Vermont.

Duties: Completed telephone recruitment for NIAAA funded Phone Health Outreach and Education study. Transferred participants into Interactive Voice Response (IVR) Technology system accordingly. Navigated numerous electronic databases to collect and maintain data. Administered telephone follow-up assessments (such as portions of the CIDI-SAM). Performed data management. Supervisor: Gail Rose, Ph.D.

2012- 2013 Research Assistant, University of Vermont Substance Abuse Treatment Center, Burlington, Vermont.

Duties: Provided routine laboratory and/or field assistance in support of a NIDA-funded treatment program following detailed methods and 
established procedures. Prepared and set up equipment and apparatus. Tested, modified and/or calibrated instruments and apparatus. Stored and disposed of laboratory specimens following specific guidelines. Collected and maintained proper copies of data. Created and maintained electronic spreadsheets. Obtained observed urine samples from same sex clients. Interviewed clients to obtain data following laboratory procedures. Supervisor: Stephen Higgins, Ph.D.

2009-2011 Research Assistant, University of Vermont Mood Disorders Laboratory and Seasonality Treatment Program, Burlington, Vermont.

Duties: Performed phone screens to access eligibility criteria for NIMHfunded randomized clinical trial, including DSM-IV-TR defined Major Depressive Episodes and seasonal pattern of recurrence. Administered and scored the Structured Interview for the Hamilton Depression Rating scale during the 6-week treatment phase and at follow-ups. Performed data management. Supervisor: Kelly Rohan, Ph.D.

2010-2011 Principle Investigator, University of Vermont Undergraduate Honors Thesis, Burlington, Vermont.

Duties: Proposed and completed an undergraduate honors thesis. Received IRB approval. Completed recruitment, data collection, analysis and interpretation. Successfully completed oral defense. Supervisor: Lynne Bond, Ph.D.

\section{PUBLICATIONS}

McDonough, S., Stetson, B., \& Mokshagundam, S. (Preparing for Submission). Continuum of obesity and diet perceptions in noninsulin using adults with type 2 diabetes. American Journal of Lifestyle Medicine.

McDonough, S., Stetson, B. (Manuscript in Preparation). Weight stigma and motivation to exercise in overweight and obese adults: Exploring mechanisms of action by integrating the selfdetermination theory. Stigma and Health.

Ward, J., Stetson, B., Rai, S.N., McDonough, S., Rai, S.P., Mokshagundam, S.P. (Preparing for Submission). Use of selfmonitoring of blood glucose for decision-making in insulinprescribed type 2 diabetes: Current clinical practices and considerations for behavioral measurement.

2015 Stetson, B. A., McDonough, S. R., \& Mokshagundam, S.P. (2015). Nutrition issues and recommendations in the management of 
diabetes and prediabetes in older adults. In Bendich \& Deckelbaum ( ${ }^{\text {th }}$ edition.), Preventive nutrition: The comprehensive guide for health professionals. Springer.

2015

Mokshagundam, S. P., Stetson, B., \& McDonough, S. (2015). Diabetes prevention: Needs and opportunities in Kentucky, The Journal of the Kentucky Medical Association, 113, 161-168.

2014

Vurbic, D., Higgins, S. T., McDonough, S. R., Skelly, J. M., \& Bernstein, I. M. (2014). Maternal body mass index moderates the influence of smoking cessation on breastfeeding. Nicotine \& Tobacco Research, 16(5), 527-535.

\section{CONFERENCE PRESENTATIONS}

\section{PUBLISHED ABSTRACTS}

Ward, J.F., Stetson, B., McDonough, S.R., McKiel, C., Mokshagundam, S.P. (2017). Illness Beliefs of Specialty Clinic Patients with Type 2 Diabetes Prescribed Insulin, Annals of Behavioral Medicine.

McDonough, S., Stetson B. (2016). Characterizing Diabetes Risk and Perceptions in High-Risk Emerging Adults. Annals of Behavioral Medicine, 50, Suppl 1, s241.

McDonough, S.R., Knight, H.M., Stetson, B., Mokshagundam, S.P. (2015). Continuum of obesity and diet perceptions in non-insulin using adults with type 2 diabetes. Annals of Behavioral Medicine, 49, Suppl 1, s257.

Ward, J.E., McDonough, S. R., Stetson, B.A., McKiel, C., DeVore, R., Gonzalez, C., Mokshagundam, S.P. (2015). Illness coherence supports decision-making and better coping in insulin treated type 2 diabetes. Annals of Behavioral Medicine, 49, Suppl 1, s100.

Knight, K.M., McDonough, S.R., Ward, J.E., Stetson, B.A., Mokshagundam, S.P. (2015). Mediation effects of health-related coping and blood glucose control in adults with type 1 diabetes. Annals of Behavioral Medicine, 49, Suppl 1, s182.

Knight, H., McDonough, S., Ward, J., Cooper, J., Stetson, B., Mokshagundam, S. (2014). Mediational Effects of Stress and Social Support on Diet in Women with T2DM and Hyperlipidemia. Annals of Behavioral Medicine, 47, Suppl 1, sl08.

Cooper, J., Stetson, B., Knight, H., McDonough, S., Ward, J.B., Mokshagundam, S.P. (2014). Self-reported health behaviors and barriers indicate differences between targeted levels of glycemic control in a clinical population. Annals of Behavioral Medicine, 47, Suppl 1, s198. 


\section{POSTER PRESENTATIONS}

McDonough, S., Slaughter, L., \& Stetson, B. (April, 2017). A health message intervention for increasing physical activity in emerging adults at-risk for diabetes. $38^{\text {th }}$ annual meeting of the Society of Behavioral Medicine, San Diego, CA.

McDonough, S., Slaughter, L., Miller, M., \& Stetson, B. (April, 2016). BMI comparisons of diet behavior and perceptions: A study of emerging adults at-risk for type 2 diabetes. $37^{\text {th }}$ annual meeting of the Society of Behavioral Medicine, Washington, D.C.

Ward, J. E., McDonough, S., DeVore, B., Stethan, A., Mokshagundam, S. P., \& Stetson, B. (April, 2014). Self-monitoring of blood glucose use as decisionmaking tool mediates relationship between adherence and glucose control in insulin-treated Type 2 diabetes. $35^{\text {th }}$ annual meeting of the Society of Behavioral Medicine, Philadelphia, PA.

Ward, J., McDonough, S., French, C., Knight, H., Cooper, J., Mokshagundam, S. P., \& Stetson, B. (April, 2014). Levels of chronic care support and associations with diet adherence level in older adults with insulin-treated Type 2 diabetes. $35^{\text {th }}$ annual meeting of the Society of Behavioral Medicine, Philadelphia, PA.

McDonough, S. (April, 2011). Effects of a Weight and Health Management Course on Undergraduates' Self Esteem. Poster presentation at the Student Research Conference, Burlington, VT.

\section{COMMUNITY PRESENTATIONS}

McDonough, S. (April, 2017). The confidence gap workshop. Collaborated with the University of Louisville Women's Center and the University of Louisville Career Development Center to provide workshop discussing the "confidence gap" phenomenon. Incorporated elements of self-compassion as a strategy for reducing self-critical judgements and fostering confidence.

McDonough, S., \& Warnecke, A. (October, 2016). Self-compassion: World Café Workshop, University of Louisville Women's Center, Louisville, KY.

McDonough, S., \& Phillips, K. (July, 2016). Coping with stress workshop. GEAR UP: Gaining Early Awareness and Readiness for Undergraduate Programs (Department of Education-funded program designed to build sustainable collegegoing culture in schools with predominantly low-income students), Louisville, KY.

Bayley-Veloso, R., Szabo, Y., McDonough, S., \& Altman, J. (April, 2016). Selfcompassion and personal identity workshop. Athena's Sisters (non-profit 
organization for female veterans), Louisville, KY.

Stetson, B., McDonough, S., \& Knight, H. (February, 2014). The emotional side of diabetes. Floyd Memorial Hospital and Joslin Diabetes Center: Annual Diabetes Update, New Albany, IN.

\section{TEACHING EXPERIENCE}

2017 Teaching Assistant, University of Louisville Graduate-level Assessment II

2016 Co-Instructor, University of Louisville Graduate-level Interviewing

2016 Teaching Assistant, University of Louisville Graduate-level Assessment II

2015 Co-Instructor, University of Louisville Graduate-level Interviewing

2015 Teaching Assistant, University of Louisville Undergraduate Social Psychology Undergraduate Life-Span Development Psychology

$2014 \quad$ Teaching Assistant, University of Louisville Undergraduate Social Psychology

2014 Teaching Assistant, University of Louisville Undergraduate Introduction to Psychology

$2013 \quad$ Teaching Assistant, University of Louisville Undergraduate Forensic Psychology Undergraduate Sensation and Perception

\section{PROFESSIONAL AND HONOR SOCIETIES}

\section{4-Present Society of Behavioral Medicine}

2013-2015 American Psychological Association, Student Affiliate, APAGS Member Inducted 2010 Psi Chi, National Honor Society in Psychology

Inducted 2011 Phi Beta Kappa, Liberal Arts and Sciences Academic Honor Society 


\section{ACTIVITIES AND LEADERSHIP}

$2017 \quad$ Military Child Appreciation Day, Veterans Memorial Park, Jeffersontown Kentucky, University of Louisville Psychological Services Center Representative

- Coordinated Psychological Services Center involvement in $2^{\text {nd }}$ annual Military Child Appreciation Day. Provided psychoeducation and resources about assessment and treatment services offered by the Psychological Services Center.

2016 Depression Screening Day, University of Louisville Psychological Services Center

- Planned and Coordinated National Depression Screening Day for community members and students within the Louisville community.

$2016 \quad$ Military Child Appreciation Day, Veterans Memorial Park, Jeffersontown Kentucky, University of Louisville Psychological Services Center Representative

- Provided psychoeducation and resources about assessment and treatment services offered by the Psychological Services Center.

$2016 \quad$ Society of Behavioral Medicine Conference, Student Volunteer

$2015 \quad$ National Association for Black Veterans, Gathering of the Eagles, Military Appreciation Day at Kentucky State Fair, University of Louisville Psychological Services Center Representative

- Provided psychoeducation and resources about assessment and treatment services offered by the Psychological Services Center.

Louisville Women Veteran Conference, University of Louisville Psychological Services Center Representative

- Provided psychoeducation and resources about assessment and treatment services offered by the Psychological Services Center.

2015 Applicant Transportation Coordinator, University of Louisville Clinical Psychology Doctoral Program

- Coordinated travel arrangements for clinical psychology doctoral program applicants.

2015 Society of Behavioral Medicine Conference, Student Volunteer

$2014 \quad$ No Kill Louisville, Advocate and Volunteer

- Advocated and volunteered for No Kill Louisville pet food bank.

2013-2014 American Psychological Association of Graduate Students: Science 
Committee, Ad-Hoc Reviewer, Basic Psychological Science Research Grant

- Reviewed Basic Psychological Science Research Grant for APAGS and collaborated with other reviewers to determine winners and honorable mentions.

2013-2017 Graduate Student Liaison, Department of Psychological and Brain Sciences, University of Louisville

- Advocate for graduate student peers and communicate with Student Representatives regularly to promote effective communication between students and faculty.

2013 Zion Baptist Health Fair, University of Louisville Psychological Services Center Representative

- Provided psychoeducation and resources about assessment and treatment services offered by the Psychological Services Center.

$2011 \quad$ Psychology Club, Member

2011 Ronald McDonald Family Room, Fletcher Allen Hospital, Volunteer

2011 University of Vermont Relay for Life, Team Captain/Fundraiser

2010 University of Vermont Relay for Life, Team Member/Fundraiser 